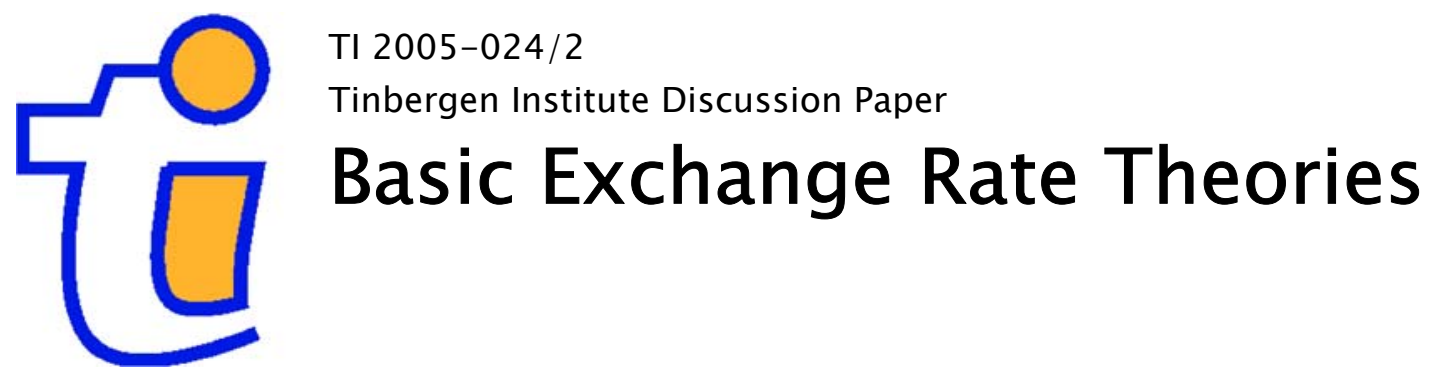

Charles van Marrewijk

Faculty of Economics, Erasmus University Rotterdam, and Tinbergen Institute. 


\section{Tinbergen Institute}

The Tinbergen Institute is the institute for economic research of the Erasmus Universiteit Rotterdam, Universiteit van Amsterdam, and Vrije Universiteit Amsterdam.

Tinbergen Institute Amsterdam

Roetersstraat 31

1018 WB Amsterdam

The Netherlands

Tel.: $\quad+31(0) 205513500$

Fax: $\quad+31(0) 205513555$

Tinbergen Institute Rotterdam

Burg. Oudlaan 50

3062 PA Rotterdam

The Netherlands

Tel.: $\quad+31(0) 104088900$

Fax: $\quad+31(0) 104089031$

Please send questions and/or remarks of nonscientific nature to driessen@tinbergen.nl.

Most TI discussion papers can be downloaded at http://www.tinbergen.nl. 


\title{
BASIC EXCHANGE RATE THEORIES
}

\author{
BY \\ CHARLES VAN MARREWIJK \\ ERASMUS UNIVERSITY ROTTERDAM \\ AND TINBERGEN INSTITUTE
}

February 2005

\begin{abstract}
This four-chapter overview of basic exchange rate theories discusses (i) the elasticity and absorption approach, (ii) the (long-run) implications of the monetary approach, (iii) the short-run effects of monetary and fiscal policy under various economic conditions, and (iv) the transition from short-run to long-run in a sticky-price model with rational expectations. We provide ample anecdotal, historical, and heuristic information on the goodness-of-fit of the various exchange rate models based on simple graphs, statistics, and tests. Details are provided in technical notes.

JEL codes: $\quad$ E, F, G
\end{abstract}

Please send all correspondence to:

Charles van Marrewijk

Erasmus University Rotterdam

Department of Economics, H8-10

P.O. Box 1738, 3000 DR Rotterdam

The Netherlands

Email: $\quad$ vanmarrewijk@few.eur.nl

Home page: http://www.few.eur.nl/few/people/vanmarrewijk 


\section{Contents}

$\begin{array}{lll}1 & \text { Elasticity and absorption } & \text { page } \\ 2 & \text { The monetary approach } & 3 \\ 3 & \text { Monetary and fiscal policy in the short-run } & 24 \\ 4 & \text { Expectations and sticky prices } & 42 \\ \text { References } & 64\end{array}$

\section{Preface}

This study into basic exchange rate theory was largely undertaken while I was visiting professor at the University of Adelaide, Australia, July - November, 2004. I am grateful to the University of Adelaide for its hospitality which made this visit possible and to the staff of the School of Economics for encouragement and friendship. This research is part of a preparation for a monograph with the working title International Economics: Theory, Application, and Policy (IETAP), to be published by Oxford University Press in due time as an update and extension of my earlier work: International Trade and the World Economy (van Marrewijk, 2002). An earlier part of this research was published under the title An introduction to international money and foreign exchange markets (van Marrewijk, 2004). The references within this monograph are consistent. Any references to chapters beyond the scale 1-4 refer to the forthcoming IETAP monograph. Comments and suggestions for improvement sent to the email address on the front page will be greatly appreciated. I would like to thank Stephan Schueller and Daniël Ottens for some of the data material and for useful comments and suggestions.

CvM, February 2005 
Basic exchange rate theories

\title{
Chapter 1 Elasticities and absorption
}

\author{
Objectives / key terms \\ Marshall - Lerner condition elasticities approach \\ volume effect and value effect pass-through analysis \\ pricing to market absorption approach \\ domestic and external equilibrium Swan diagram \\ Tinbergen rule assignment problem
}

Principle of effective market classification

The elasticities approach focuses on the relationship between exchange rates and the current account balance. The absorption approach extends this framework to include income effects, which enables the analysis of some simple policy-adjustment problems.

\subsection{Introduction}

Our discussion on the economic consequences of (changes in) exchange rates first focuses on their impact on the current account. It is important to keep in mind that this chapter will therefore basically ignore the capital account of the balance of payments and any role it may have on influencing exchange rates and exchange rate equilibrium. One reason for this neglect of the capital account, which will be remedied in the chapters to come, is the tight capital controls that were in place during the time period the theories discussed below was pit forward. An advantage of this neglect is that it allows us to build up our knowledge on the impact of exchange rates gradually, thus making it easier for us to understand at a later stage how the capital account will influence our earlier acquired insights. The remainder of this chapter will start with an analysis of changes in the real exchange rate, which is the price of foreign goods relative to domestic goods. We then incorporate basic income effects into this analysis, which allows us to analyze simple adjustment problems. 
Famous economists box: Alfred Marshall

Figure 1.1 Alfred Marshall

\subsection{Elasticities and the Marshall-Lerner condition}

In chapter 21 we defined the real exchange rate $Q$ as the product of the nominal exchange rate $S$ and the ratio of the price indices $P$ for the two countries, see section (21.4). Suppose the EU is the Home country and the US is the foreign country. We let $S$ denote the nominal exchange rate of the US dollar, so it is the number of euros we have to pay in order to purchase one dollar, and we let $P_{E U}$ and $P_{U S}$ be the price level in the EU and the US, respectively. Obviously, the price level is measured in euros in the EU and in dollars in the US. The real exchange rate is defined as:

(1.1) $Q=S \frac{P_{U S}}{P_{E U}}$

Note that the real exchange rate is a dimensionless number, since it is the exchange rate measured in $€ / \$$ multiplied by the price ratio in $\$ / €$. It is therefore a relative price, namely the price of American goods relative to European goods. The real exchange rate increases, that is American goods become more expensive relative to European goods, if:

- the nominal exchange rate $S$ increases (say from 0.80 to 1.20 euros per dollar),

- the price level in America increases, or

- the price level in Europe decreases.

For a consumer, whether she is living in Europe or America, any of these three changes indicates that American goods become more expensive relative to European goods. In general, therefore, we expect an increase in the real exchange rate to cause a substitution away from American goods towards European goods in both countries.

The elasticities approach focuses on the relationship between the (real) exchange rate and the flow of goods and services as measured by the current account balance. Let $X$ denote the exports of European goods to America and let $M$ denote the imports of American goods into Europe. As argued above, these export and import levels are 


\section{Basic exchange rate theories}

functions of the real exchange rate, which is the price of American goods relative to European goods. If the real exchange rate $Q$ increases, American goods become more expensive, which not only reduces the European demand for imports $M$ but also increases the demand for European exports $X$. We can summarize both effects in the current account balance $C A$, which measures our net exports. Suppose we use European goods as numéraire, then the current account balance is given as:

$$
C A(Q)=X(\stackrel{+}{Q})-Q \cdot M(\stackrel{-}{Q})
$$

Note that we must pre-multiply our imports $M$ from America, which is measured in American goods, with the real exchange rate $Q$, the relative price of American goods, to ensure that all our measurements are in European goods. The equation summarizes how our export and import levels, and hence our current account balance, depend on the real exchange rate.

\section{Figure 1.2 The exchange rate and current account equilibrium}

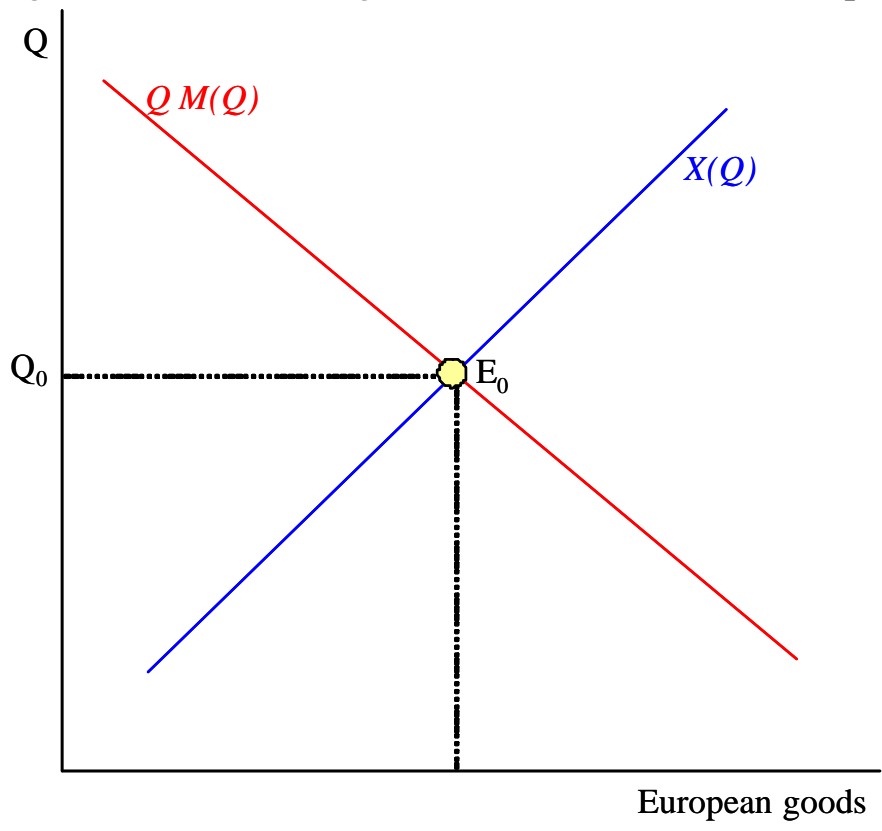

If we ignore the capital account of the balance of payments or if capital flows are severely restricted or very limited, as they have been in the past for currently developed countries and are at present for some developing countries, equation (1.2) can be viewed as a simple equilibrium condition for the real exchange rate $Q$, namely by requiring 
equilibrium on the current account $(C A=0)$. This is illustrated in Figure 1.2, where the current account is in equilibrium at the point of intersection of the $X$ and $Q M$ curves (point $E_{0}$ ), leading to the equilibrium real exchange rate $Q_{0}$. Moreover, as is evident from equation (1.1), if we assume that the price levels in Europe and America are constant (or their ratio is constant), then equation (1.2) is tantamount to an equilibrium condition for the nominal exchange rate $S$, see Box 1.1. Under that additional assumption, then, the analysis below on the real exchange rate also holds for the nominal exchange rate.

A rise in net exports is frequently referred to as an improvement of the current account and a fall as a deterioration. Although this terminology is confusing from a welfare perspective, as there is nothing particularly good or bad about such changes in the current account, it does make sense from a stability perspective in this framework. Note that the curve $Q M$ is drawn downward sloping in Figure 1.2, which implicitly assumes that the value effect of a rise in $Q$, which given the import level ( $\bar{M}$ say) raises the term $Q \bar{M}$, is more than compensated by the volume effect of the fall in imports $M$ caused by the increase in the real exchange rate. In general, this need not be the case, which led Marshall (1923) and Lerner (1944) to analyze under which conditions an increase in the real exchange rate leads to an improvement of the current account. To do this they defined the price elasticity of export demand $\varepsilon_{x} \equiv(Q / X) X^{\prime}>0$ and the price elasticity of import demand $\varepsilon_{m} \equiv-(Q / M) M^{\prime}>0$ to derive what is now known as the Marshall Lerner condition (starting from initial equilibrium, see Technical Note 1.1):

$$
C A^{\prime}(Q)>0 \Leftrightarrow \varepsilon_{x}+\varepsilon_{m}>1
$$

Suppose there is a surplus on the European current account $(X>Q M)$, indicating that the value of European exports of goods and services to America is higher than the value of European imports from America. If we see that as an indication that American goods are too expensive (or European goods are too cheap), we should expect the relative price of American goods to decline $(Q \downarrow)$. Similarly, if there is a deficit on the European 


\section{Basic exchange rate theories}

current account we should expect the relative price of American goods to increase. Under this, admittedly rather simple, adjustment mechanism, the Marshall - Lerner condition determines whether or not the equilibrium real exchange rate is stable, or not. This is illustrated in Figure 1.3 in which, in contrast to Figure 1.2, there is a range of real exchange rates for which the value effect dominates the volume effect of $Q M$. This gives rise to multiple equilibria, denoted $E_{0}, E_{1}$, and $E_{2}$, with concomitant real exchange rate $Q_{0}, Q_{1}$, and $Q_{2}$. The dashed arrows in the figure indicate whether the real exchange rate is rising or falling, showing that equilibria $E_{0}$ and $E_{2}$ are stable, whereas equilibrium $E_{1}$ is not. Equivalently, the Marshall - Lerner condition is satisfied for equilibria $E_{0}$ and $E_{2}$, and not for equilibrium $E_{1}$.

\section{Figure 1.3 The Marshall - Lerner condition and stability}

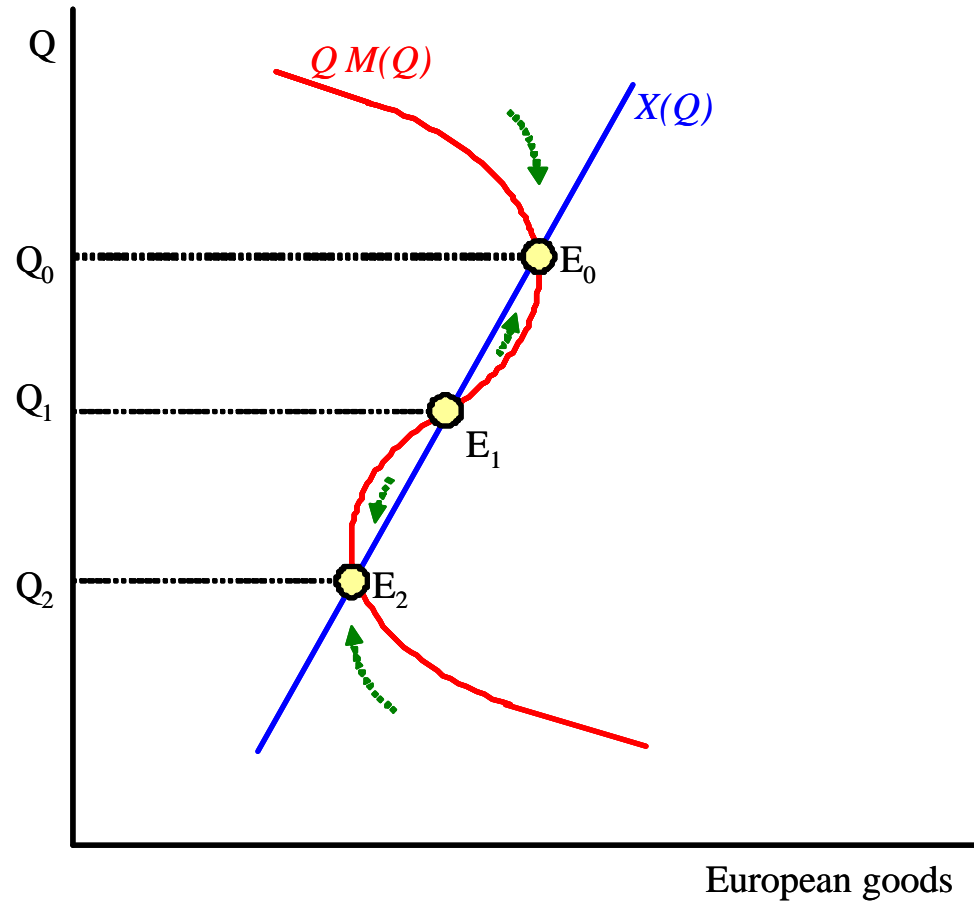

\section{Box 1.1 Fixed exchange rates and intervention}

The framework of section 1.2 can easily be used to illustrate the fundamentals of fixing exchange rates if we, as suggested in the main text, assume that the price levels in Europe 
and America are fixed. For simplicity, we normalize the ratio of the price levels to unity, such that equation (1.1) simplifies to $Q=S$ and equation (1.2) becomes:

\section{(1.2') $\quad C A(S)=X(S)-S \cdot M(S)$}

This is illustrated in Figure 1.4, with the initial equilibrium at point $A$ and the associated exchange rate equal to $S_{0}$.

\section{Figure 1.4 Fixed exchange rates and intervention}

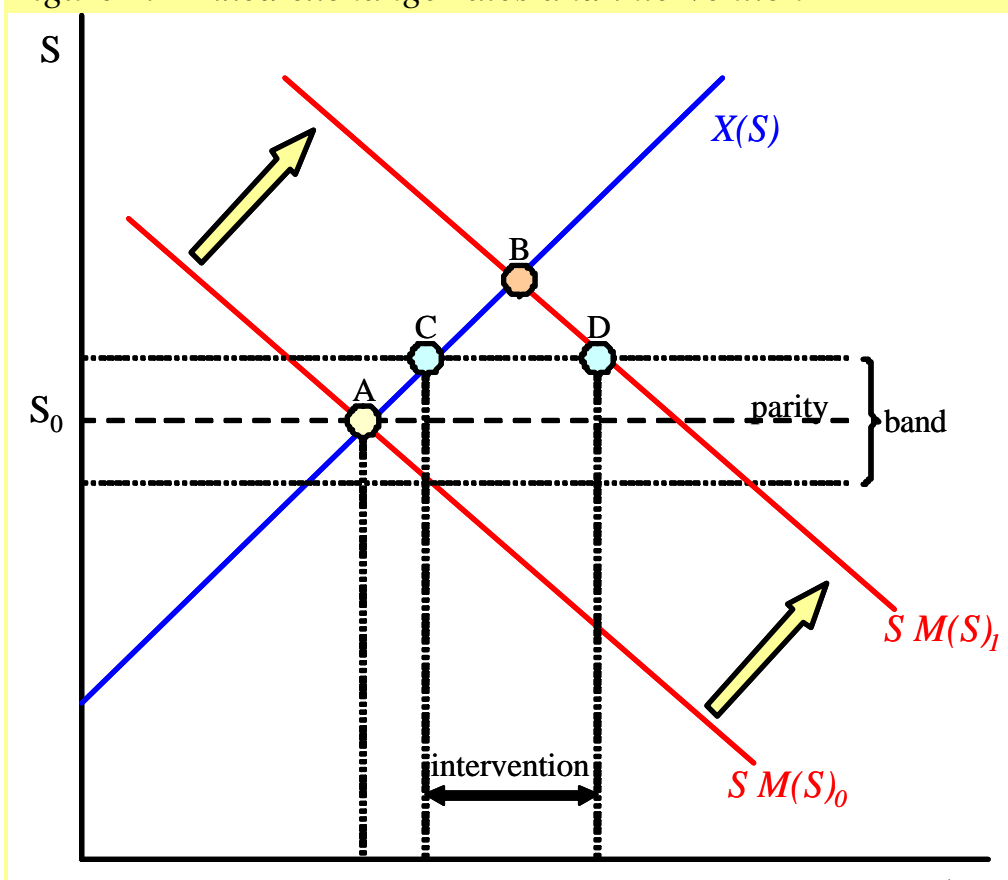

European goods

Now suppose that the $S M(S)$ curve shifts to the right, perhaps because Europeans have developed an extra taste for American goods and want to import more of these goods for any given exchange rate. Under flexible exchange rates this shift would lead to a new equilibrium at point $B$ in Figure 1.4 and a concomitant appreciation of the US dollar (and equivalent devaluation of the euro). If the ECB wants to fix the value of the euro at the old equilibrium level $S_{0}$, however, it will not allow the dollar to appreciate by that much. As illustrated in Figure 1.4, fixed exchange rate regimes usually allow for a band width around the parity rate $S_{0}$, which implies that the dollar exchange rate will appreciate to $S_{0}+$ band / 2 with the difference between the demand and supply of dollars, as given by the points $\mathrm{D}$ and $\mathrm{C}$ in Figure 1.4, supplied by the ECB. 


\section{Basic exchange rate theories}

\subsection{Elasticities and time: the J-curve}

The analysis in section 1.2 shows under which condition an appreciation of the US dollar (which is a depreciation of the euro) leads to an improvement of the European current account balance. We did not say anything about the time required to achieve this improvement. Here we have to distinguish between the value effect of the real exchange rate appreciation of the dollar, which is instantaneous, and the volume effect that the change of the relative price of American goods has on our export and import levels, which requires time to adjust.

Let's first focus on the value effect, starting from an initial current account equilibrium, say $0=\bar{X}-\bar{Q} \bar{M}$. If the real exchange rate rises at time $t_{1}$ to $\hat{Q}>\bar{Q}$ and there is no instantaneous adjustment of the export and import levels, the impact effect of the dollar appreciation is a deterioration rather than an improvement of the European current account since $\bar{X}-\hat{Q} \bar{M}<\bar{X}-\bar{Q} \bar{M}=0$. As illustrated in Figure 1.5, this follows from the simple fact that the price increase of American goods has made our imports more expensive, leading to an immediate deterioration of the current account at the old export and import levels.

Figure 1.5 The J-curve

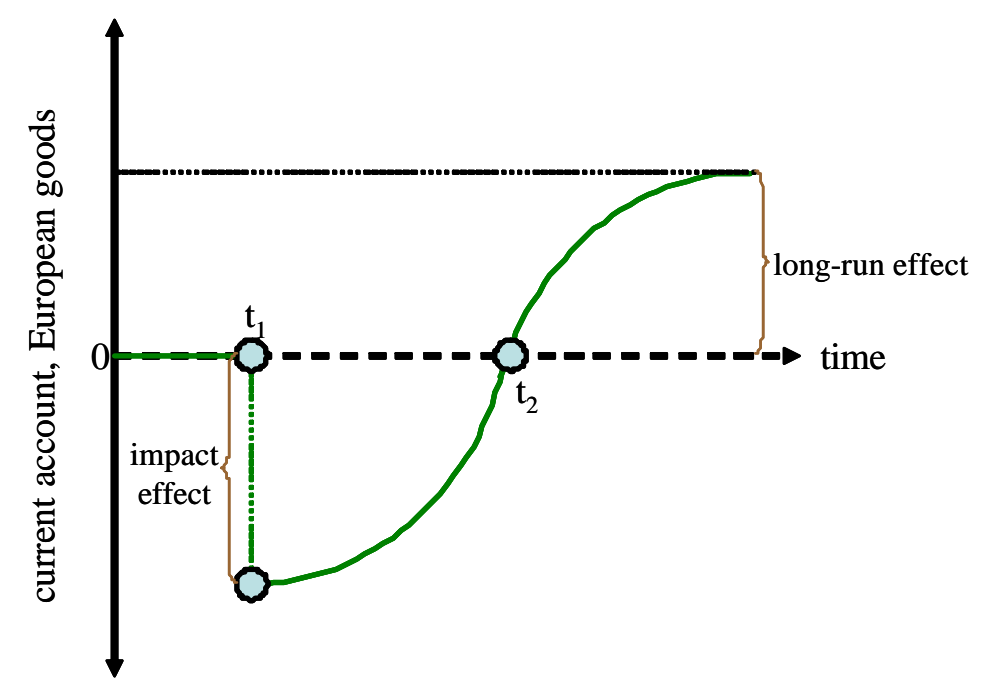




\section{Basic exchange rate theories}

Turning now to the volume effects of the real exchange rate change, it is clear that the substitution away from American to European goods requires time to adjust. Consumers need time to substitute between different goods and adjust their consumption patterns and producers need time to attract new capital, install new plants, hire workers, build new distribution channels, etc. We should expect, therefore, that the price elasticities of export and import demand are gradually increasing over time, leading only gradually to the required improvement of the current account balance. As illustrated in Figure 1.5, the current account balance is only back to its initial position at time $t_{2}$, leading to an improvement thereafter as denoted by the long-run effect. Since the shape of the initial deterioration in between the time periods $t_{1}$ and $t_{2}$ resembles the letter $\mathrm{J}$, this is called the J-curve effect.

Figure 1.6 shows IMF empirical estimates of the J-curve effect for five countries and three different time periods. It provides estimated price elasticities of export and import demand after an adjustment of six months (short-run), one year (medium-run), and the ultimate effect when the adjustment is complete (long-run). In all cases, the estimated elasticities increase when the adjustment period increases. With the exception of Denmark, the Marshall - Lerner condition is not satisfied for the short-run, indicating an initial deterioration of the current account balance after a real depreciation of the domestic currency in accordance with the J-curve effect. For all countries in the figure, the medium- and long-run estimated elasticities do satisfy the Marshall - Lerner condition, indicating that an adjustment lag of one year is usually sufficient to ensure a depreciation of the domestic currency leads to an improvement of the current account. The next section discusses the J-curve for the USA in the 1980s. 
Figure 1.6 Estimated price elasticities for trade in manufactured goods

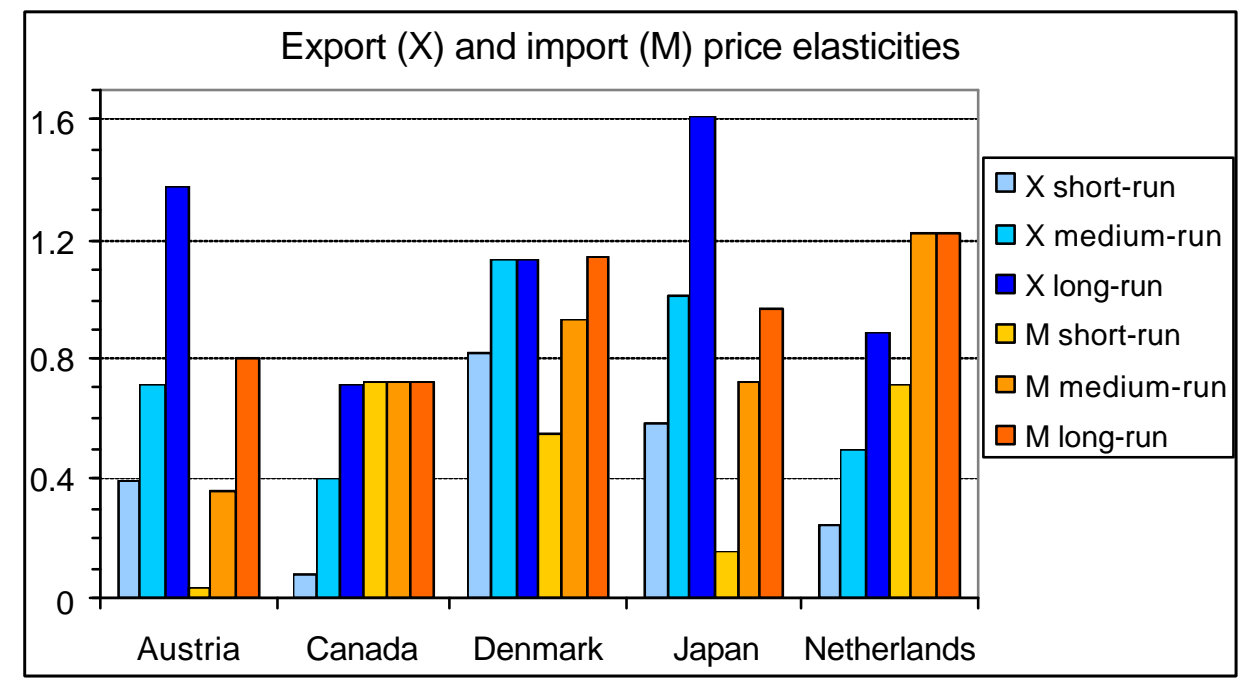

Data source: Artus and Knight (1984, Table 4); See the main text for details.

\section{Box 1.2 Pass-through analysis and pricing to market}

As noted and analyzed in Box 1.1, the economic consequences of changes in the real exchange rate are identical to those of changes in the nominal exchange rate if the domestic and foreign price levels are fixed in the short-run. This remark, however, implicitly assumes that exporters and importers completely pass through changes in the nominal exchange rate to changes in the price level charged in the foreign country, as well as implicitly assuming that either the Law of One Price holds or some version of PPP, see chapter 21. In practice, this is not the case, as studied in pass-through analysis.

Suppose, for example, that the Word ${ }^{\mathrm{TM}}$ program sells for $\$ 100$ in the US. If the exchange rate is $€ 1$ per dollar, it should sell for $€ 100$ in Europe according to the Law of One Price. If the dollar appreciates to $€ 1.10$ per dollar, the Word program should be selling for $€ 110$ if Microsoft ${ }^{\circledR}$ decides to completely pass-through the increase in the dollar exchange rate. And it should be selling for $€ 90$ if one week later the dollar depreciates to $€ 0.90$ per dollar. There are two good reasons why Microsoft may decide not to do this. First, changing the price in local currency (in this case in euros) is costly, so rather than announcing daily changes in its price level Microsoft will rather change its prices less frequently, reflecting somewhat longer term changes in the exchange rate. Second, 
Microsoft will realize that changes in its European price level will affect its competitive position. Since it has the power to determine its own price, it will take into consideration how changes in its European price level will alter its competitive position. This pricingto-market behaviour will make it unlikely that Microsoft will completely pass-through an appreciation of the US dollar to higher European prices (at least in the short-run), see Dornbusch (1987) and Krugman (1987)

\subsection{Application: Plaza, Louvre, and the J-curve}

The fall of the Shah of Iran in 1979 initiated a second oil shock, with prices rising rapidly from $\$ 13$ to $\$ 32$ per barrel. ${ }^{1}$ This led to high inflation rates and a sharp recession with high unemployment rates in the oil importing countries, including the United States. In October 1979 Paul Volcker, Chairman of the Federal Reserve, announced a tightening of monetary policy to fight inflation. Ronald Reagan was elected president in November 1980 and kept his promise to lower taxes starting in 1981 (he also promised to balance the budget, but that is another matter). The combined effects of the tight monetary policy, high interest rates, and the fiscal expansion started to drive the value of the US dollar up on the foreign exchange markets from 1981 onwards, see Figure 1.7. The appreciation of the dollar made it easier to fight inflation, so monetary policy could be relaxed. Together with the continued fiscal expansion, the American economy started to grow rapidly and unemployment fell, which in turn led to a further appreciation of the dollar.

\footnotetext{
${ }^{1}$ The first oil shock was in 1973.
} 
Figure 1.7 USA; Plaza, Louvre, and J-curve

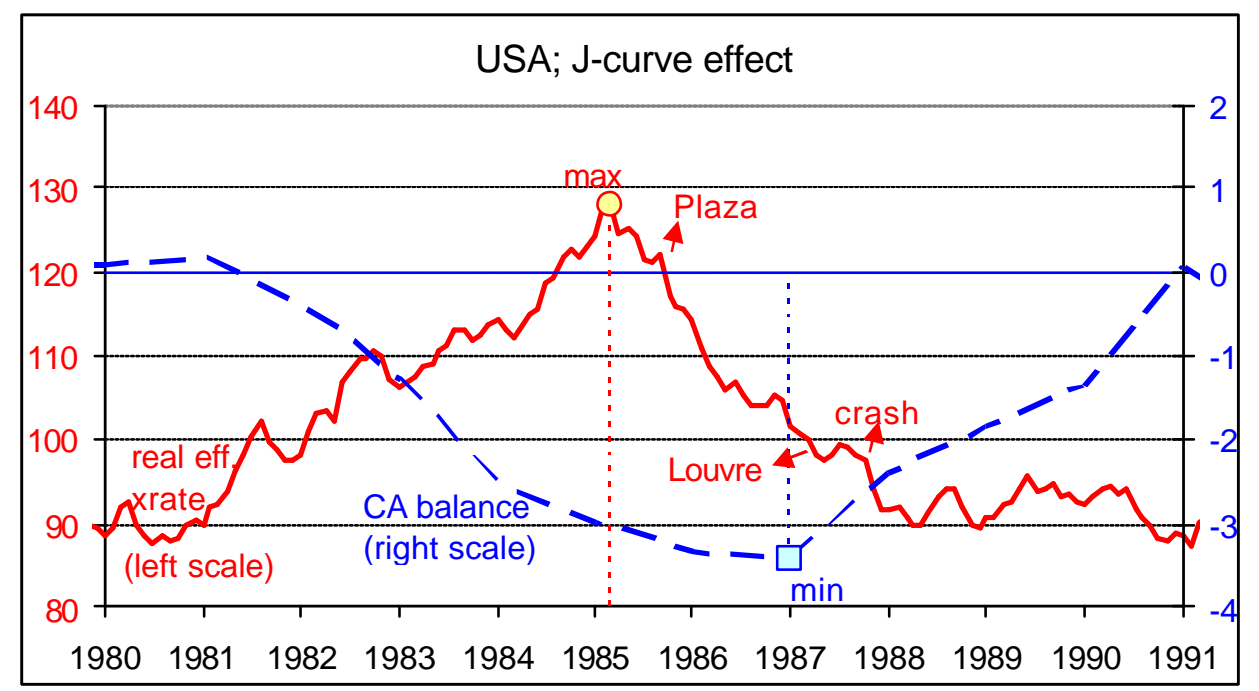

Sources: $\underline{w w w . f e d e r a l r e s e r v e . g o v}$; real eff. xrate = real effective exchange rate (broad index), and World Bank Development Indicators CD-ROM 2003; CA balance = current account balance (\% of GDP)

The American current account balance was -0.01 per cent of GDP in 1979. In accordance with the J-curve effect, it improved slightly in 1980 and 1981 (to 0.08 and 0.16 per cent, respectively) before it started to deteriorate with a delay from 1982 onwards. Since the dollar was continuing to appreciate in real terms, the current account continued to deteriorate with a delay. Eventually, the dollar would reach its maximum real value in February 1985, about 46 per cent higher than it had been in June 1980. The lowest value on the current account balance of -3.42 per cent of GDP was reached in 1987.

In the course of 1985 it was clear that the dollar was overvalued, which contributed to the American economic slow down which had started in 1984 and to mounting protectionist pressure in America. On 22 September 1985 the Reagan Administration no longer ignored this link between the strong dollar and mounting protectionism and announced at a meeting in the Plaza Hotel in New York that the Group of Five (G-5 = USA, Japan, Germany, Britain, and France) countries would jointly intervene in the foreign exchange market to reduce the value of the dollar. This led to a sharp fall the next day, which continued for about one and a half year until February 1987 when the real value of the dollar had reached a level about 30 per cent below its peak level of two years earlier. In a new meeting at the Louvre in Paris the G-5 declared that the dollar was "broadly 


\section{Basic exchange rate theories}

consistent with underlying economic fundamentals". For a while there was an implicit agreement to intervene in the foreign exchange market if the dollar would move outside of a band of plus or minus 5 per cent of certain parity rates relative to Germany and Japan. This period ended with the US stock market crash in October 1987, driving the real value of the dollar down until it reached a level in March 1988 about similar to the level it had been in December 1980.

\subsection{Absorption approach}

The elasticities approach discussed in section 1.2 focuses exclusively on the effect of changes in relative prices on imports, exports, and the current account balance. This implies that it ignores the influence of income effects for determining these variables. After all, if the European income level rises, we should expect an increase in the level of European imports from America for any given relative price of American goods. The absorption approach, see Alexander (1951) and Black (1959), remedies this shortcoming of the elasticities approach in a simple Keynesian framework. The term absorption, which we will denote by $A$, refers to the total spending level in an economy and is equal to the sum of consumption spending $C$, investment spending $I$, and government spending $G$. Let $Y$ denote income. Recall the simple income equation:

$$
Y=\underbrace{C+I+G}_{\text {absorptio¥A }}+(X-M) \Leftrightarrow Y-A=X-M
$$

The second part of equation (1.4) clarifies that if income exceeds absorption there is a current account surplus, while if absorption exceeds income there is a current account deficit. The absorption approach thus emphasizes that the excess of domestic demand over domestic production will have to be met by imports. 


\section{Figure 1.8 Domestic equilibrium}

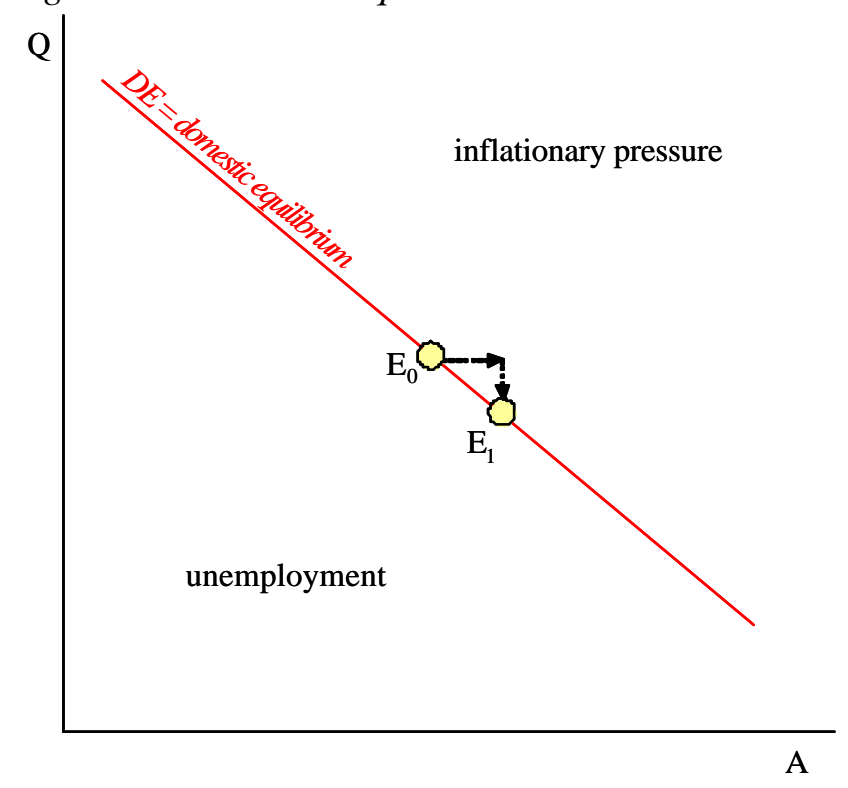

We are now in a position to describe macroeconomic equilibrium and characterize different types of disequilibria. Let's start with the domestic equilibrium, defined to be that level of output corresponding to the natural rate of unemployment, that is the rate of unemployment that does not lead to an accelerating rate of inflation, see Friedman (1968). In this simple framework output depends on the level of absorption $A$ and on the real exchange rate of the US dollar $Q$ :

(1.5) $Y=Y(\stackrel{+}{A}, \stackrel{+}{Q})$

As indicated by equation (1.5), the influence of both variables on output is positive. This leads to a negatively sloped curve representing domestic equilibrium in $(A, Q)$-space, as illustrated in Figure 1.8. Suppose we start from point $E_{0}$, a point of initial domestic equilibrium, and the level of absorption increases. At a given real exchange rate $Q$, this increased demand for domestic goods lowers unemployment and therefore leads to inflationary pressure in the economy. To restore equilibrium, the relative price of American goods $Q$ will have to decline such that he reduced demand in America for European export goods and the increased demand in Europe for American import goods reduces the European output level and returns us back to the natural rate of unemployment. As also illustrated in Figure 1.8, everywhere above the curve 
representing domestic equilibrium the economy will experience inflationary pressure, while everywhere below the line the economy will experience unemployment.

\section{Figure 1.9 External equilibrium}

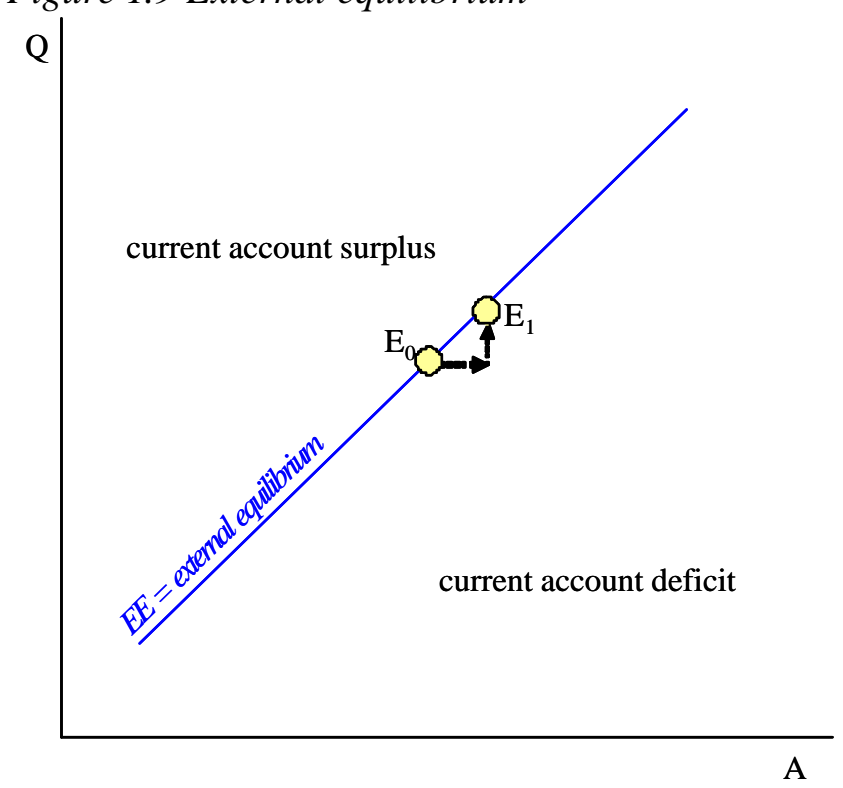

We turn now to the external equilibrium, that is combinations of absorption $A$ and the real exchange rate $Q$ for which the current account is in equilibrium. ${ }^{2}$ The current account balance depends negatively on the level of absorption because an increase in domestic spending leads to an increased demand for import goods. It depends positively on the real exchange rate $Q$, provided the Marshall - Lerner condition is fulfilled:

$$
C A=C A(\bar{A}, \stackrel{+}{Q})
$$

Figure 1.9 depicts combinations of absorption and the real exchange rate with external equilibrium. On the basis of equation (1.6), the curve is upward sloping in $(A, Q)$-space. Starting from point $E_{0}$, a point of initial external equilibrium, an increase in the level of absorption for a given real exchange rate will lead to additional import demand and therefore a current account deficit. To restore external equilibrium the relative price of American goods $Q$ will have to increase, such as to increase the demand in America for European exports and reduce the demand in Europe for American imports and eliminate

2 The discussion in the text assumes that external equilibrium implies $\mathrm{CA}=0$. If there are steady capital inflows or capital outflows in the economy, these can be accommodated for an external equilibrium with a steady current account deficit or surplus. 


\section{Basic exchange rate theories}

the European current account deficit. As also illustrated in Figure 1.9, everywhere below the curve representing external equilibrium Europe experiences a current account deficit, while everywhere above this curve it experiences a current account surplus.

\section{Figure 1.10 The Swan diagram}

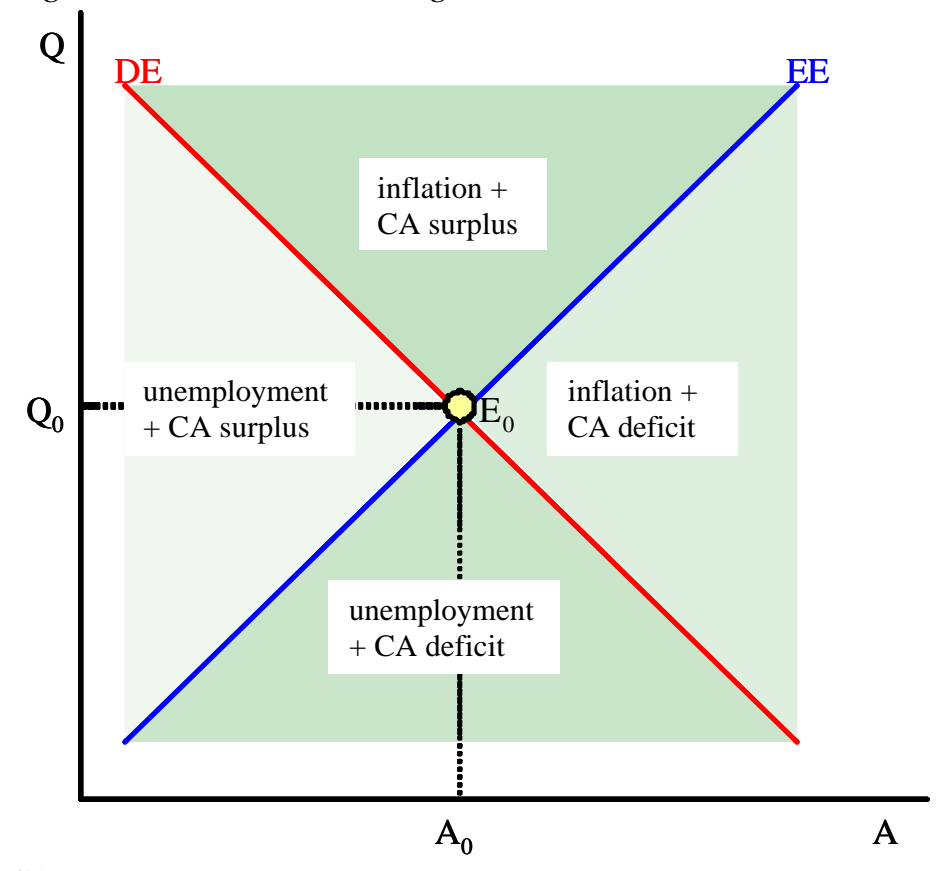

$\mathrm{CA}=$ current account

Figure 1.10 combines the information on domestic equilibrium and external equilibrium in one graph. It is named after the Australian economist Trevor Swan. There is a unique combination of absorption and the real exchange rate $\left(A_{0}, Q_{0}\right)$ for which the economy is both in domestic equilibrium and in external equilibrium, see Swan (1955). For any other combination of absorption and the real exchange rate the economy is in one of four disequilibrium regimes, namely (i) unemployment + CA deficit, (ii) unemployment + CA surplus, (iii) inflation + CA deficit, or (iv) inflation + CA surplus.

\subsection{Adjustment problems}

On the basis of the absorption - elasticity framework developed in section 1.5 and summarized by the Swan diagram we can illustrate several types of adjustment problems. In this section we will focus on two of these problems, namely the Tinbergen rule and the assignment problem. The former can be illustrated using the dilemma analyzed by Meade 
(1951). Suppose we are investigating a small country with a fixed exchange rate regime and sticky prices. It cannot influence the foreign price level, so we take that as given. This implies that the real exchange rate is fixed (since the domestic price level is sticky, the foreign price level is given, and the nominal exchange rate is fixed), say at $Q_{0}=S \cdot P_{\text {foreign }} / P_{\text {home }}$. Moreover, suppose that the country is initially facing a current account deficit and unemployment, such as illustrated by point $E_{0}$ in Figure 1.11.

Figure 1.11 Violation of the Tinbergen rule: two objectives - one instrument

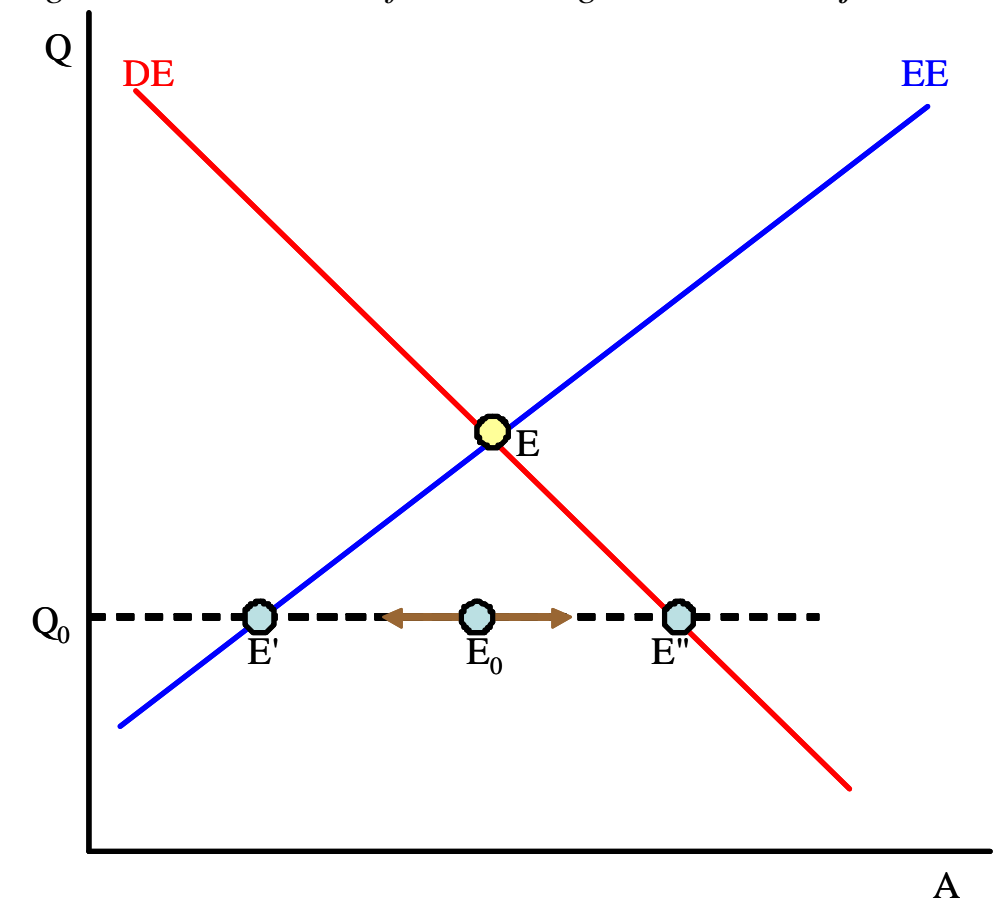

As long as the country maintains it fixed exchange rate and its domestic prices are sticky, the economy cannot move away from the horizontal line at $Q=Q_{0}$ in Figure 1.11. The policy makers now face the following dilemma. To alleviate the domestic unemployment problem they may try to stimulate an increase in absorption, thus moving the economy from point $E_{0}$ into the direction of point $E$ ". Although this movement lowers the level of unemployment it comes at a price, namely an increase in the current account deficit because the economy is simultaneously moving away from the external equilibrium curve. Alternatively, the policy ma kers may decide to alleviate the current account deficit by trying to stimulate a reduction in absorption, thus moving the economy from point $E_{0}$ 
into the direction of point $E^{\prime}$. Although this movement lowers the current account deficit it again comes at a price, namely an increase in unemployment because the economy is simultaneously moving away from the domestic equilibrium curve. In short, the policy makers face a choice: they can either try to achieve domestic equilibrium or external equilibrium, but not both simultaneously. The problem arises because the policy makers violate the Tinbergen rule, that is they try to achieve two objectives (domestic and external equilibrium) with one policy instrument (the level of absorption). According to Tinbergen (1952) this is not possible. This is formulated in the

Tinbergen rule: a government can only achieve any number of policy objectives if it has at least the same number of independent policy instruments available.

In this case, the government can reach both domestic and external equilibrium if it adjusts both the level of absorption and the exchange rate. ${ }^{3}$

This brings us to the second adjustment problem. Suppose the government decides to give up on fixing the exchange rate and uses the level of absorption and the exchange rate to achieve both domestic and external equilibrium. Which instrument should it use for which policy target? To answer this assignment problem Mundell (1962) developed the:

Principle of effective market classification: each policy instrument should be assigned to the target variable on which it has the greatest relative effect.

A simple illustration of this principle is given in Figure 1.12 in an admittedly rather restrictive framework (see, however, the discussion below). Suppose we start initially again at a point of unemployment and current account deficit, such as point $E_{0}$ in the figure. Furthermore, suppose the policy makers can somehow sequentially adjust the level of absorption and the real exchange rate to achieve domestic and external equilibrium, where they decide to use the level of absorption to achieve domestic equilibrium and the real exchange rate to achieve external equilibrium. The hypothetical path the economy would then follow if we first try to achieve domestic equilibrium is

\footnotetext{
${ }^{3}$ Note that this discussion is a special case of the policy trilemma, see Chapter 23.
} 
indicated by the points $1,2,3,4, .$. It is clear that the economy will eventually reach both domestic and external equilibrium at point $E$ if this path is followed indefinitely. ${ }^{4}$ If we, however, were to reverse the instrument - target selection in this case, that is use the absorption level to achieve external equilibrium and the real exchange rate to achieve domestic equilibrium, then we would move away from full equilibrium at point $E$ rather than towards it. This is most easily seen in Figure 1.12 by starting at point 7 and reversing the arrows to points $6,5,4$, etc., moving further and further away from full equilibrium. The latter pairing of instruments and targets is thus a violation of the principle of effective market classification. Clearly, which instrument should, according to this rule, be used for which target depends crucially on the relative slopes of the domestic and external equilibrium curves.

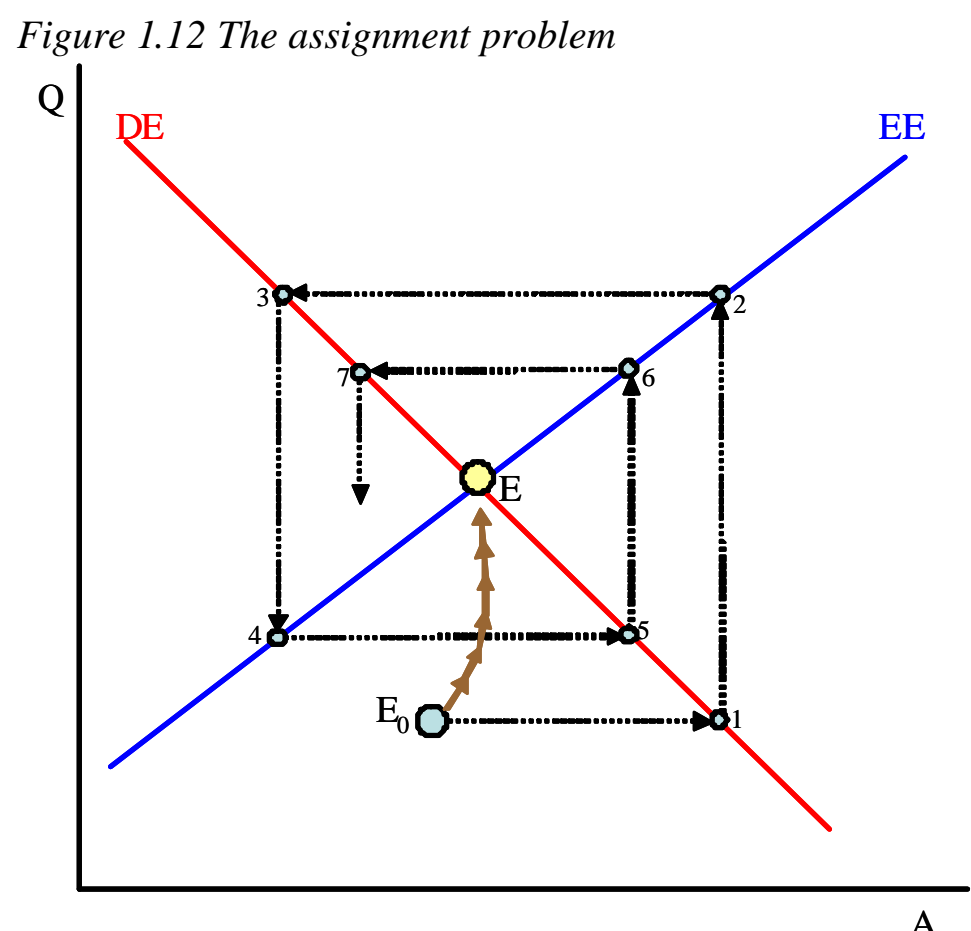

Although useful to discuss the principle of effective market classification, we should, of course, note that no actual economy adjusts to market disequilibria in the way illustrated by the cobweb 1, 2, 3, 4,.. in Figure 1.12. Not only because no policy maker has complete control over the level of absorption and the real exchange rate such as to enable

\footnotetext{
${ }^{4}$ Note that starting from point $\mathrm{E}_{0}$ we would reach it quicker if we first tried to achieve external equilibrium. This depends, of course, on the initial situation and does not materially affect the remainder of the analysis.
} 


\section{Basic exchange rate theories}

this adjustment path, but also because it appears to be very inefficient to reach full equilibrium in such a roundabout way. In practice, some gentler steering and gradual simultaneous adjustment of both the evel of absorption and the real exchange rate, as indicated by the arrows leading more directly from point $E_{0}$ to point $E$, seems to be preferable. It remains, of course, questionable whether any government is able to gather and process sufficient information such as to steer the economy directly from point $E_{0}$ to point $E$. It is, moreover, also questionable whether it actually needs to do this. If prices, wage rates, and exchange rates are not sticky or fixed but react to regular market forces, we should expect simultaneous adjustment of the level of absorption and the real exchange rate to the disequilibria as depicted in Figure 1.12 more or less in accordance with the arrows as drawn from point $E_{0}$ to point $E$. The exact path will, of course, depend on the speed with which wages, prices, expenditure levels, and exchange rates adjust.

\section{Box 1.3 Adjustment problems in Italy, 1986-1993}

At the end of the 1980s and early 1990s Italy was a member of the European Monetary System (EMS). This system of fixed exchange rates, a forerunner of EMU, used regular small realignments in the parity rates prior to 1987 to avoid a build-up of economic tension in the system arising from different macroeconomic and monetary policies. After 1987, however, it evolved in a system of rigidly fixed exchange rates, despite the fact that the Italian inflation rate remained much higher than the German inflation rate (the EMS benchmark country), see Figure 1.13. As a result of the higher inflation rate coupled with a rigidly fixed exchange rate, the lire became increasingly overvalued. This caused competitiveness problems for the Italian economy, resulting in increasing current account deficits. It became clear that the Italian government would have to start using both instruments at its disposal to try to achieve both domestic and external equilibrium, that is it would have to devalue the Italian lire. Speculators realized this dilemma and took action accordingly, which led Italy to drop out of the EMS altogether in September 1992. The lire started a sharp decline in value and the current account balance started to improve one year later. 
Figure 1.13 Italian adjustments, 1986-1993

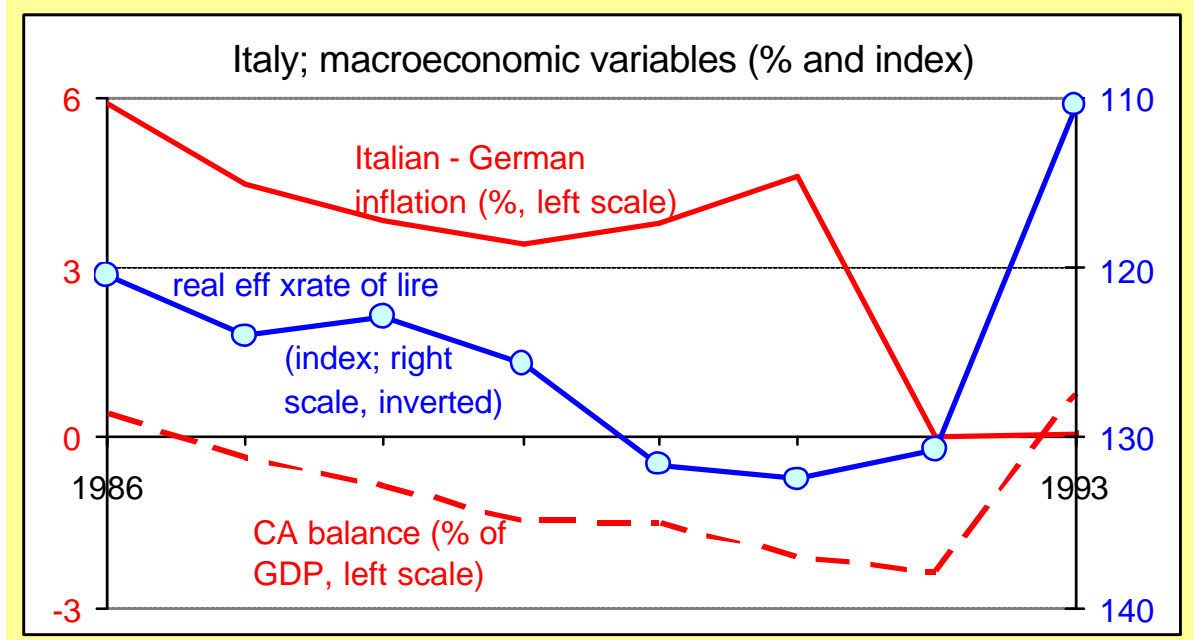

Data source: World Bank Development Indicators CD-ROM (2003); the figure shows Italian inflation in deviation from the German inflation rate; note that the real effective exchange rate of the lire (domestic currency) is depicted on an inverted scale to make movements commensurate to changes in Q in the text.

\subsection{Conclusions}

The elasticities approach focuses on the relative price effects on the current account balance. According to the Marshall - Lerner condition, which states that the sum of the price elasticities of export and import demand must exceed unity, a depreciation of the domestic currency will improve the current account balance. Empirical estimates show that the Marshall - Lerner condition is fulfilled for most countries, but only after a sufficiently long period of time has elapsed to ensure that the export and import quantitities can adjust to the change in relative prices. According to this J-curve effect, the initial response to a depreciation of the domestic currency is to deteriorate the current account balance, leading to an improvement only after an adjustment period of about one year. The absorption approach incorporates income effects into the analysis of the current account balance. This allows for a typology of types of disequilibria and the analysis of some simple adjustment problems. We discussed the Tinbergen rule (to achieve a certain number of economic objectives you need the same number of policy instruments to reach these objectives) and the assignment problem (each instrument should be used on the target for which it has the greatest relative effect). 
Basic exchange rate theories

\section{Technical Note 1.1 Derivation of the Marshall - Lerner condition}

Equation (1A.1) recalls the definition of the current account balance, where $X$ is exports, $M$ is imports, and $Q$ is the real exchange rate. Totally differentiating this equation with respect to $Q$ gives equation (1A.2).

(1A.1) $C A(Q)=X(\stackrel{+}{Q})-Q \cdot M(\stackrel{-}{Q})$

(1A.2) $C A^{\prime}(Q)=X^{\prime}-Q M^{\prime}-M$

Divide both sides by $M$, use the initial current account balance condition $X=Q M$, and the elasticity definitions $\varepsilon_{x} \equiv(Q / X) X^{\prime}>0$ and $\varepsilon_{m} \equiv-(Q / M) M^{\prime}>0$ to get:

(1A.3) $\frac{C A^{\prime}(Q)}{M}=\frac{X^{\prime}}{M}-\frac{Q M^{\prime}}{M}-1=\frac{Q X^{\prime}}{X}-\frac{Q M^{\prime}}{M}-1 \equiv \varepsilon_{x}+\varepsilon_{m}-1$

Clearly, $C A^{\prime}>0$ if, and only if, $\varepsilon_{x}+\varepsilon_{m}>1$, as stated in the main text. 
Basic exchange rate theories

\section{Chapter 2 The monetary approach}

\section{Objectives / key terms}

monetary approach

price flexibility

stocks and flows

expectations price specie flow mechanism

hoarding and dishoarding

asset approach

exchange rates corrections

The monetary approach emphasizes the fact that the exchange rate is the relative price of two monies. The demand for money therefore plays an important role in the adjustment process and in determining exchange rate levels. We also discuss the degree of price flexibility and the role of expectations formation.

\subsection{Introduction}

The elasticities approach and the absorption approach discussed in Chapter 1 were popular theories for the balance of trade for a couple of decades. As we have seen, these theories emphasize the current account (trade in goods and services), but have little to say about capital flows. Since international interactions in the world today are also characterized by large capital flows in well-developed financial markets, we must go beyond the role of trade flows and incorporate the role of financial assets for a better understanding of the balance of payments. This is what the monetary approach does.

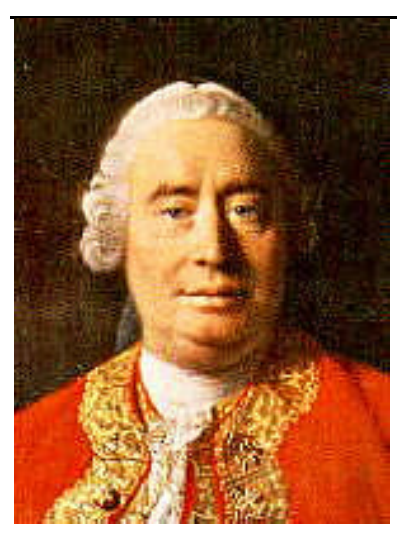

Figure 2.1 David Hume 1711 - 1776

Born in Edinburgh, David Hume was one of the most important figures in the Scottish Enlightenment. As a contemporary of Adam Smith, he was a philosopher, essayist and historian who is now best known for "A treatise of human nature" (1739-40), which was not well-received at the time and according to Hume "fell dead-born from the press." He noted that when we observe one event always following after another event, we think there is a connection between the two that makes the second event follow from the first. We can, 
however, never be sure that one event causes the other. Associated with this problem of causation is his rejection of the principle of induction. His most important contribution to economics is on the price specie flow mechanism, see section 2.3 .

\subsection{Money, price flexibility and the modelling of exchange rates}

Suppose we draw two lines in the balance of payments, one to determine the current account and one to determine the private capital account, such that the remainder directly affects the money supply (through changes in official holdings of gold, foreign exchange, special drawing rights, and eserves at the IMF), see Chapter 2 and equation (2.1). According to the monetary approach, a balance of payments disequilibrium is a monetary disequilibrium, that is a disequilibrium between the amount of money supplied and the amount of money people wish to hold. Simply stated: if the domestic demand for money is higher than what is supplied by the central bank, the excess demand for money will be satisfied by an inflow of money from abroad and vice versa if the demand for money is lower than what is supplied by the central bank. This principle and the socalled price specie flow mechanism of disequilibrium adjustment (see the next section) were already formulated by the Scottish philosopher David Hume in the $18^{\text {th }}$ century (1752; II V 9):

"Suppose four-fifths of all the money in Great Britain to be annihilated in one night, and the nation reduced to the same condition, with regard to specie, as in the reigns of the Harrys and the Edwards, what would be the consequence? Must not the price of all labour and commodities sink in proportion, and everything be sold as cheap as they were in those ages? What nation could then dispute with us in any foreign market, or pretend to navigate or to sell manufactures at the same price, which to us would afford sufficient profit? In how little time, therefore, must this bring back the money we had lost, and raise us to the level of all neighbouring nations? Where, after we have arrived, we immediately lose the advantage of the cheapness of labor and commodities; and the farther flowing in of money is stopped by our fulness and repletion."

In short, Hume argues that a sudden drop in England's money supply will lower prices, such that exports rise and imports fall. This current account surplus leads to an inflow of money from abroad, that is an inflow of gold and silver in Hume's days, which raises prices until equilibrium is restored. 
We have repeatedly emphasized in the previous chapters that the exchange rate is a price, namely the price of one currency relative to another currency, or equivalently the price of foreign money expressed in domestic money. The most direct explanation of the relative price of money then comes from analyzing the money market, which is what the monetary approach to the balance of payments does. Based on simple accounting identities, the analysis ex post must lead to the same answers as given by other (e.g. the elasticities and absorption) approaches. However, since exchange rates are a monetary phenomenon, it seems more appropriate and direct to include an analysis of the money market, as most of the remaining chapters will do. Suppose, for example, that we analyze an economy in which there are goods, bonds, and money. The balance of payments flows will be constrained as follows:

$$
\left(X_{\text {goods }}-I m_{\text {goods }}\right)+\left(X_{\text {bonds }}-I m_{\text {bonds }}\right)+\left(X_{\text {money }}-I m_{\text {money }}\right)=0,
$$

where $X$ denotes exports and Im denotes imports. The three accounts - for goods, bonds, and money - must sum to zero. An analysis of the balance of payments can, of course, focus on the current (goods and services) and capital (bonds) account, but that implies that the nature of the money market is ignored, which seems unwarranted (and rather roundabout) if one wants to explain the relative price of money.

Figure 2.2 Degrees of price flexibility

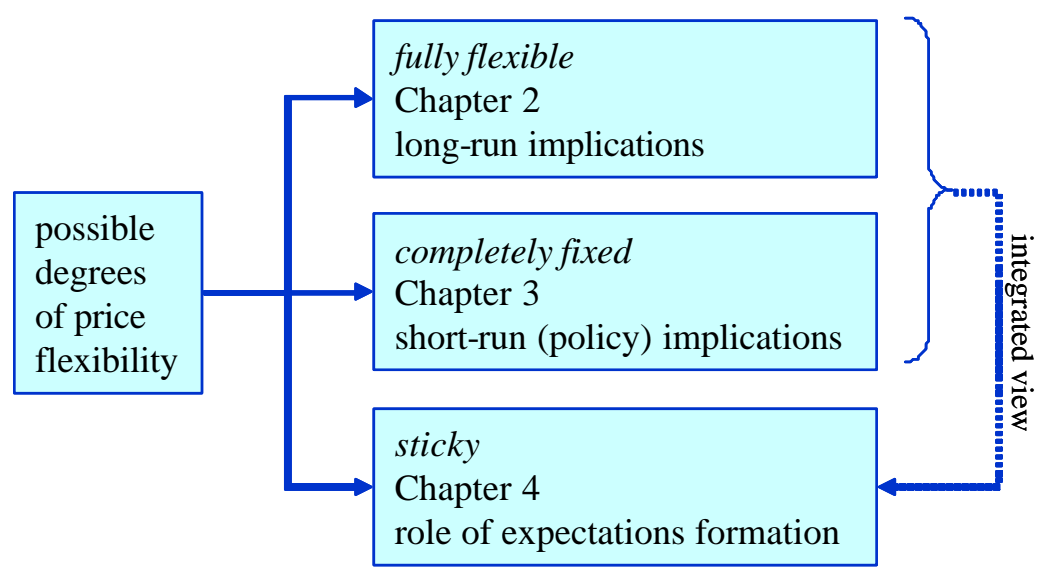

The above does not mean, of course, that the price of goods is not important for determining equilibrium, if only because it affects the nominal demand for money, see Chapter 19. This brings us to an important topic, namely the degree of price flexibility in 


\section{Basic exchange rate theories}

determining the balance of payments, possibly relative to exchange rate flexibility. We can distinguish between three main possibilities, each of which has been analyzed separately for good reasons (and we will do so too, see Figure 2.2), namely:

- prices are fully flexible and determined by equilibrium conditions; this possibility is analyzed in this chapter, focusing on the monetary approach to the balance of payments. Although full price flexibility is assumed to hold at any point in time in this analysis, both for fixed and floating exchange rate regimes, it is probably best to interpret the analytic results as providing insight into long-run economic relationships.

- prices are completely fixed and exogenously given throughout the analysis; this possibility allows for disequilibrium situations on the goods market (unemployment) and is analyzed in Chapter 3, which focuses on the (short-run) implications of fiscal and monetary policy under various circumstances.

- prices are sticky, that is they are fixed in the short-run and gradually adjust over time towards their long-run equilibrium level; this possibility is analyzed in Chapter 4, where it is assumed, more specifically, that prices are sticky whereas exchange rates are fully flexible. This turns out not only to allow us to integrate the insights gaine $\mathrm{d}$ in Chapters 2 and 3 into a single framework, but also to focus on the issue of expectations formation and the empirically observed degree of exchange rate variability relative to price variability, see also Box 2.1.

\section{Box 2.1 Price and exchange rate flexibility in Europe}

It is quite clear that prices of goods and services change over time, as does the exchange rate. We already noted in Chapter 20 that exchange rates change very frequently, not only from month to month, but even from week to week, day to day, and hour to hour. We are not used to such frequent changes in prices of goods and services. The IKEA catalogue in the Netherlands, for example, is published in August of every year with prices that are valid for one year. The prices of magazines, haircuts, etc. are changed regularly, but rather infrequently. The degree of price flexibility relative to the degree of exchange rate flexibility is, of course, an empirical question. Figure 2.3 uses monthly European data and the US dollar - euro exchange rate to show that, indeed, exchange rate changes are much larger from one period to the next than are price changes, providing some support 
for the argument that prices are sticky relative to exchange rates. One important explanation for this observed price stickiness is the fact that the wages of workers, which represent a large fraction of the costs of providing goods and services, are written into long-term contracts and negotiated only periodically.

Figure 2.3 Price and exchange rate flexibility

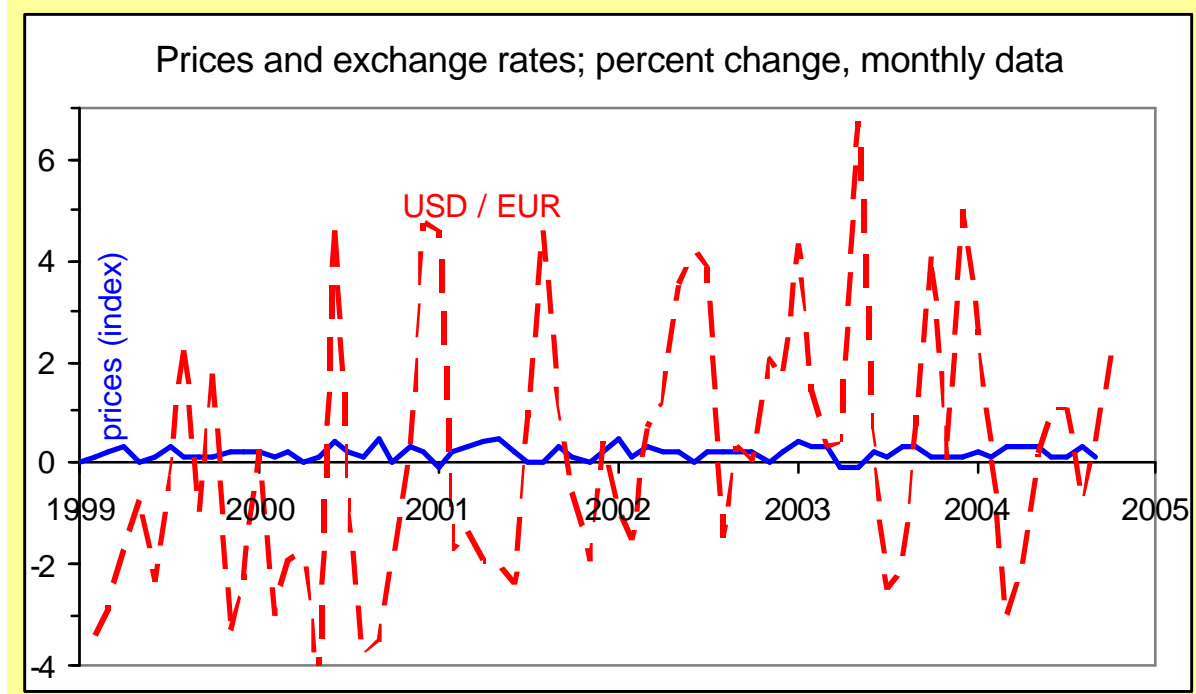

Data source: http://www.ecb.int (HICP, 14 November 2004)

Figure 2.3 is, of course, somewhat biased as it depicts changes in the overall price index, which is a composite of several individual prices (such that increases in one price may cancel with decreases in another price) relative to a single exchange rate. A similar picture emerges, however, if we use nominal effective exchange rates, see Chapter 20. Alternatively, we can analyze the variability of individual components of the European harmonized index of consumer prices (HICP) relative to the variability of some other exchange rates. This is done in Table 2.1, which shows that the individual consumer price components (food, processed food, industrial goods, energy, and services) have a much lower variability, that is a lower standard deviation and a lower range of changes (= maximum - minimum) than the exchange rate changes. It also shows that in this particular period energy is by far the most variable component of consumer prices, but not quite as variable as the exchange rates reported in the second part of the table. 
Basic exchange rate theories

Table 2.1 Summary statistics of monthly changes, Europe (percent)

\begin{tabular}{l|cccccc}
\hline \hline & \multicolumn{5}{|c}{ changes in prices } \\
& overall & proc food & food & ind goods & energy & services \\
\hline mean & 0.18 & 0.21 & 0.19 & 0.07 & 0.42 & 0.20 \\
st dev & 0.14 & 0.19 & 0.55 & 0.12 & 1.38 & 0.12 \\
min & -0.10 & -0.10 & -0.60 & -0.30 & -2.90 & -0.10 \\
max & 0.50 & 1.20 & 2.50 & 0.50 & 4.20 & 0.60 \\
\hline & USA & Australia & S. Korea & Hong Kong & Japan & S. Africa \\
& 0.14 & -0.08 & 0.11 & 0.15 & 0.09 & 0.28 \\
\hline mean & 2.55 & 2.35 & 3.07 & 2.53 & 2.77 & 4.23 \\
st dev & -4.33 & -5.79 & -5.74 & -4.29 & -6.42 & -6.86 \\
min & 6.77 & 6.72 & 9.99 & 6.76 & 8.91 & 20.03 \\
max & & \multicolumn{7}{c}{ changes in exchange rates } \\
Data source: www.ecb.int $;$ st dev = standard deviation, min = minimum, max = maximum, proc
\end{tabular}

$=$ processed, ind $=$ industrial $;$ data range: February $1999-$ September 2004

\subsection{The monetary model and the price specie flow mechanism}

This section presents a simple version of the monetary model with fully flexible prices under fixed exchange rates to highlight the role of money in payments adjustment, also known as the (price) specie flow mechanism. ${ }^{5}$ Since exchange rates are fixed, the central bank has to intervene by buying or selling international reserves to maintain the fixed exchange rates, see Box 1.1. This implies that the money supply becomes an endogenous variable. Using a simple mechanistic money supply process, see Box 19.2, money supply is equal to a money multiplier (which we set equal to one for convenience) times high powered money, that is domestic credit $D$ plus net foreign assets $R$.

$$
M=D+R
$$

A change in the money supply is then caused by a change in the domestic component $D$ or a change in the reserves $R$, where the latter is equal to the sum of the current and capital account balance in a system of fixed exchange rates, see Chapter 19.

\footnotetext{
${ }^{5}$ Whitman (1975) calls it a global monetarist model.
} 
We distinguish between two countries, called Home and Foreign. Variables without any subscripts will refer to Home, whereas variables with a subscript $f$ will refer to Foreign. Throughout the analysis, we will focus attention on the Home country although similar functions and remarks also hold for the foreign country. Assuming that, as a result of fully flexible prices, output is always at its full employment level we pose the simplest possible money demand function in equation (2.3), where nominal money demand $M$ is equal to the velocity $V$ times the price level $P{ }^{6}$ The homogeneity of money in prices implies that there is no money illusion, such that money is neutral in the long-run.

$$
M^{d}=V P \quad M_{f}^{d}=V_{f} P_{f}
$$

One of the implications of the monetary approach to the balance of payments is that it focuses attention on the stock of money as an equilibrium condition, that is it is a stock approach rather than, for example, the elasticities approach which focuses on the flow demand of goods and services. Any stock approach is simultaneously also a flow approach to the extent that the change of a stock variable over time is a flow variable. For that reason, it is convenient to have a clear separate notation for the change of a variable over time, for which we will use an over dot. That is, we henceforth use the following

Convention: an over dot over a variable denotes its derivative with respect to time t, that is its change over time, so $\dot{x} \equiv d x / d t$.

Equation (2.3) gives the long-run implications of the money demand function, but as discussed above individuals in an open economy can only adjust the money stock gradually through the balance of payments. This short-run money market adjustment mechanism is given in equation (2.4), where individuals believe that at current prices they can adjust the money stock by hoarding (spending less than income) or dishoarding (spending more than income) and $\alpha$ is the speed of adjustment. Our simple model is completed in equation (2.5) by invoking the law of one price in this one good world.

\footnotetext{
${ }^{6}$ Given the fixed income level, this is a so-called 'Cambridge' money demand function.
} 
Basic exchange rate theories

$$
\dot{M}=\alpha(V P-M) \quad \dot{M}_{f}=\alpha_{f}\left(V_{f} P_{f}-M_{f}\right)
$$

$$
P=S P_{f}
$$

\section{Figure 2.4 Equilibrium hoarding and dishoarding}

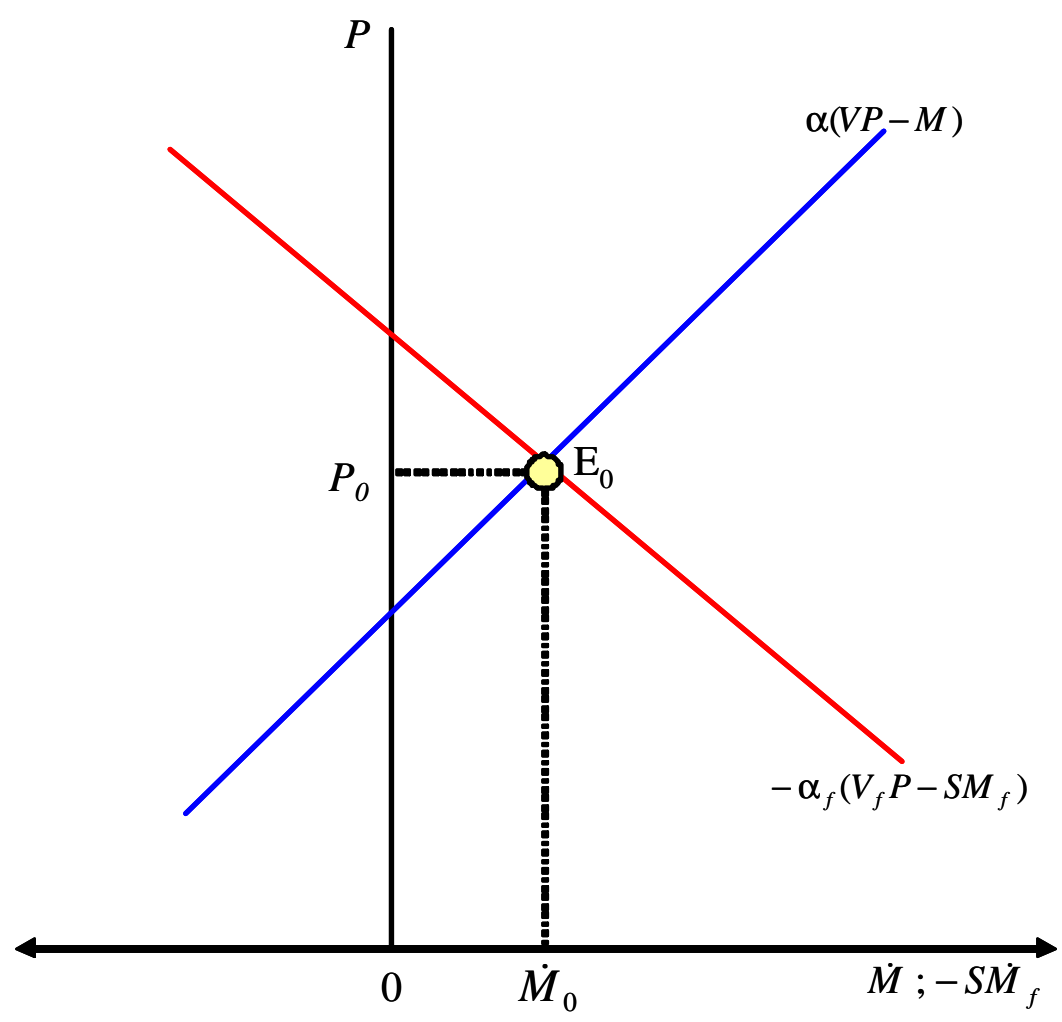

Figure 24 shows the equilibrium rate of hoarding $\dot{M}$ for the Home economy. As the price level rises, the nominal demand for money increases, which creates a stock excess demand for money and thus an incentive for hoarding to adjust the money stock. Since the exchange rate is fixed, we can depict Foreign's rate of dishoarding $-S \dot{M}_{f}$ in the same diagram as a decreasing function of the price level for similar reasons. Equilibrium in the figure is reached at point $E_{0}$, where the domestic rate of hoarding is equal to the foreign rate of dishoarding. This determines the equilibrium price level $P_{0}$ and the equilibrium rate of hoarding $\dot{M}_{0}$ as a function of the demands for money and the current distribution of the world money stock $M+S M_{f}$ over the two countries. Note, however, that the equilibrium at point $E_{0}$ affects the distribution of the world money stock. More 
specifically, the Home country is hoarding money, so its money stock is increasing, while the foreign country is dishoarding, so its money stock is decreasing. This change in the distribution of the world money stock affects the equilibrium depicted in the figure.

Figure 2.5 Price specie flow adjustment process

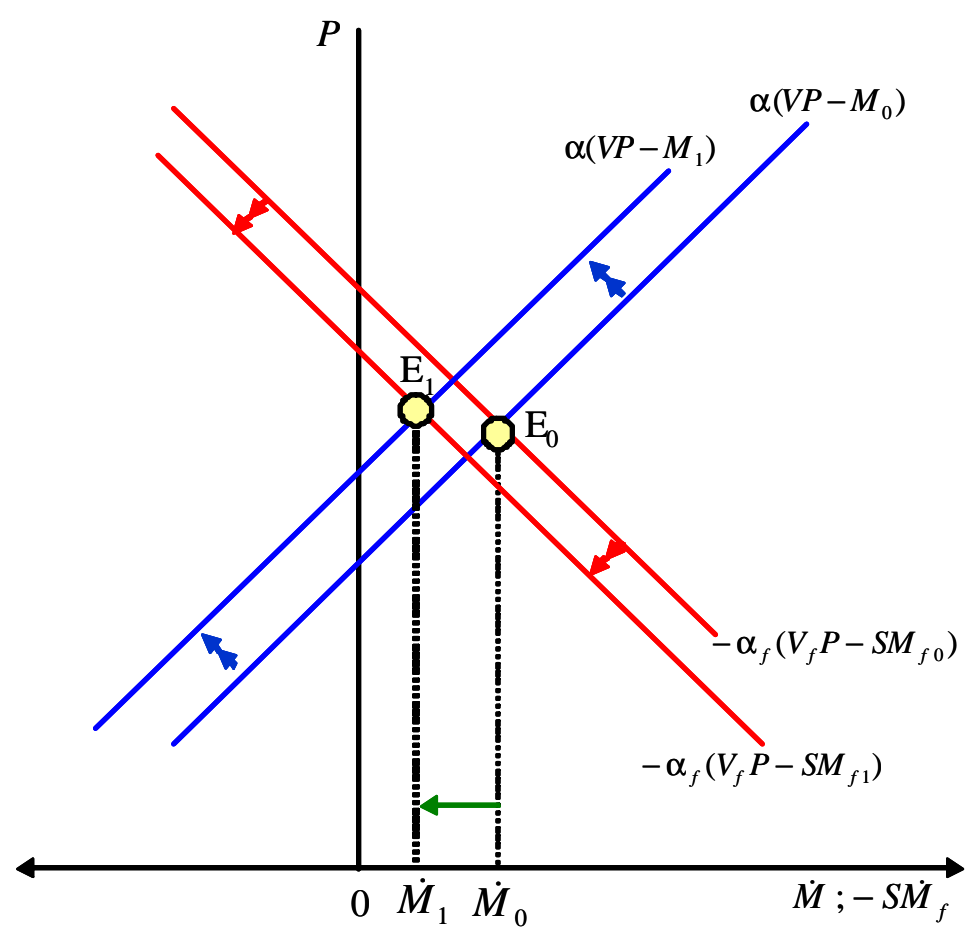

Figure 2.5 illustrates this price specie flow adjustment process over time. The equilibrium rate of hoarding resulting from domestic income being larger than domestic spending leads to an increase in assets, that is an increase in the domestic money stock, which shifts Home's equilibrium hoarding schedule up and to the left over time. Similarly, the decrease in the money stock abroad shifts Foreign's dishoarding schedule up and to the left over time as well. As the world money stock is redistributed across the two countries the equilibrium therefore shifts to the left (in the figure from $\mathrm{E}_{0}$ to $\mathrm{E}_{1}$ ) and reduces the degree of hoarding and dishoarding until a long-run equilibrium is reached along the vertical axis (not shown). During this process the world price level may either rise or fall. Figure 2.5 illustrates a situation in which the price level is rising as the world money stock is redistributed from Foreign to Home, which occurs if, and only if, Home's adjustment parameter is larger than Foreign's, that is if $\alpha>\alpha_{f}$. If these two parameters 


\section{Basic exchange rate theories}

are the same, a redistribution of the world money stock will not affect the equilibrium price level, see Technical Note 2.1.

\section{Box 2.2 Effect of a devaluation in the basic monetary model}

What is the effect of a devaluation of the Home currency in the model of section 2.3? Suppose the exchange rate (the price of the foreign currency in terms of domestic currency) rises from $S_{0}$ to $S_{1}$. Since there is only one good and the law of one price holds, a devaluation cannot change the relative price of goods. Moreover, since there is full employment, there are no income and employment effects. As Dornbusch (1980a, pp. 125-126) puts it: "What then can a devaluation do? In the present model a devaluation is a change in the relative price of two monies. (This is always true. Here it is the only aspect of a devaluation.)"

Figure 2.6 Effect of a devaluation of the Home currency

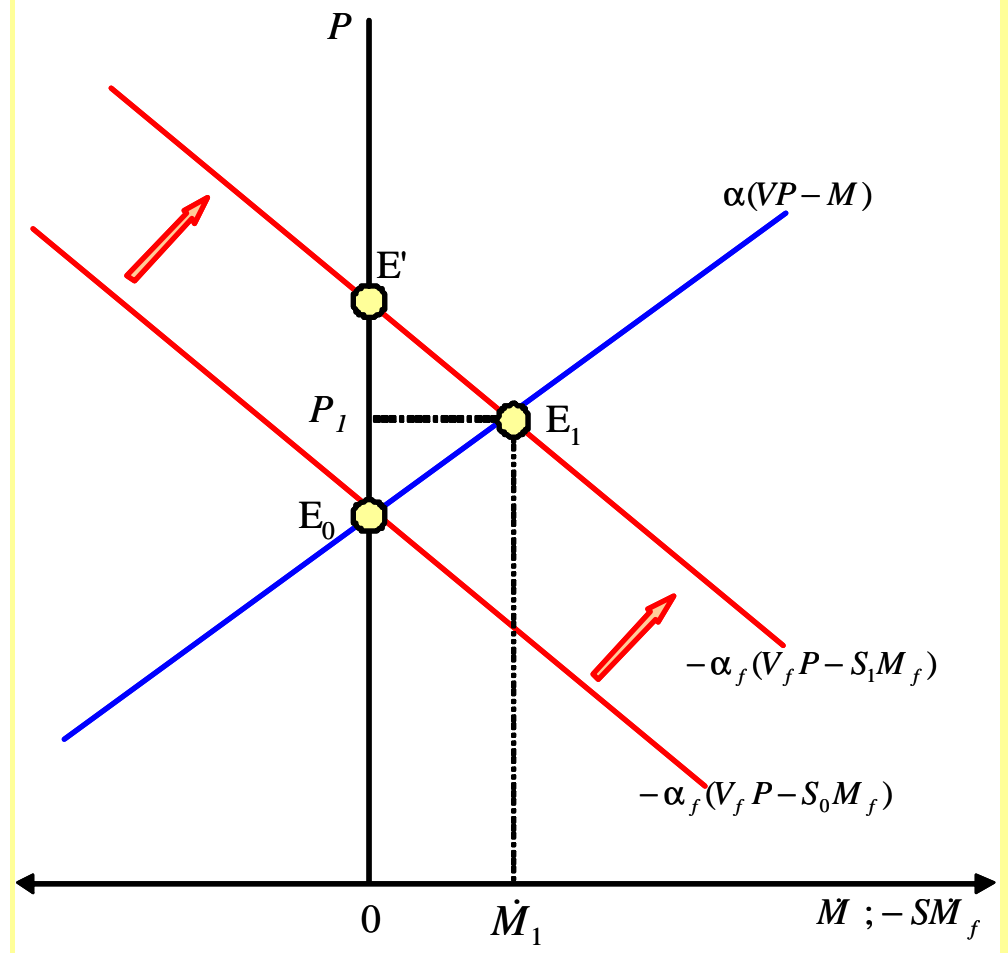

At initial prices in terms of Home currency $\mathrm{t}$ follows from $P=S P_{f}$ that foreign prices would fall proportionally to the devaluation. Foreign's money demand $M_{f}^{d}=V_{f} P_{f}$ would therefore fall, see equation (2.3), which results in an incentive to dishoard in Foreign at 


\section{Basic exchange rate theories}

current domestic prices. This is illustrated in Figure 2.6 by the shift to the right of Foreign's dishoarding schedule. The new short-run equilibrium is at point $E_{l}$ with higher prices in terms of domestic currency. The prices measured in foreign currency must have fallen since the domestic prices are increased from $E_{0}$ to $P_{1}$ while the increase in the exchange rate was proportional to the rise from $E_{0}$ to $E^{\prime}$. The Home country thus creates a surplus on the current account in response to the devaluation of the domestic currency, setting in motion an adjustment process to increase the domestic money supply. This is caused by the fact that at constant domestic prices the devaluation causes foreign prices to fall and the purchasing power of cash balances abroad to increase. Foreigners increase their spending as a result of this excess real balance, leading to a price rise in domestic currency. Over time the current account balance implies a redistribution of the world money stock, leading to rising expenditure in Home and a falling expenditure abroad until equilibrium is restored. The effects of the devaluation of the Home currency are therefore transitory.

\subsection{Flexible price monetary approach}

Section 2.3 introduced the basic monetary model and discussed the price specie flow adjustment mechanism in a system of fixed exchange rates. Since the early 1970s, however, most large trading blocks have moved to a system of floating exchange rates relative to one another (while they might maintain fixed exchange rates within the trading block, as is the case for most European countries), see Chapter 23. This section therefore discusses how the monetary approach can be used to determine the exchange rate in a system of floating exchange rates.

As already emphasized in Chapters 20-22, one of the most important empirical characteristics of the floating exchange rate experience is the high volatility of exchange rates. To a considerable extent this high volatility was not expected, because Friedman (1953) argued that stability of a flexible exchange rate regime was ensured by the stabilizing behaviour of speculators. The asset approach to the exchange rate, a simple version of which is discussed in this section, explains this high volatility by emphasizing that the exchange rate is an asset price (namely the relative price of monies). To 


\section{Basic exchange rate theories}

determine the exchange rate, we should therefore use the tools for the determination of asset prices, such as bond prices or share prices, see Mussa $(1976,1979)$. A strong point of this view is that we observe that exchange rate volatility is similar in magnitude to the volatility of other asset prices. The price of an asset, such as a share of ING bank, changes because the market changes its view of what the asset is worth, presumably something like the expected discounted value of future profits. This means that in the asset approach substantial changes in the exchange rate can take place without observing substantial underlying trade taking place. It also means that in the asset approach expectations formation is important for understanding exchange rate levels and changes. The expectations issue is touched upon in Box 2.3, but we reserve a more thorough analysis of expectations formation for Chapter 4.

As in section 2.3, we analyze a two-country world, where Foreign variables are identified by the sub index $f$. Prices are fully flexible and instantaneously adjust to ensure equilibrium on the money market. The real demand for money $M / P$ is more complete than in the analysis of section 2.3; it is a standard positive function of the income level $y$ (transactions demand) and a negative function of the interest rate $i$ (opportunity costs). Using a logarithmic specification, equilibrium on the money market is given by:

$$
m-p=\alpha y-\beta i \quad m_{f}-p_{f}=\alpha y_{f}-\beta i_{f}
$$

Note that we have assumed for simplicity that the money demand parameters $\alpha$ and $\beta$ are the same for the two countries, although this is by no means necessary. The two countries produce an identical good, which is viewed as a perfect substitute. Recalling that $S$ is the exchange rate (the price of foreign currency in terms of home currency) and invoking the law of one price implies:

$$
p=s+p_{f}
$$

Combining the information given in equations (2.5) and (2.6) determines the exchange rate, see Technical Note 2.1 and equation (2.8). Box 2.3 discusses some potential complications of (2.8) regarding uncovered interest parity and expectations formation.

$$
s=\left(m-m_{f}\right)-\alpha\left(y-y_{f}\right)+\beta\left(i-i_{f}\right)
$$


The results of this flexible price monetary approach for determining the exchange rate as reflected in equation (2.8) are straightforward:

- A more rapid increase in the domestic money supply than in the foreign money supply increases the exchange rate one for one (and thus leads to a domestic currency depreciation). Like all other prices, the exchange rate (which is the price of foreign currency) increases proportionally with the money stock.

- An increase in the domestic income level reduces the exchange rate (and thus leads to a domestic currency appreciation). The increase in income increases the transactions demand for money. Given the nominal money supply, equilibrium on the money market can only be restored if the domestic price level falls, which given the law of one price requires a reduction in the exchange rate.

\section{Box 2.3 Expectations}

Equation (2.8) gives a first indication of the relationship between exchange rates, money stocks, income levels, and interest rates. As discussed in Chapter 22, however, the interest rates in the two countries are related to one another through a simple mechanism of arbitrage under risk neutrality by the uncovered interest arbitrage condition, see equa tion 22.4. More specifically, the expected change in the exchange rate must be equal to the difference between Home and Foreign interest rates:

$$
s_{t+1}^{e}-s_{t}=\left(i_{t}-i_{f, t}\right)
$$

Figure 2.7 Interdependencies between expectations and realizations

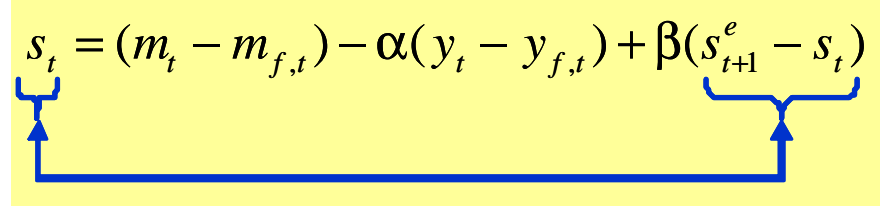

Taking this additional relationship into consideration means that equation (2.8) is not the end of the flexible price monetary approach story, because substituting the uncovered interest parity condition (29) into the equilibrium relationship (2.8) gives rise to an interdependency between expectations and realizations, as illustrated in Figure 2.7 (where 


\section{Basic exchange rate theories}

we have added a time sub index $t$ to be specific about the timing of each variable). Note that there is a nested reasoning in which the exchange rate today depends on the expected exchange rate tomorrow, while the exchange rate tomorrow will depend on the expected exchange rate as of tomorrow for the day after tomorrow, etc. We must have some method to solve this infinitely nested problem. As this is an important and mon-trivial expectations issue, we postpone its analysis until Chapter 4.

\subsection{Money, income, and exchange rates}

In a continuation of our discussion in section 21.3, where we argued that there is indeed a long-run relationship between exchange rates and prices (relative PPP), we will now argue that there is indeed a long-run relationship between exchange rates, money stocks and income levels. The monetary approach, as summarized in equation (2.8), can in this respect essentially be viewed as providing the main reasons why price levels in different countries may change, namely because the money stock changes or because the income level changes. For reasons explained in Box 2.3, we will ignore the influence of changes in the interest rate in the sequel.

As the monetary approach is an extension of the PPP approach discussed in Chapter 21 and we already know that relative PPP is a long-run and not a short-run relationship, we will use the same procedure as used in section 21.3 by analyzing changes over a long enough time period. More specifically, using World Bank data and the US as a benchmark, we take the time difference of equation (2.8) from 2001 to 1960 to estimate changes in the US dollar foreign exchange rate as a function of changes in the domestic money stock (M2) relative to the US money stock and changes in the domestic income level (measured in constant 1995 US dollar) relative to the US income level. This gives:

$$
\begin{aligned}
s_{2001}-s_{1960}= & -\underset{(0.283)}{0.557}-\underset{(0.294)}{0.898} \times\left[\left(y_{c j, 2001}-y_{c j, 1960}\right)-\left(y_{U S, 2001}-y_{U S, 1960}\right)\right]+ \\
& +\underset{(0.060)}{0.936} \times\left[\left(m_{c j, 2001}-m_{c j, 1960}\right)-\left(m_{U S, 2001}-m_{U S, 1960}\right)\right]
\end{aligned}
$$

The estimated equation (2.10) explains about 84 per cent of the variance in exchange rates $\left(R^{2}=0.84\right)$ and indicates that the exchange rate depends positively on relative changes in the money stock and negatively on relative changes in output. Simple 


\section{Basic exchange rate theories}

hypothesis tests would show that the estimated coefficient for differences in the money stock (0.936) does not differ significantly from one while the estimated coefficient for differences in output does differ significantly from zero, all of which is in accordance with the flexible price monetary apprach discussed in section 2.4 (see Box 21.1 for some information on econometrics and hypothesis testing).

Figure 2.8 Money and exchange rates (corrected for output)

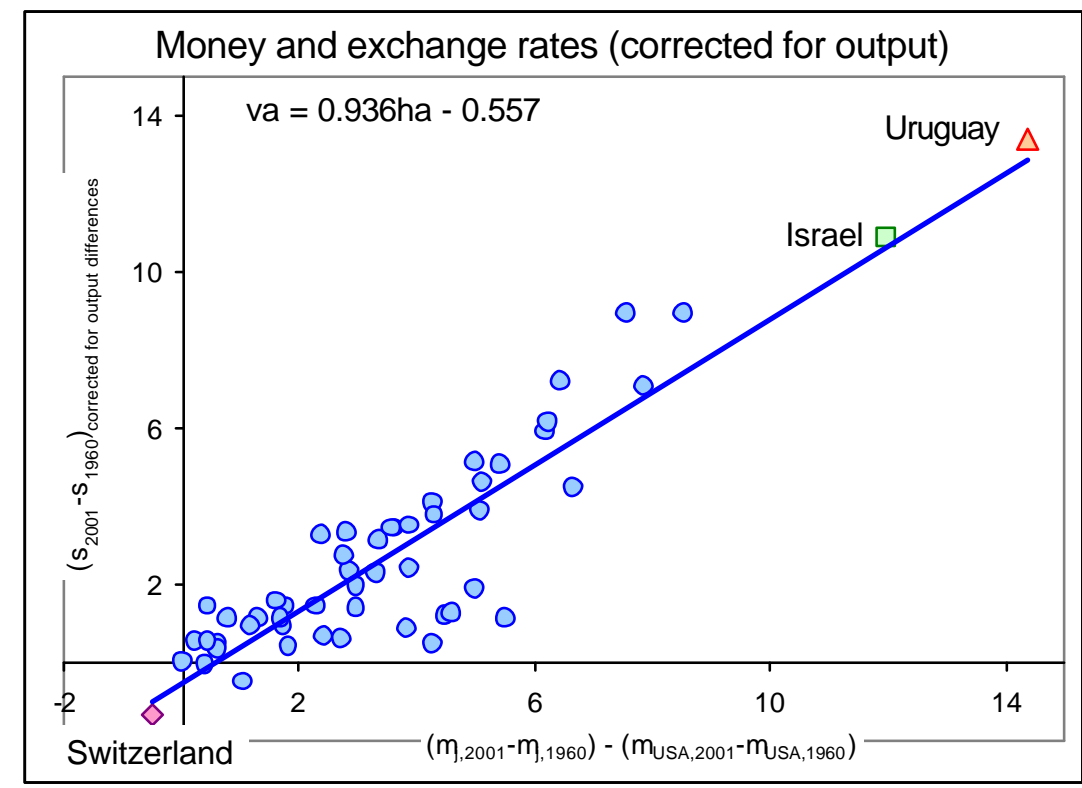

Data source: World Bank Development Indicators CD-Rom 2003; va = vertical axis, ha = horizontal axis

\section{Box 2.4 Exchange rate corrections}

If we want to illustrate the empirical results of equation (2.10), we have to overcome an elementary obstacle. Since the exchange rate depends both on differences in the money stocks and on differences in output, if we were to draw a picture with changes in the exchange rate on the vertical axis and the difference in changes of the money stock on the horizontal axis, part of the depicted observed change in the exchange rate should actually be attributed to the change in output (and not to the change in money depicted on the horizontal axis). To overcome this graphical obstacle, it is customary to calculate corrected changes in the exchange rate before depicting them in a graph, that is if we want to illustrate the relationship between exchange rates and the money stock we first neutralize the effect of output on the exchange rate, while if we want to illustrate the 


\section{Basic exchange rate theories}

relationship between exchange rates and output we first neutralize the effect of money on the exchange rate. So how do we perform this neutralization or correction? Well, that is actually quite simple. Once we have an empirical estimate of the influence of one variable on another, the correction simply subtracts this influence from the observations. More specifically, using the empirical estimates of equation (2.10) we get:

$$
\begin{aligned}
& \left(s_{2001}-s_{1960}\right)_{\text {corrected for output }}=s_{2001}-s_{1960}+0.898 \times\left[\left(y_{c j, 2001}-y_{c j, 1960}\right)-\left(y_{U S, 2001}-y_{U S, 1960}\right)\right] \\
& \left(s_{2001}-s_{1960}\right)_{\text {corrected for money }}=s_{2001}-s_{1960}-0.936 \times\left[\left(m_{c j, 2001}-m_{c j, 1960}\right)-\left(m_{U S, 2001}-m_{U S, 1960}\right)\right]
\end{aligned}
$$

It is these exchange rates corrected for other influences which best illustrate the influence of a specific variable. This is used to produce Figures 2.8 and 29 .

Figure 2.8 illustrates the impact of differences in changes in the money stock on the exchange rate, after the latter is corrected for differences in output (see Box 2.4). Countries such as Uruguay, which have experienced a large increase in the money stock relative to the US, were confronted with a large increase in the US dollar exchange rate. The opposite holds for countries which experienced a decline in the money stock relative to the US, such as Switzerland. Similarly, Figure 2.9 illustrates the impact of differences in changes in output on the exchange rate, after the latter is corrected for differences in money. Countries such as Israel which have experienced an increase in output relative to the US, are confronted with a decrease in the exchange rate of the US dollar (an appreciation of the domestic currency) after the latter is corrected for the change in the money stock. The opposite holds for countries such as Switzerland, which experienced a decrease in output relative to the US. As a comparison of the two figures indicates, the impact of the money stock on the exchange rate seems to be more convincing than the impact of output on the exchange rate. This suggestion, which can be corroborated by statistical tests, is not surprising as the exchange rate is a monetary phenomenon. Nonetheless, the impact of output on the demand for money does have a noticeable and significant impact on long-run changes in the exchange rate. 
Figure 2.9 Output and exchange rates (corrected for money)

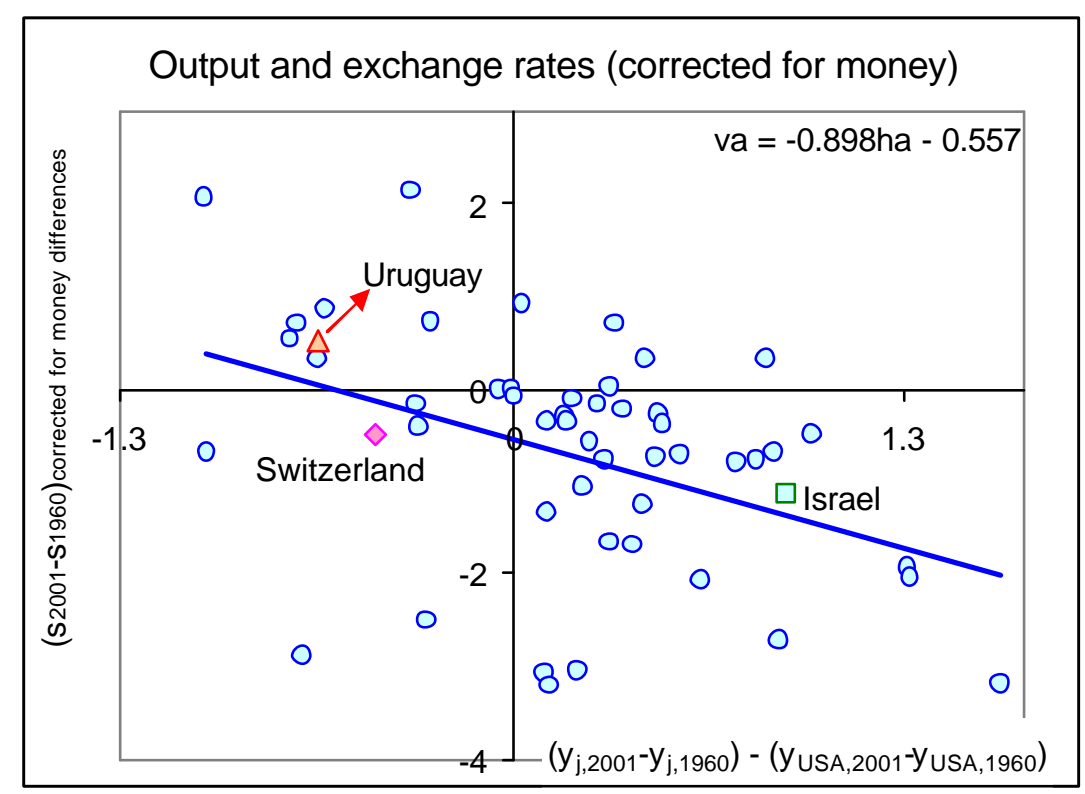

Data source: World Bank Development Indicators CD-Rom 2003; va = vertical axis, ha = horizontal axis

\subsection{Conclusions}

The monetary approach to the balance of payments stresses the fact that the exchange rate is the relative price of two monies. Accordingly, a disequilibrium results if the demand for money differs from the amount supplied by the monetary authorities. In the basic monetary model with fixed exchange rates (see section 23), such a disequilibrium gives rise to an adjustment process (Hume's price specie flow mechanism) which redistributes the world's money stock between the two countries until a new (stock) equilibrium is reached. In the flexible price monetary approach under flexible exchange rates (see section 2.4), such a disequilibrium gives rise to an immediate adjustment of the exchange rate to equilibrate the demand for and supply of money. The latter approach indicates that the domestic currency depreciates one for one if the money supply increases and appreciates if the income level increases. Both of these effects are supported by (longrun) empirical evidence. The degree of price flexibility has important consequences for the modelling of exchange rate behaviour. Assuming, as we have done in this chapter, that prices are fully flexible is probably best interpreted as indicative of long-run exchange rate behaviour. We analyze the consequences of (short-run) fixed and (medium-run) sticky prices in the next two chapters. The modelling of expectations 
Basic exchange rate theories

formation also has important consequences for understanding exchange rate behaviour. This issue is further analyzed in Chapter 4.

Technical Note 2.1 Equilibrium price in the basic monetary model

The equilibrium in the basic monetary model of section 2.3 requires that the domestic rate of hoarding is equal to the foreign rate of dishoarding, that is $\dot{M}=-S \dot{M}_{f}$. Using equation (2.4), this gives the equilibrium condition:

(2A.1) $\alpha(V P-M)=-\alpha_{f}\left(V_{f} S P_{f}-S M_{f}\right)$

Substituting the law of one price (2.5) and solving for the equilibrium price level gives:

(2A.2) $P=\frac{\alpha M+\alpha_{f} S M_{f}}{\alpha V+\alpha_{f} V_{f}}$

Technical Note 2.2 Flexible price monetary approach

By solving equations (2.6) for the respective price levels and subtracting, we obtain:

(2A.3) $p-p_{f}=[m-(\alpha y-\beta i)]-\left[m_{f}-\left(\alpha y_{f}-\beta i_{f}\right)\right]$

Solving (2.7) for the exchange rate and substituting (2A.3) gives

(2A.4) $s=p-p_{f}=\left(m-m_{f}\right)-\alpha\left(y-y_{f}\right)+\beta\left(i-i_{f}\right)$ 
Basic exchange rate theories

\section{Chapter 3 Monetary and fiscal policy in the short-run}

\section{Objectives / key terms}

Fixed exchange rates

Instantaneous adjustment

Monetary expansion

Short-run

Offset coefficient
Perfect substitutes

Capital mobility

Fiscal expansion

Mundell - Fleming model

Crowding out

We analyze the short-run implications of monetary and fiscal policy for small and large countries, under different exchange rate regimes, and varying degrees of capital mobility.

\subsection{Introduction}

The previous chapter focused on the long-run determination of the money stock (fixed exchange rates) or the exchange rate (flexible exchange rates), using the monetary approach to the balance of payments if prices are fully flexible. Monetary and fiscal authorities and politicians are, however, frequently more interested in the short-run implications of policy changes, in an effort, for example, to reduce unemployment, boost output, and increase the chance of being re-elected. Consequently, this chapter focuses on the short-run implications of monetary and fiscal policy under various economic circumstances. We take the price level as fixed and do not consider the implications of price adjustment, changes in wealth, or expectations formation. These issues are analyzed in Chapter 28.

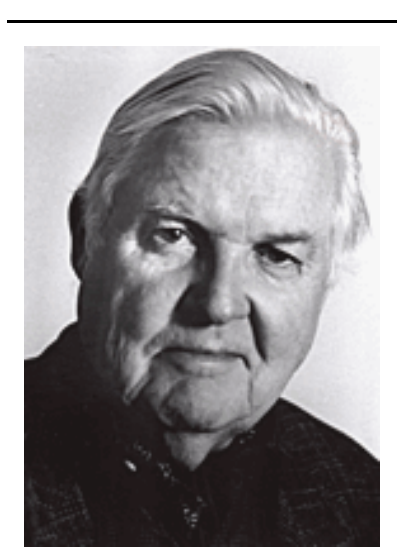

Figure 3.1 Robert Mundell 1932 -

The Canadian Robert Mundell studied at MIT and the London School of Economics. He joined Columbia University in 1974, but also worked inter alia at the IMF, the University of Chicago, and the Graduate Institute in Geneva. Using formal analysis and intuitive interpretation of the results, he provided the foundations for the analysis of the implications of monetary and fiscal policy 


\section{Basic exchange rate theories}

under different exchange rate regimes and various degrees of capital mobility. Similar work in the 1960s by Marcus Fleming, a long time Deputy Director of the IMF research department, ensured that textbooks refer to the Mundell - Fleming model, although it is clear that Mundells influence and contribution predominates, as is evident from the Dornbusch quote in the main text. Mundell had a keen eye for answering questions with important policy implications, as he also did when analyzing the theory of optimum currency areas, which greatly influenced the policy debate on Europe's EMU many years later. This influence was clearly acknowledged when he was awarded the Nobel prize in economics in 1999, where the press release states: "At a given point in time academic achievements might appear rather esoteric; not long afterwards, however, they may take on great practical importance."

The fundamental insights exposed in this chapter were developed by Robert Mundell (1962, 1963, and 1968) and Marcus Fleming (1962). The framework of analysis is therefore known as the Mundell - Fleming model. A thorough understanding of the main implications of this framework is crucial for policy makers up to this day, to know what they can and cannot do under particular circumstances. This derives mainly from Robert Mundell's contributions who, as Dornbusch (1980b, pp. 45) notes:

"created models and concepts that rapidly became the Volkswagens of the field easy to drive, reliable, and sleek. Mundell drew on the Canadian experience to point out the striking implications of capital mobility for the conduct of stabilisation policy. .. his innovation went beyond imposing important new questions in that he created simple, forceful models to serve as organizing frameworks for thought and policy and as springboards for posing new problems."

The Mundell - Fleming model analyzes the interactions of output, money, and interest bearing assets in an open economy. The effectiveness of fiscal and monetary policy is influenced by three factors, namely (i) the exchange rate regime, (ii) he size of the country, and (iii) the degree of capital mobility. As summarized in Figure 3.2, we analyze these influences sequentially in the remainder of this chapter, starting with a fixed exchange rate regime for a small country under perfect capital mobility. This setting finds fiscal policy to be very effective and monetary policy entirely ineffective, due to the 
endogeneity of the money stock under fixed exchange rates. These strong policy conclusions are mitigated for large countries (section 3.3) and under imperfect capital mobility (section 3.4). The effectiveness of fiscal and monetary policy for a small country under perfect capital mobility is reversed under a regime of flexible exchange rates (section 3.5), in which case monetary policy is very effective and fiscal policy is entirely ineffective. These conclusions are again mitigated for large countries and under imperfect capital mobility (section 3.6).

Figure 3.2 Overview of Chapter 3, short-run analysis

\section{Fixed exchange rates}

3.2 Small country, perfect capital mobility

3.3 Large country, perfect capital mobility

3.4 Small country, imperfect substitutability

\section{Flexible exchange rates}

3.5 Small country, perfect capital mobility

3.6 Large country and imperfect substitutability

\subsection{Fixed exchange rates (small country, perfect capital mobility)}

We analyze a setting in which there are two assets: money and bonds, where money holdings do not earn an interest rate whereas bond holdings do. There are both domestic and foreign bonds, which we assume to be perfect substitutes. Economic agents are therefore indifferent between holding either domestic or foreign bonds, such that their yields must be equalized. Since exchange rates are fixed and there is no exchange rate uncertainty, this implies that the domestic and foreign interest rates must be the same. Moreover, we assume that portfolio adjustment is instantaneous. The combination of perfect substitutability and instantaneous portfolio adjustment is called perfect capital 
mobility. It implies that yields are continuously equalized and asset holders are always in portfolio equilibrium. As we will discuss in the sequel, the degree of capital mobility has important implications for the ability to conduct monetary policy.

In this section we analyze a small open economy which is not able to influence economic conditions in the rest of the world economy. As we focus on the short-run and prices are fixed, we will normalize the domestic and foreign price level and the fixed exchange rate equal to 1 (taking logs therefore means that they do not show up in the equations). Consequently, the demand for money $m$ depends positively on transactions demand from changes in output $y$ and negatively on the opportunity cost from increases in the interest rate $i$, see equation (3.1). We label this the $L M$ equation. In the short-run, given fixed prices and a fixed exchange rate, demand in the economy is determined by a simple open economy $I S$ equation, where output depends negatively on the interest rate (associated with the costs of investment) and positively on output in the rest of the world, see equation (3.2). As in Chapter 2, variables without any subscripts will refer to Home, whereas variables with a subscript $f$ will refer to Foreign. The term $u$ in equation (3.2) is a demand shift parameter. Note that the real exchange rate, as analyzed in Chapter 1 , does not yet play a role in equation (3.2) since prices and the nominal exchange rate are fixed (its impact is therefore subsumed in the parameter $\kappa_{1}$ ). This will change whe $n$ we analyze a flexible exchange rate regime in sections 3.5-6. Equation (3.3), finally, indicates that perfect capital mobility implies that the domestic interest rate is equal to the foreign interest rate. Since we are analyzing a small country which cannot influence economic conditions in the rest of the world, the foreign interest rate is fixed, as is the foreign output level.

$$
\begin{aligned}
& m=\alpha y-\beta i \\
& y=\kappa_{1}-\kappa_{2} i+\kappa_{3} y_{f}+u \\
& i=i_{f}
\end{aligned}
$$


Basic exchange rate theories

Figure 3.3 Money expansion (dashed line accomodates) small country, fixed exchange rates, perfect capital mobility, short-run

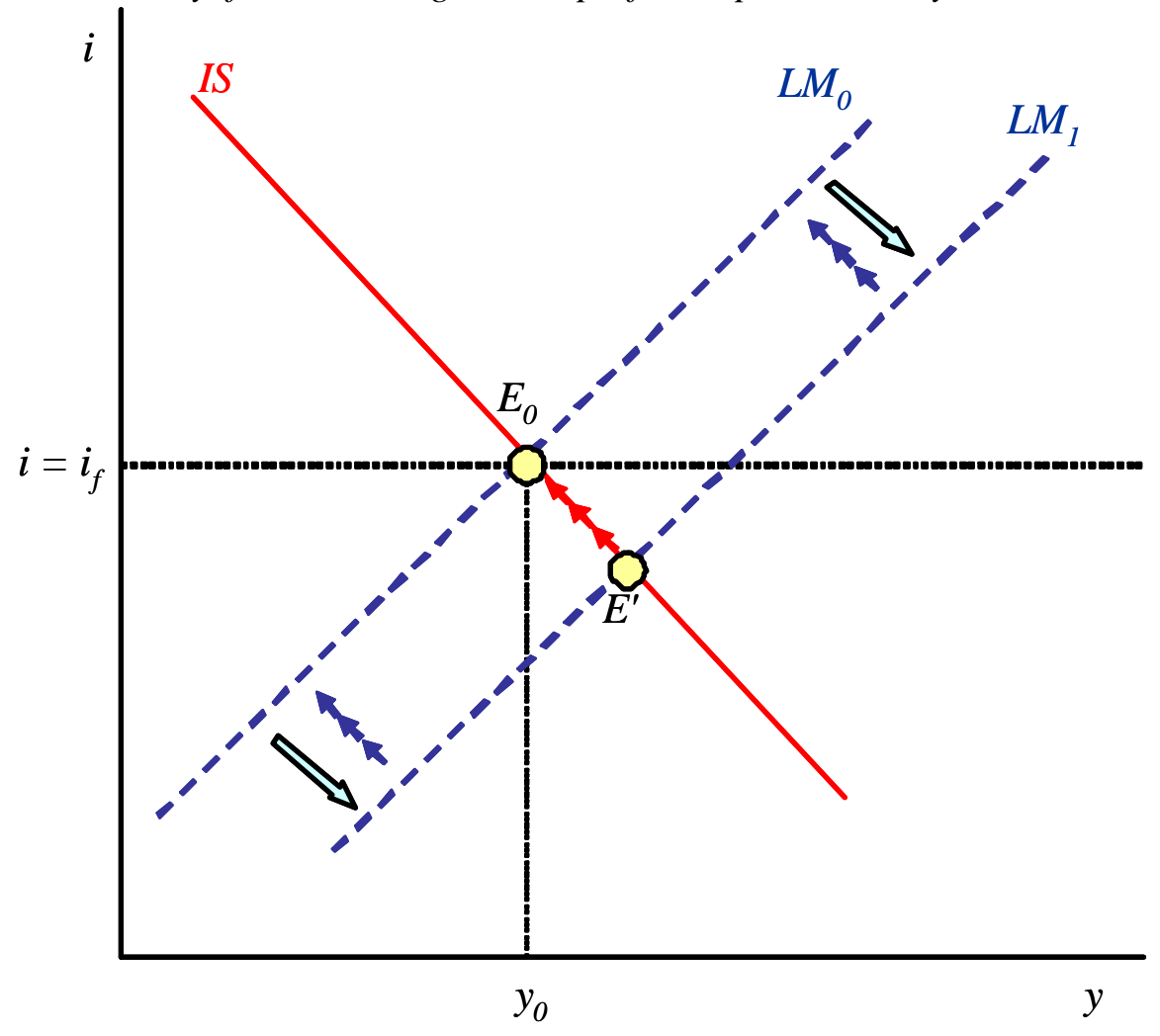

As illustrated in Figure (3.3) at the initial equilibrium point $E_{0}$, the model is solved quite easily. First, perfect capital mobility (equation 3.3) determines the interest rate. Second, using this information, the IS curve (equation 3.2) determines output. Third, using these interest rate and output levels, the $L M$ curve (equation 3.1) determines money demand. As already explained in Chapter 2, under a fixed exchange rate regime money supply is endogenous (since the central bank has to intervene by buying or selling international reserves to maintain the fixed exchange rate). The $L M$ curve therefore accomodates to whatever level of money demand ensures equilibrium in the economy. This implies that if the monetary authorities conduct monetary policy by increasing domestic credit, indicated by the outward shift of the $L M$ curve from $L M_{0}$ to $L M_{l}$ in Figure 3.3, the impact of this monetary policy is completely reversed by an offsetting contraction of the international reserves, which shifts the $L M$ curve back from $L M_{1}$ to $L M_{0}$. Thus, for a small country with fixed exchange rates under perfect capital mobility, monetary policy is entirely ineffective. 
Basic exchange rate theories

Figure 3.4 Fiscal expansion (dashed line accomodates) small country, fixed exchange rates, perfect capital mobility, short-run

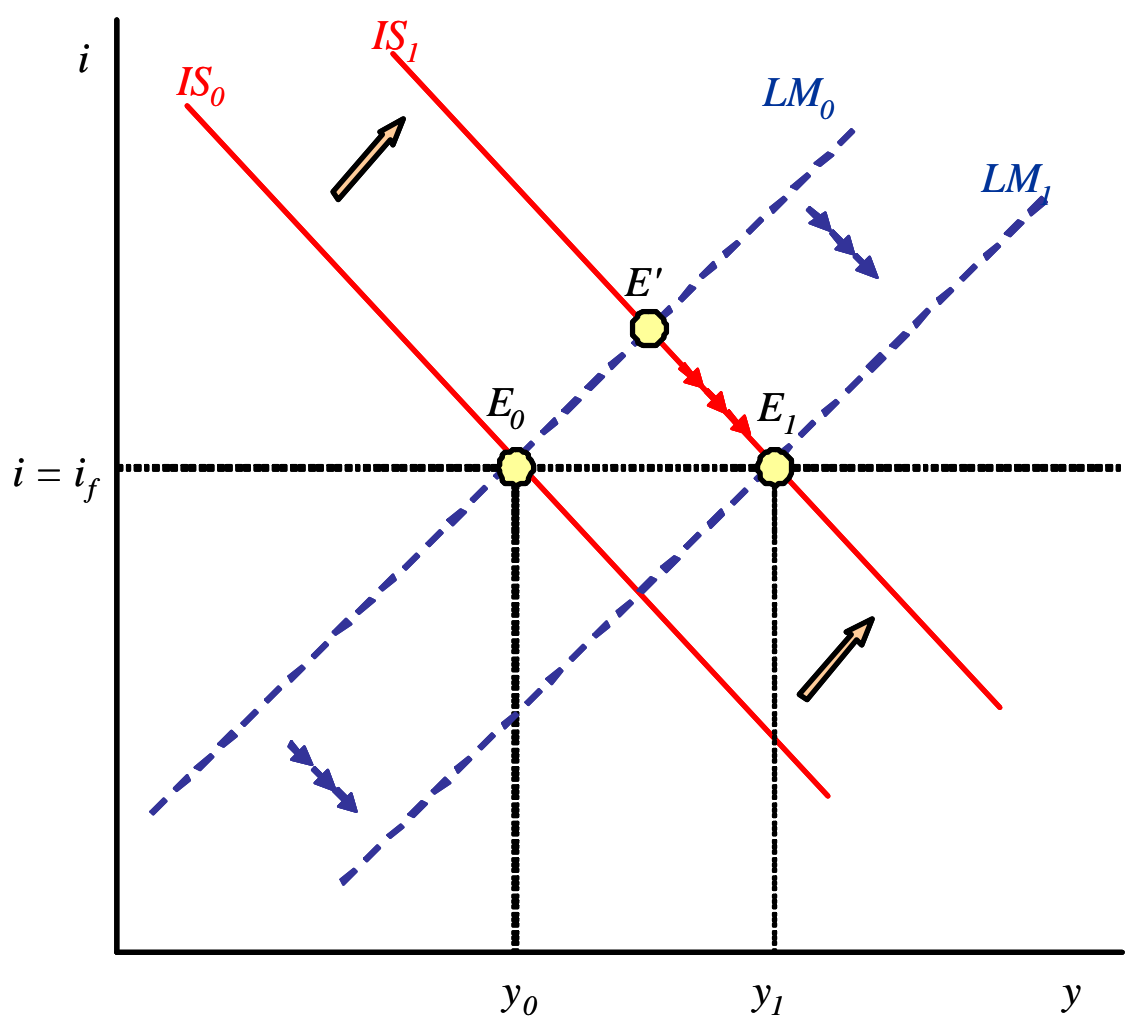

Figure 3.4 illustrates what happens under these circumstances if there is a fiscal expansion in the Home country. First, the fiscal expansion shifts the $I S$ curve to the right, from $I S_{0}$ to $I S_{1}$. Point $E$ ' in Figure 3.4 cannot be an equilibrium as it would imply a higher interert rate in Home than in Foreign. Consequently, there is an inflow of international reserves and an accomodating expansion of the domestic money supply which shifts the $L M$ curve to the right, from $L M_{0}$ to $L M_{l}$. The new equilibrium is therefore at point $E_{l}$, where output has expanded considerably as a result of fiscal policy, not only from the fiscal expansion itself, but also because of the accomodating monetary expansion. We therefore arrive at the following strong:

Policy conclusion I: for a small country with fixed exchange rates under perfect capital mobility, fiscal policy is very effective whereas monetary policy is entirely ineffective. 
Basic exchange rate theories

\subsection{Fixed exchange rates and large countries (perfect capital mobility)}

The strong policy conclusions for a small country faced with a fixed exchange rate and perfect capital mobility derived in section 3.2 are mitigated if the country is 'large' instead of 'small', indicating that its economic policies are influential enough to affect equilibrium conditions in the rest of the world economy. We analyze this in our twocountry setting by adding an $L M$ curve and an $I S$ curve for Foreign, see equations (3.1') and (3.2'), respectively. Foreign's money demand rises from an increase in transactions demand if its output level rises and falls as a result of an increase in opportunity costs if the interest rate rises. Similarly, Foreign's output level falls with an increase in the interest rate and rises if demand from abroad increases as a result of an increase in Home's output. With perfect capital mobility, the interest rate must be the same in the two countries, that is equation (3.3) must hold. Together these five equations determine money demand at Home and in Foreign, the output level at Home and in Foreign, and the interest rate.

(3.1') $m_{f}=\alpha_{f} y_{f}-\beta_{f} i_{f}$

(3.2') $y_{f}=\kappa_{1 f}-\kappa_{2 f} i_{f}+\kappa_{3 f} y$

Note that an increase in Foreign's output level would increase Home's output (3.1), which in turn would increase Foreign's output (3.1'), which would increase Home's output, etc. As shown in Technical Note 3.1, these types of interconnections in the world economy can be summarized by deriving equilibrium $I S$ and $L M$ equations. These are shown in equations (3.1") and (3.2"), where a prime (') indicates a newly defined (positive) parameter and $m_{w}$ denotes the world demand for money $\left(m_{w} \equiv m+m_{f}\right)$.

(3.1") $L M_{e}: \quad m_{w}=\alpha^{\prime} y-\beta^{\prime} i+\alpha_{f} \kappa_{1 f}$

(3.2") IS $: \quad y=\kappa_{1}{ }^{\prime}+u^{\prime}-\kappa_{2}{ }^{\prime} i$

All newly defined parameters in (3.1") and (3.2") are larger than their counterparts in (3.1) and (3.2), that is $\alpha^{\prime}>\alpha, \quad \beta^{\prime}>\beta, \quad u^{\prime}>u, \quad \kappa_{1}{ }^{\prime}>\kappa_{1}$, and $\kappa_{2}{ }^{\prime}>\kappa_{2}$. These two equilibrium relationships jointly determine Home's output level and the world interest rate, as illustrated at the initial point of intersection $E_{0}$ of the upward sloping $L M_{e}$ curve and the downward sloping $I S_{e}$ curve in Figure 3.5. The $I S$ curve is flatter than in the small 
country case (since $\kappa_{2}{ }^{\prime}>\kappa_{2}$ ), indicating that a decline in interest rates is more expansionary as a result of the mutual international repercussion effects.

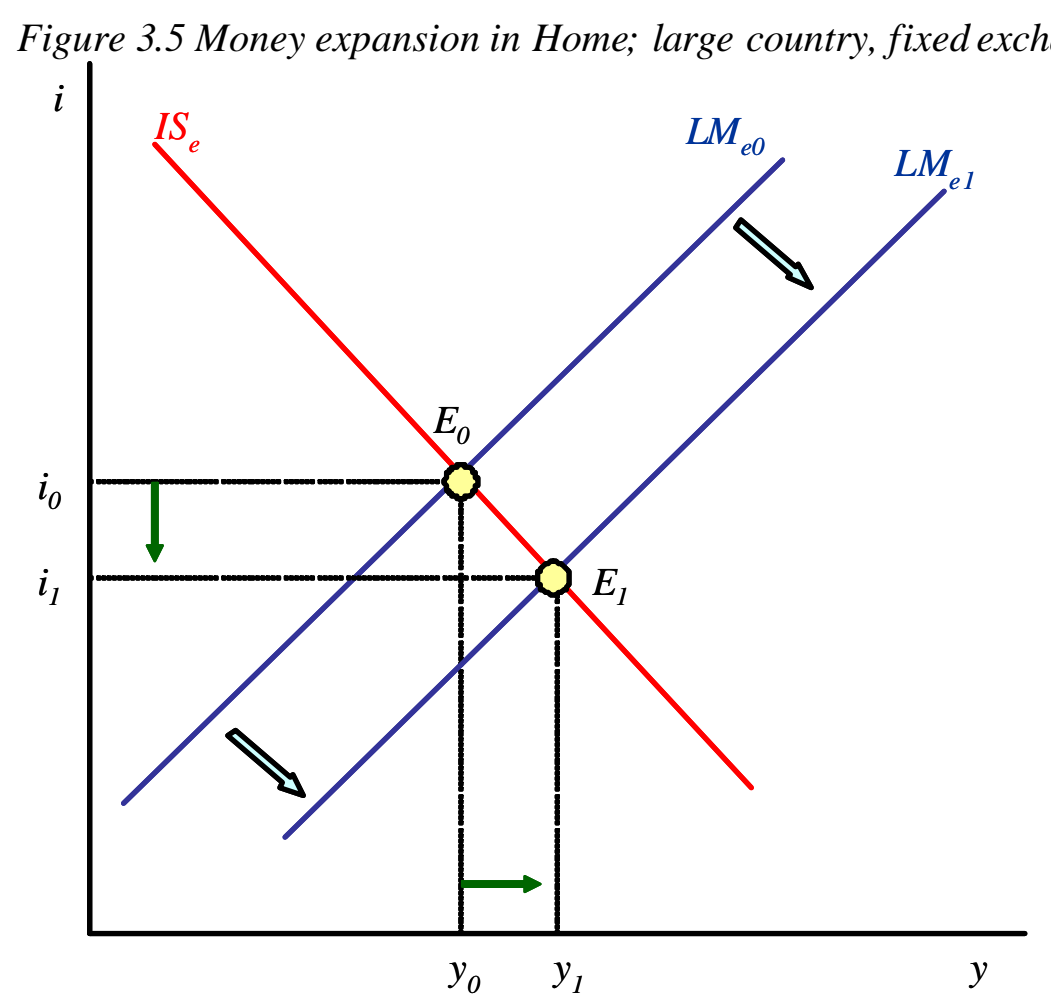

Figure 3.5 illustrates that the ineffectiveness of monetary policy under fixed exchange rates exposed in section 3.2 is mitigated if such a policy is conducted by a large country able to influence the world interest rate. A credit expansion in Home increases the world money stock and shifts the $L M_{e}$ curve to the right. The new equilibrium is at point $E_{l}$, where the interest rate has fallen and Home's output has increased. Output in Foreign also increases, both as a result of the fall in the interest rate and as a result of the output expansion in Home. A similar analysis of a fiscal expansion in Home would shift the $I S$ curve to the right (not shown in the figure), increase Home's output, and increase the interest rate. In that case, the effect on Foreign's output is ambivalent. On the one hand foreign output will expand as a result of the increase in Home's output. On the other hand, foreign output will contract as a result of the rise in interest rates. The net effect is uncertain. To conclude: once mutual repercussion effects are taken into consideration 
both fiscal and monetary policy are effective. The main difference is that a domestic fiscal expansion may lower income abroad, whereas a domestic monetary expansion will always increase income abroad.

\subsection{Imperfect substitutability (small country, fixed exchange rates)}

A second possibility to mitigate the strong policy conclusions for a small country faced with a fixed exchange rate and perfect capital mobility derived in section 3.2, is to allow for imperfect substitutability between domestic and foreign assets. Retaining the small country assumption, that is taking Foreign's interest rate and level of output as given, the domestic interest rate is determined by equilibrium in the home securities market. Since they are imperfect substitutes for foreign securities, irrespective of whether or not domestic securities are internationally traded, their equilibrium yield is determined endogenously. Capital market equilibrium is therefore given in equation (3.3'), where $K$ is the stock of domestic securities held by the private sector and $\sigma$ is the demand for domestic securities. ${ }^{7}$ Obviously, the demand for our securities rises with an increase in the domestic interest rate and falls with an increase in the foreign interest rate.

(3.3') $K=\sigma\left(i, i_{f}, y, y_{f}\right)$

Equilibrium in Home's financial markets is determined by money market equilibrium (3.1) and equilibrium in the security market (3.3'). In view of the fixed exchange rate regime, which makes the money supply process endogenous, financial equilibrium determines the money stock or, for given domestic credit $D$, the stock of international reserves $R$ (see section 2.3) and the yield on domestic securities. So what happens if there is a domestic credit expansion, such that the central bank buys domestic debt and creates money $(-d K=d D>0)$ ? The reduction in the stock of securities creates an excess demand and theryby lowers Home's interest rate. The extent of this reduction depends on the degree of asset substitutability. If Home and Foreign securities are almost perfect substitutes, the domestic interest rate will remain very close to the foreign interest rate. If they are very imperfect substitutes, however, there must be a large change in Home's interest rate in order to accept the shift in portfolio composition. 
Basic exchange rate theories

As explained earlier, if Home and Foreign securities are perfect substitutes, there will be no change in Home's interest rate and consequently no change in the demand for money. Under those conditions, in view of the endogeneity of the money supply under fixed exchange rates, the domestic credit expansion must be completely offset by a contraction of international reserves, that is $d R=-d D$. If Home and Foreign securities are imperfect substitutes, however, the domestic credit expansion will result in a fall in the domestic interest rate. This reduction in the interest rate is more substantial if the degree of substitutability falls. Associated with the fall in the domestic interest rate is a rise in the demand for money, see equation (3.1). Consequently, in view of the rising demand for money, the domestic credit expansion is no longer completely offset by a contraction of international reserves, that is $-d R / d D<1$. Again, this effect is larger if it is harder to substitute between domestic and foreign securities. One method for determining the degree of assets substitutibility is therefore to empirically estimate the offset coefficient $d R / d D$. Our discussion on the degree of asset substitutability is summarized in equation (3.4), whereas Box 3.1 discusses some empirical estimates of offset coefficients.

$$
-\frac{d R}{d D}= \begin{cases}1, & \text { if perfect asset substitutdbility } \\ <1, & \text { if imperfectasset substitutability }\end{cases}
$$

The implications for our discussion on the effectiveness of monetary policy is illustrated in Figure 3.6, which shows the downward sloping $I S$ curve along with the $K K$ curve with equilibrium in the market for domestic securities. The slope of the $K K$ curve is determined by the degree of asset substitutability. Under perfect capital mobility, the $K K$ curve is horizontal. The initial equilibrium is at point $E_{0}$. As explained above, a domestic credit expansion shifts the $K K$ curve down from $K_{0} K_{0}$ to $K_{l} K_{l}$. The extent of the downward shift depends on the degree of asset substitutability or the offset coefficient. With imperfect substitutability, the interest rate falls and output expands to reach the new equilibrium $E_{l}$. Monetary policy now works, while the effects of fiscal policy will be dampened (not shown). With perfect substitutability, the $K K$ curve is flat, the downward shift is zero, and monetary policy is entirely ineffective.

\footnotetext{
${ }^{7}$ The impact of changes in wealth on the demand for securities is ignored in equation (3.3').
} 


\section{Figure 3.6 Monetary expansion}

small country, fixed exchange rates, imperfect substitutability, short-run

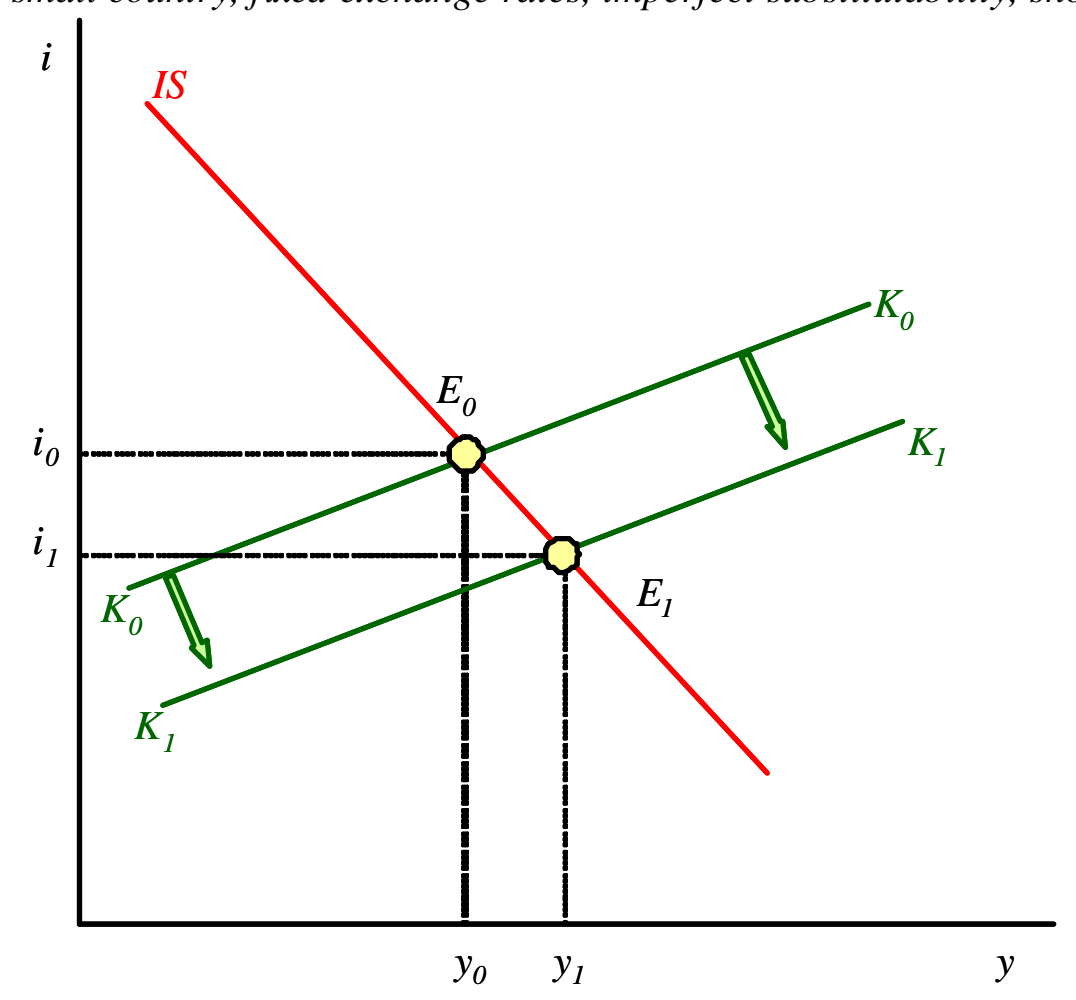

Box 3.1 Empirically estimated offset coefficients

The offset coefficient measures the degree to which a domestic credit expansion is offset by a contraction of international reserves in a system of fixed exchange rates, see equation (3.4) and the discussion in the main text. With some caveats, it can be interpreted as a measure of the degree of asset substitutability. Early work on estimating offset coefficients was done by Kouri and Porter (1974), soon followed by Bean (1976), Connoly and Taylor (1976), Genberg (1976), Guittan (1976), and Zecher (1976). Using these studies, as reported and discussed in Hallwood and MacDonald (2000), Figure 3.7 illustrates some estimated offset coefficients. In four cases, identified by the shaded bars in the figure, the estimate is not statistically significantly different from minus one, suggesting perfect substitutability between domestic and foreign assets. In the five other cases the offset coefficient is smaller than one in absolute terms, suggesting imperfect asset substitutability or (in the cases of Germany and Japan) a large country effect. 
Figure 3.7 Estimated offset coefficients, various countries

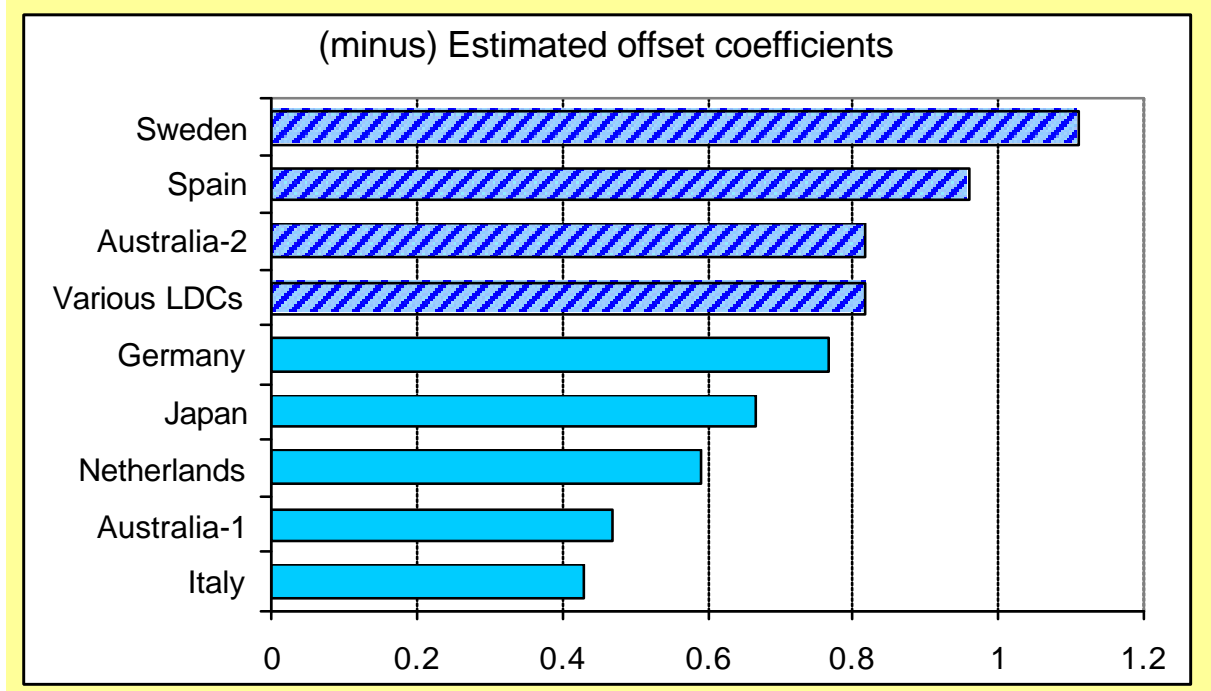

Data source: Hallwood and MacDonald (2000, p. 171). Shaded bars do not differ statistically significantly from (-) one. Estimation period is 1959-70 (Japan, Various LDCs), 1951-70 (Sweden), 1955-71 (Spain), 1951-61 (Australia-2), 1961-72 (Australia-1), 1960-70 (Germany, the Netherlands), and 196470 (Italy).

\subsection{Flexible exchange rates (small country, perfect capital mobility)}

The remainder of this chapter analyzes the short-run impact of fiscal and monetary policy under a flexible exchange rate regime in which payments are balanced and the money stock is fully controlled by the monetary authorities. This section focuses on a small country facing perfect capital mobility to arrive at effectiveness conclusions diametrically opposed to those derived in section 3.2 under fixed exchange rates. More specifically, we show that under flexible exchange rates monetary expansion is very effective for raising output, whereas fiscal expansion leads to full crowding out through a deterioration of the current account balance and is therefore entirely ineffective. The next section again mitigates these conclusions for large countries and imperfect substitutability.

Although we assume, as before, that domestic and foreign prices are fixed in this shortrun analysis, the fact that the nominal exchange rate $S$ is fully flexible implies that the real exchange rate $S P_{f} / P$, which is the price of Foreign relative to Home goods, can change. Since the real exchange rate plays a crucial role in the ensuing analysis, we do not normalize the domestic and foreign price levels to unity (so the log terms $p$ and $p_{f}$ show up in the equations below), while realizing that any change in the real exchange rate 
is only brought about by a change in the nominal exchange rate. Moreover, we restrict attention in this chapter to static expectations regarding the exchange rate, such that with an integrated world capital market nominal interest rates are equated internationally. The more interesting (and more complicated) analysis of expectations formation is postponed until Chapter 28.

Figure 3.8 Money expansion (dashed line accomodates) small country, flexible exchange rates, perfect capital mobility, short-run

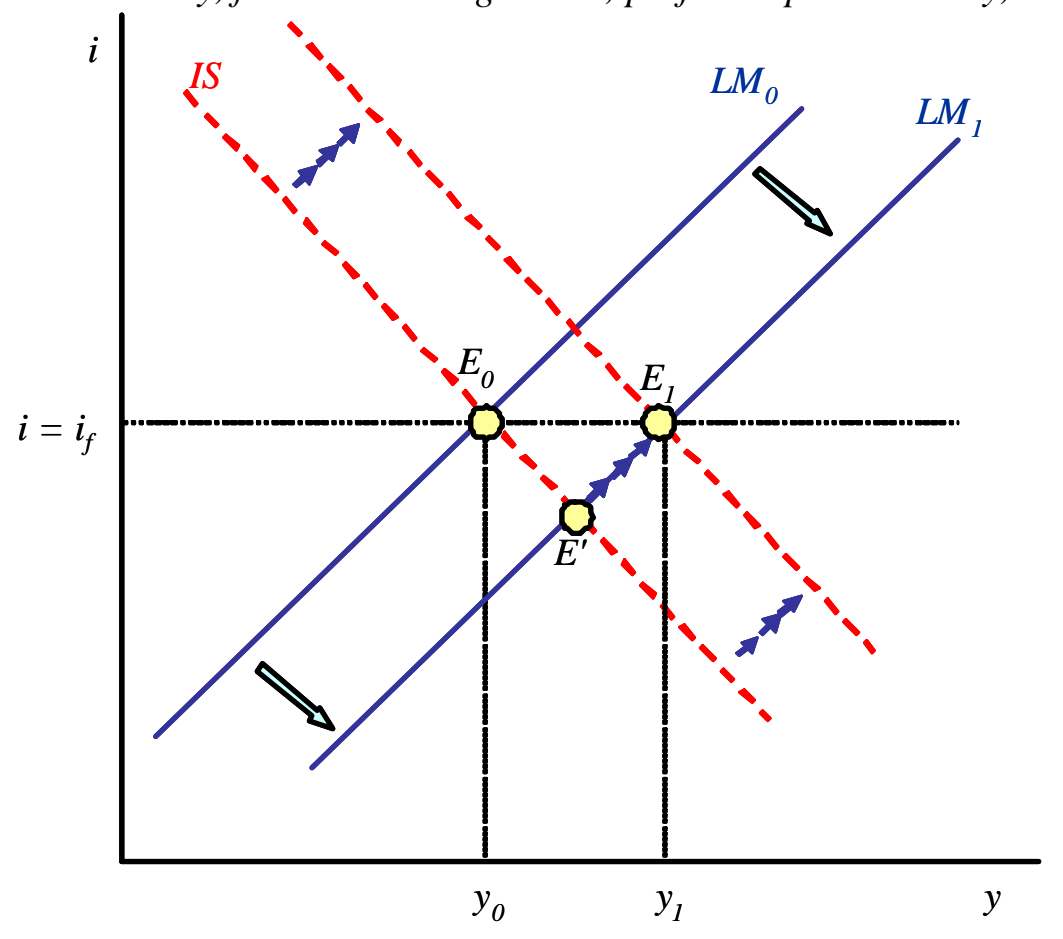

Monetary equilibrium is given in the $L M$ equation (3.5), where the real money stock $m-p$ is equal to money demand, which depends positively on output (transactions demand) and negatively on the interest rate (opportunity costs). Output is demand determined, as given in the $I S$ equation (3.6). We distinguish four different factors influencing demand. First, net exports are determined by the real exchange rate, where an increase (a rise in the relative price of foreign goods) leads to an improvement of the current account (provided the Marshall - Lerner condition holds, see Chapter 1). Second, an increase in the interest rate reduces investment demand. Third, an increase in foreign output increases demand for our goods. Fourth, and finally, the term $u$ is a demand shift 
parameter. Equation (3.7) closes the model by requiring that the domestic interest rate is equal to the foreign interest rate.

$$
\begin{aligned}
& m-p=\alpha y-\beta i \\
& y=\kappa_{1}\left(s+p_{f}-p\right)-\kappa_{2} i+\kappa_{3} y_{f}+u \\
& i=i_{f}
\end{aligned}
$$

As illustrated in Figure 3.8 at the initial equilibrium point $E_{0}$, the model is solved quite easily. First, perfect capital mobility (equation 3.6) determines the interest rate. Second, using this information and given the money stock completely controlled by the monetary authorities, the $L M$ curve (equation 3.4) determines output. Third, using these interest rate and output levels, the $I S$ curve (equation 3.5) determines the nominal exchange rate. In this setting, therefore, the $I S$ curve accomodates to whatever level of the exchange rate ensures equilibrium in the economy.

The effectiveness of monetary policy in this setting is also illustrated in Figure 3.8. A monetary expansion shifts the $L M$ curve to the right, from $L M_{0}$ to $L M_{l}$, because the fixed price level implies that a rise in nominal balances also increases real balances. This shift leads to a fall in interest rates and an expansion of output. In the absence of capital mobility, the new equilibrium would be at point $E$ ', where the goods and money markets clear and the current account balance has deteriorated. Taking capital mobility into consideration, however, impliest that point $E^{\prime}$ cannot be an equilibrium because the domestic interest rate has fallen below the foreign interest rate, creating a tendency for capital to flow out and thus causing a depreciation of the domestic currency (a rise in $S$ ). This depreciation, in turn, lowers the relative price of domestic goods and shifts the accomodating $I S$ curve up and to the right, leading to a further increase in domestic output, but this time accompanied by a rise in the domestic interest rate (closing the gap with the foreign interest rate). The depreciation of the domestic currency continues until monetary equilibrium is restored at the foreign interest rate (point $E_{l}$ ). Under these circumstances, therefore, monetary policy is very effective. First because output increases as a result of the monetary expansion and subsequently as a result of the accomodating depreciation of the domestic currency which improves the current account balance. 
Basic exchange rate theories

Figure 3.9 Fiscal expansion (dashed line accomodates) small country, flexible exchange rates, perfect capital mobility, short-run

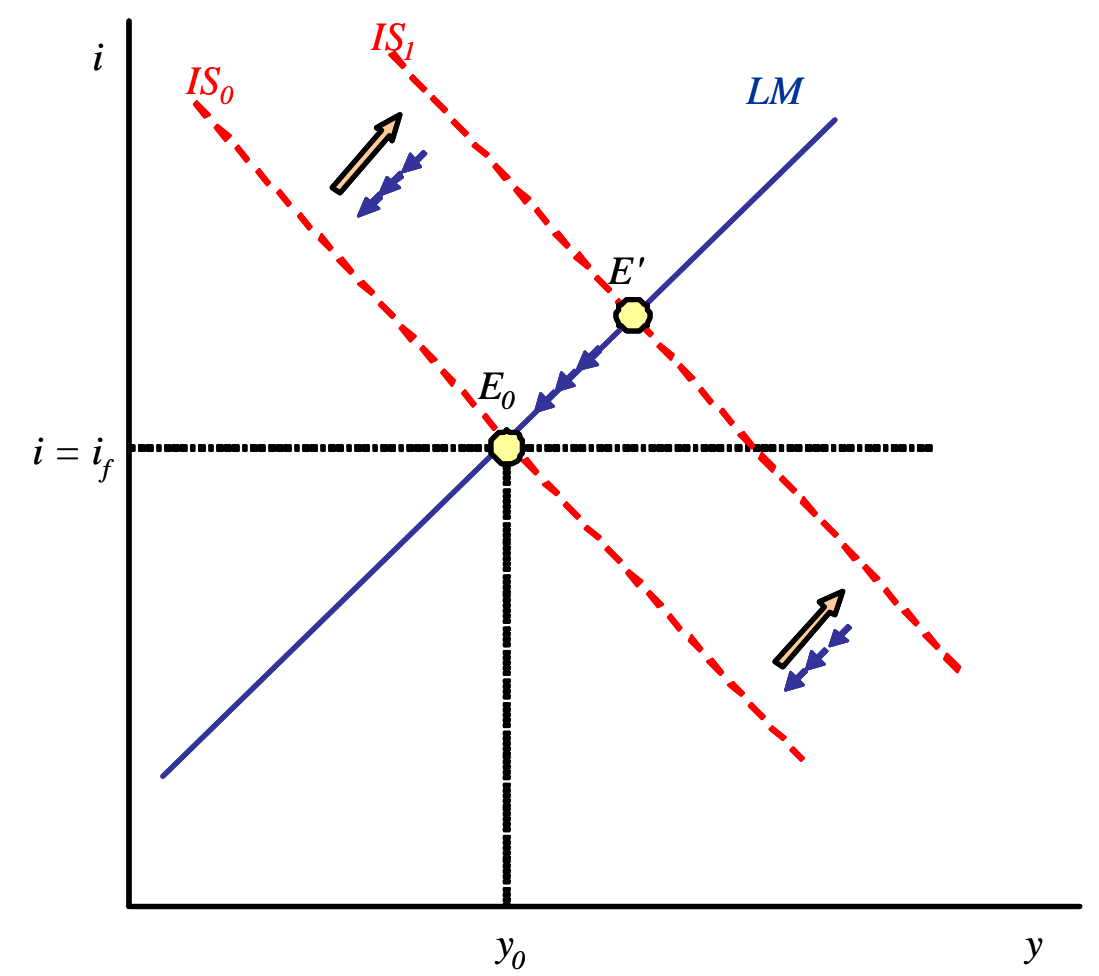

Figure 3.9 illustrates the effects of a fiscal expansion which, given the initial exchange rate, shifts the $I S$ curve up from $I S_{0}$ to $I S_{l}$. Again, in the absence of capital flows the new equilibrium would be at $E^{\prime}$, where output and the interest rate have increased. Taking capital mobility into consideration, this cannot be the final equilibrium since the domestic interest rate is higher than the foreign interest rate, creating a tendency for capital to flow in and thus causing an appreciation of the domestic currency (a fall in $S$ ). This appreciation shifts demand away from domestic to foreign goods. Since the appreciation of the domestic currency will continue until the initial equilibrium (determined by the foreign interest rate and the $L M$ curve) is reached, the $I S$ curves shifts all the way back from $I S_{1}$ to $I S_{0}$. The appreciation of the domestic currency therefore leads to complete crowding out, that is a current account deterioration which completely offsets the initial demand expansion. To summarize, we arrive at the following strong:

Policy conclusion II: for a small country with flexible exchange rates and perfect capital mobility, monetary policy is very effective whereas fiscal policy is entirely ineffective. 
Basic exchange rate theories

\subsection{Flexible exchange rates, large countries, and imperfect substitutability}

The strong policy conclusions derived in the previous section on the effectiveness of monetary and the ineffectiveness of fiscal policy under a flexible exchange rate regime are again mitigated if we analyze large countries or allow for imperfect substitutability. As we will see, the analysis of large countries which are able to influence economic conditions in the rest of the world is a bit more involved than in the case of fixed exchange rates discussed in section 3.3. We can analyze international repercussions in a two-country setting by adding an $L M$ curve and an $I S$ curve for Foreign analogous to those for Home, see equations (3.5') and (3.6'), respectively. Note that the impact of a change in the real exchange rate $s+p_{f}-p$ for Foreign's demand is, of course, opposite to the impact on Home's demand, compare (3.6) and (3.6').

(3.5') $\quad m_{f}-p_{f}=\alpha_{f} y_{f}-\beta_{f} i_{f}$

(3.6') $y_{f}=-\kappa_{1 f}\left(s+p_{f}-p\right)-\kappa_{2 f} i_{f}+\kappa_{3 f} y$

With perfect capital mobility, the interest rate must be the same in the two countries, that is equation (3.7) must also hold. Together these five equations determine the output level in Home and Foreign, the interest rate in Home and Foreign, and the nominal exchange rate. For comparative static purposes it is most convenient to reduce this system to two equilibrium equations, which we do in two steps.

First, we substitute (3.7) into the other equations and note that income demand at home depends in part on the income level abroad (3.6), while income demand abroad depends in part on the income level at home (3.6'). These two equations therefore jointly and simultaneously determine the income level in each country as a function of the real wage and the interest rate. As shown in Technical Note 3.2, which also defines the positive parameters $\kappa_{1}{ }^{\prime}, \kappa_{1 f}{ }^{\prime}, \kappa_{2}{ }^{\prime}, \kappa_{2 f}{ }^{\prime}$, and $u^{\prime}$, the net effect of these interactions is equal to:

$$
\begin{aligned}
& y=\kappa_{1}{ }^{\prime}\left(s+p_{f}-p\right)-\kappa_{2}{ }^{\prime} i+u^{\prime} \\
& y_{f}=-\kappa_{1 f}{ }^{\prime}\left(s+p_{f}-p\right)-\kappa_{2 f}{ }^{\prime} i+\kappa_{3 f} u^{\prime}
\end{aligned}
$$


Other things equal, therefore, the real exchange rate has a positive effect on the income level at home and a negative effect on the income level abroad. For both countries, an increase in the interest rate reduces output, while an increase in the Home demand shift paramater increases income at home stronger than income abroad.

Second, we realize that general equilibrium in both countries requires that the income levels determined in equation (3.8) have to be consistent with the income levels for monetary equilibrium, see equations (3.5) and (3.5'). Full equibrium for the Home economy can therefore be derived by substituting Home's output level from (3.8) into (3.5). This gives us combinations of the world interest rate $i$ and the real exchange rate $s+p_{f}-p$ with full equilibrium in the Home economy, see Technical Note 3.2 and equation (3.9) below. As illustrated in Figure 3.10, it is an upward sloping curve since an increase in the real exchange rate, which is a depreciation of the Home currency, raises income in Home after taking into account international repercussion effects. A higher interest rate is therefore required to restore equilibrium. Similarly, full equibrium for the Foreign economy can be derived by substituting Foreign's output level from (3.8) into $\left(3.5^{\prime}\right)$. This gives us combinations of the world interest rate $i$ and the real exchange rate $s+p_{f}-p$ with full equilibrium in the Foreign economy. This curve is downward sloping since an increase in the real exchange rate, which is an appreciation of the Foreign currency, reduces income in Foreign after taking into account international repercussion effects. A lower interest rate is therefore required to restore equilibrium. Taken together, this gives us two curves in interest rate and real exchange rate space determining full equilibrium in the world economy. The details of this derivation are given in Technical Note 3.2, which also defines the positive parameters $\gamma_{1}, \gamma_{1 f}, \gamma_{2}$, and $\gamma_{2 f}$. Equation (3.9) summarizes the resulting full equilibrium relationships for the Home and Foreign economy. As illustrated by the initial equilibrium at point $\mathrm{E}$ in Figure 3.10, the two curves jointly determine the equilibium interest rate and real exchange rate.

$$
\begin{array}{ll}
\text { Home : } & i=\gamma_{1}\left(s+p_{f}-p\right)+\gamma_{2}\left(\alpha u^{\prime}-(m-p)\right) \\
\text { Foreign: } & i=-\gamma_{1 f}\left(s+p_{f}-p\right)+\gamma_{2 f}\left(\alpha_{f} \kappa_{3 f} u^{\prime}-\left(m_{f}-p_{f}\right)\right)
\end{array}
$$


Figure 3.10 Fiscal expansion in Home; large country, flexible exchange rates

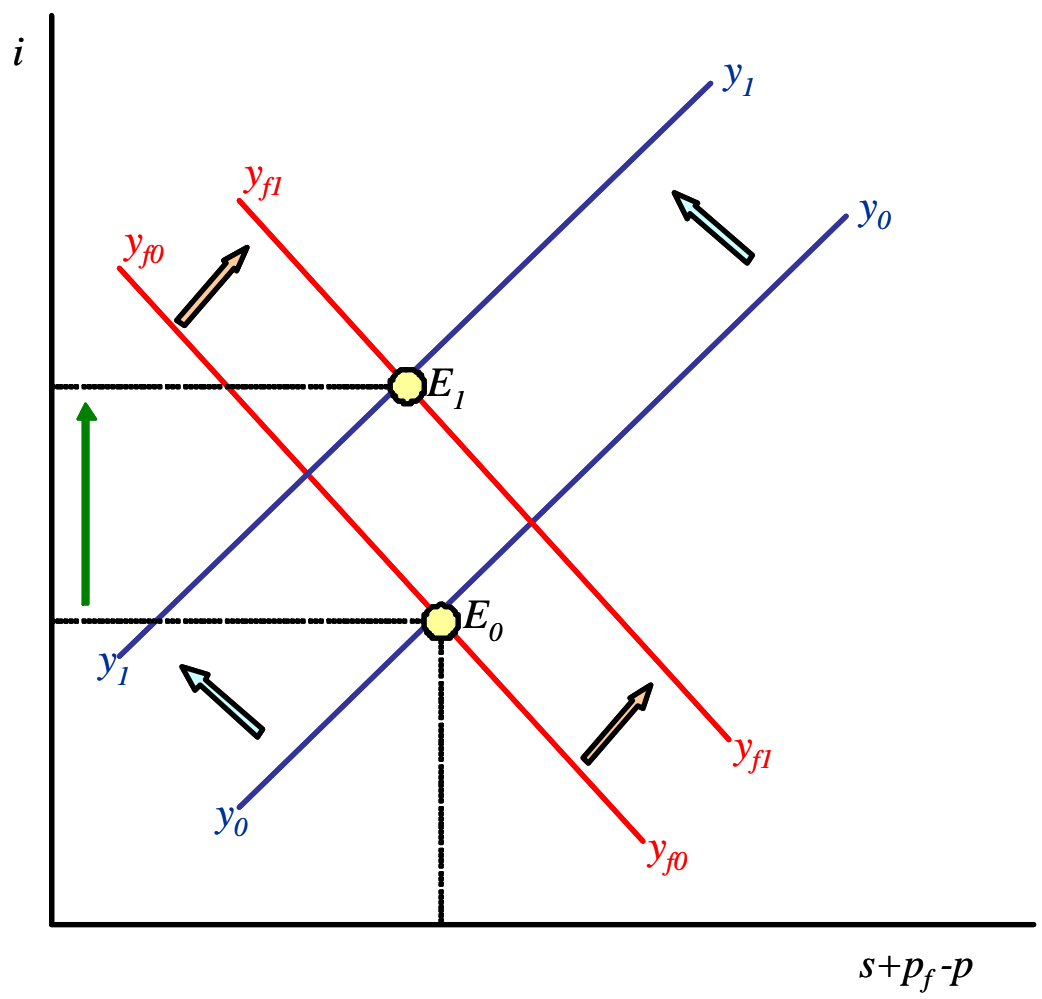

Figure 3.10 illustrates the effects of a fiscal expansion in Home on the world economy. The initial equilibrium is at $E_{0}$, the point of intersection of the upward sloping $y_{0} y_{0}$ curve (depicting combinations of interest rate and real exchange rate with equilibrium in the Home economy) and the downward sloping $y_{f o} y_{f 0}$ curve (depicting combinations of interest rate and real exchange rate with equilibium in the Foreign economy). At the initial real exchange rate, the fiscal expansion in Home (the term $u^{\prime}$ in equation 3.9), taking international repercussions into account, will raise income in both countries. To restore equilibrium the interest rate must rise, shifting the $y_{0} y_{0}$ curve up to $y_{1} y_{1}$ and the $y_{f o} y_{f 0}$ curve up to $y_{f 1} y_{f 1}$. The interest rate must therefore unambiguously rise as a result of the fiscal expansion. The net effect on the real exchange rate is uncertain as it depends on the relative shifts of the equilibrium schedules. The effects of the fiscal policy on income can be deduced from the money market equilibrium conditions (3.5) and (3.5'). Since the money supply has not changed and the interest rate has increased, the income level must have increased in both countries. In short, since a large country can affect the interest rate 
it faces in the world economy, fiscal policy under a regime of flexible exchange rates is no longer ineffective. There is, therefore, no complete crowding out.

The effect of monetary policy can be analyzed similarly. A monetary expansion in Home would shift the $y y$ curve down and to the right (not shown in the figure) and leave the foreign equilibrium schedule $y_{f} y_{f}$ unaffected. It therefore results in a decrease in the world interest rate and an increase in the real exchange rate, that is a depreciation of the Home currency. This raises income in Home. Remarkably, the opposite is true in Foreign. Again, using the monetary equilibrium condition (3.5') and noting that the foreign money supply has not changed, it is clear that the decline in interest rate must be offset by a decrease in foreign income to restore monetary equilibrium.

It has become clear from the above analysis that both fiscal and monetary policy can be effective if a country can influence the interest rate it faces. Since this is also possible in the case of imperfect asset substitutability, which is more completely analyzed in section 3.4, it should come as no surprise that fiscal policy can be effective even for a small country under flexible exchange rates if domestic and foreign assets are imperfect substitutes. Obviously, the extent of this effectiveness is influenced by the degree of asset substitubility. In the limit, with perfect substitutes, a small country cannot influence its own interest rate and fiscal policy is ineffective under flexible exchange rates.

\subsection{Conclusions}

We analyzed the effectiveness of fiscal and monetary policy under various conditions, namely for small and large countries, under fixed and flexible exchange rates, and for varying degrees of capital mobility. As summarized in Table 3.1, we arrived at very strong policy conclusions for small countries under conditions of perfect capital mobility, namely that fiscal policy is very effective and monetary policy entirely ineffective under fixed exchange rates, whereas monetary policy is very effective and fiscal policy is entirely ineffective under flexible exchange rates. Although these strong conclusions are mitigated for large countries able to influence the world interest rate and in the case of imperfect capital mobility, there is broad consensus that, in view of the generally high 


\section{Basic exchange rate theories}

degree of international capital mobility, fiscal policy is more effective in the short-run under fixed exchange rates and monetary policy is more effective in the short-run under flexible exchange rates.

Table 3.1 Effects of fiscal and monetary policy under perfect capital mobility

a. Fixed exchange rate regime

\begin{tabular}{l|cc|cc} 
& \multicolumn{2}{|c|}{$\begin{array}{l}\text { Monetary expansion in Home } \\
\text { Effect on output in }\end{array}$} & \multicolumn{2}{|c}{ Fiscal expansion in Home } \\
Home is & Home & Foreign & Home & Foreign \\
\hline Small country & 0 & 0 & + & 0 \\
Large country & + & + & + & $?$ \\
\hline
\end{tabular}

b. Flexible exchange rate regime

\begin{tabular}{|c|c|c|c|c|}
\hline \multirow[b]{2}{*}{ Home is } & \multicolumn{2}{|c|}{$\begin{array}{c}\text { Monetary expansion in Home } \\
\text { Effect on output in }\end{array}$} & \multicolumn{2}{|c|}{$\begin{array}{l}\text { Fiscal expansion in Home } \\
\text { Effect on output in }\end{array}$} \\
\hline & Home & Foreign & Home & Foreign \\
\hline Small country & + & 0 & 0 & 0 \\
\hline Large country & + & - & + & + \\
\hline
\end{tabular}

Table 3.1 also summarizes the international spillover effects of short-run fiscal and monetary policy. It shows a clear international conflict of interests. Under fixed exchange rates a small country can only boost output through a fiscal expansion, which if the country is large may reduce output abroad. Similarly, under flexible exchange rates a small country can only boost output through a monetary expansion, which if the country is large will reduce output abroad for sure. In this respect, when facing unemployment the rest of the world will always support the less effective policy expansion in Home, as it will never hurt and may benefit the foreign output level. 


\section{Basic exchange rate theories}

\section{Technical Note 3.1 Large country solution, fixed exchange rates}

Imposing perfect capital mobility, the interest rates in the two countries must be the same $\left(i=i_{f}\right)$. If we now substitute (3.2') in (3.2) and rearrange, we get the large country full equilibrium $I S_{e}$ equation, see (3A.1). Note that we assume $1-\kappa_{3} \kappa_{3 f}>0$.

$$
\begin{gathered}
\text { (3A.1) } y=\left(\kappa_{1}+u-\kappa_{2} i\right)+\kappa_{3} y_{f}=\left(\kappa_{1}+u-\kappa_{2} i\right)+\kappa_{3}\left(\kappa_{1 f}-\kappa_{2 f} i+\kappa_{3 f} y\right) \\
\left(1-\kappa_{3} \kappa_{3 f}\right) y=\kappa_{1}+u+\kappa_{3} \kappa_{1 f}-\left(\kappa_{2}+\kappa_{3} \kappa_{2 f}\right) i \\
y=\frac{\kappa_{1}+\kappa_{3} \kappa_{1 f}}{\left(1-\kappa_{3} \kappa_{3 f}\right)}+\frac{u}{\left(1-\kappa_{3} \kappa_{3 f}\right)}-\frac{\left(\kappa_{2}+\kappa_{3} \kappa_{2 f}\right)}{\left(1-\kappa_{3} \kappa_{3 f}\right)} i=\kappa_{1}{ }^{\prime}+u^{\prime}-\kappa_{2}{ }^{\prime} i \\
\text { where } \quad \kappa_{1}{ }^{\prime} \equiv \frac{\kappa_{1}+\kappa_{3} \kappa_{1 f}}{\left(1-\kappa_{3} \kappa_{3 f}\right)} ; \quad u^{\prime} \equiv \frac{u_{h}}{\left(1-\kappa_{3} \kappa_{3 f}\right)} ; \quad \kappa_{2}{ }^{\prime} \equiv \frac{\left(\kappa_{2}+\kappa_{3} \kappa_{2 f}\right)}{\left(1-\kappa_{3} \kappa_{3 f}\right)}
\end{gathered}
$$

Similarly, world money demand is the sum of the demand from the individual countries (3.1) and (3.1'). Substituting (3.2') now gives us the large country equilibrium $L M_{e}$ equation, see (3A.2).

(3A.2) $m_{w} \equiv m+m_{f}=(\alpha y-\beta i)+\left(\alpha_{f} y_{f}-\beta_{f} i\right)$

$$
\begin{aligned}
& m_{w}=\alpha y-\left(\beta+\beta_{f}\right) i+\alpha_{f}\left(\kappa_{1 f}-\kappa_{2 f} i+\kappa_{3 f} y\right) \\
& m_{w}=\left(\alpha+\alpha_{f} \kappa_{3 f}\right) y-\left(\beta+\beta_{f}+\alpha_{f} \kappa_{2 f}\right) i+\alpha_{f} \kappa_{1 f}=\alpha^{\prime} y-\beta^{\prime} i+\alpha_{f} \kappa_{1 f}
\end{aligned}
$$

where

$$
\alpha^{\prime} \equiv \alpha+\alpha_{f} \kappa_{3 f} ; \quad \beta^{\prime} \equiv \beta+\beta_{f}+\alpha_{f} \kappa_{2 f}
$$

\section{Technical Note 3.2 Large country solution, flexible exchange rates}

We combine equations (3.6) and (3.6') in matrix notation, see (3A.3). We invert this system (using for example Cramer's rule) to get (3A.4). Multiplication the $\mathrm{n}$ gives (3A.5). We assume $1-\kappa_{3} \kappa_{3 f}>0$ and that the direct income effect dominates the indirect effect, that is $\kappa_{1}-\kappa_{3} \kappa_{1 f}>0$ and $\kappa_{1 f}-\kappa_{3 f} \kappa_{1}>0$. Consistency of the solutions (3A.5) for income with monetary equilibrium, see (3.5) and (3.5'), gives (3A.6).

$$
\left[\begin{array}{cc}
1 & -\kappa_{3} \\
-\kappa_{3 f} & 1
\end{array}\right]\left[\begin{array}{l}
y \\
y_{f}
\end{array}\right]=\left[\begin{array}{l}
\kappa_{1}\left(s+p_{f}-p\right)-\kappa_{2} i+u \\
-\kappa_{1 f}\left(s+p_{f}-p\right)-\kappa_{2 f} i
\end{array}\right]
$$

$$
\left[\begin{array}{c}
y \\
y_{f}
\end{array}\right]=\left(\frac{1}{1-\kappa_{3} \kappa_{3 f}}\right)\left[\begin{array}{cc}
1 & \kappa_{3} \\
\kappa_{3 f} & 1
\end{array}\right]\left[\begin{array}{l}
\kappa_{1}\left(s+p_{f}-p\right)-\kappa_{2} i+u \\
-\kappa_{1 f}\left(s+p_{f}-p\right)-\kappa_{2 f} i
\end{array}\right]
$$


Basic exchange rate theories

(3A.5) $\left[\begin{array}{c}y \\ y_{f}\end{array}\right]=\left[\begin{array}{c}\kappa_{1}{ }^{\prime}\left(s+p_{f}-p\right)-\kappa_{2}{ }^{\prime} i+u^{\prime} \\ -\kappa_{1 f}{ }^{\prime}\left(s+p_{f}-p\right)-\kappa_{2 f}{ }^{\prime} i+\kappa_{3 f} u^{\prime}\end{array}\right]$

where $\quad \kappa_{1}{ }^{\prime} \equiv \frac{\kappa_{1}-\kappa_{3} \kappa_{1 f}}{1-\kappa_{3} \kappa_{3 f}} ; \quad \kappa_{2}{ }^{\prime} \equiv \frac{\kappa_{2}+\kappa_{3} \kappa_{2 f}}{1-\kappa_{3} \kappa_{3 f}} ; \quad u^{\prime} \equiv \frac{u}{1-\kappa_{3} \kappa_{3 f}}$

$\kappa_{1 f}^{\prime} \equiv \frac{\kappa_{1 f}-\kappa_{3 f} \kappa_{1}}{1-\kappa_{3} \kappa_{3 f}} ; \quad \kappa_{2 f}{ }^{\prime} \equiv \frac{\kappa_{2 f}+\kappa_{3 f} \kappa_{2}}{1-\kappa_{3} \kappa_{3 f}}$

(3A.6) Home: $\kappa_{1}{ }^{\prime}\left(s+p_{f}-p\right)-\kappa_{2}{ }^{\prime} i+u^{\prime}=(1 / \alpha)(m-p+\beta i)$

or $\quad i=\gamma_{1}\left(s+p_{f}-p\right)+\gamma_{2}\left(\alpha u^{\prime}-(m-p)\right)$

where $\quad \gamma_{1} \equiv \frac{\alpha \kappa_{1}{ }^{\prime}}{\beta+\alpha \kappa_{2}{ }^{\prime}} ; \quad \gamma_{2} \equiv \frac{1}{\beta+\alpha \kappa_{2}{ }^{\prime}}$

Foreign: $-\kappa_{1 f}{ }^{\prime}\left(s+p_{f}-p\right)-\kappa_{2 f}{ }^{\prime} i+\kappa_{3 f} u^{\prime}=\left(1 / \alpha_{f}\right)\left(m_{f}-p_{f}+\beta_{f} i\right)$

or $\quad i=-\gamma_{1 f}\left(s+p_{f}-p\right)+\gamma_{2 f}\left(\alpha_{f} \kappa_{3 f} u^{\prime}-\left(m_{f}-p_{f}\right)\right)$

where $\quad \gamma_{1 f} \equiv \frac{\alpha_{f} \kappa_{1}{ }^{\prime}}{\beta_{f}+\alpha_{f} \kappa_{2 f}{ }^{\prime}} ; \quad \gamma_{2 f} \equiv \frac{1}{\beta_{f}+\alpha_{f} \kappa_{2 f}{ }^{\prime}}$ 
Basic exchange rate theories

\title{
Chapter 4 Expectations and sticky prices
}

\author{
Objectives / key terms \\ Dornbusch - overshooting model Sticky prices \\ Rational expectations Phase diagram \\ Adaptive expectations Individual expectations \\ Mathematical - statistical expectations Bubbles and sunspots \\ Chartists and fundamentalists Random walks
}

The Dornbusch - overshooting - sticky-price model provides a bridge between short-run and long-run analysis. We also evaluate the crucial role of expectations formation.

\subsection{Introduction}

This chapter focuses on a crucial aspect in international monetary economics, namely the role of expectations formation in determining the exchange rate. At the same time, the chapter provides a bridge between the short-run fixed price analysis of Chapter 3 and the long-run flexible price analysis of Chapter 2 , by investigating exchange rate formation in a sticky-price model. Created by Dornbusch (1976), this model assumes that prices cannot adjust instantaneously, but instead respond to discrepancies in long-run equilibrium fundamentals. As it was the first model to explain the important empirical phenomenon of exchange rate overshooting and is still central to international monetary analysis today, it is referred to both as the Dornbusch model and the overshooting model.

The chapter consists of two basic parts. The first part, sections $4.2-4.5$, focuses on the bridge between short-run and long-run equilibrium by analyzing the transition process from the short-run equilibrium (with a given price level) to the long-run equilibrium (with fully flexible prices). The role of the expectations formation process turns out to be vital for determining this transition path. The second part of the chapter, sections 4.6-4.8, then analyzes the expectations formation process in more detail using the flexible price monetary model, see Chapter 2. We will discuss some problems, such as indeterminacy, and some fascinating possibilities, such as rational bubbles. 


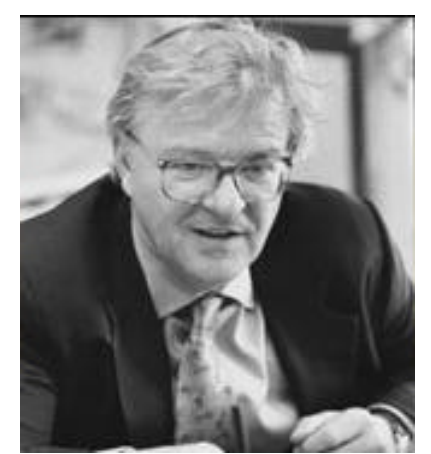

Figure 4.1 Rudiger Dornbusch, 1942 - 2002

The German economist Rudiger Dornbusch studied at the Graduate Institute in Geneva, Switzerland, and the University of Chicago. He briefly worked at Rochester, the London School of Economics, and Chicago before moving to MIT. As a good debater and with his lively personality he had a profound impact on many prominent disciples, policy issues, and the intellectual climate. His most influential contribution on policy and research in international finance, which appeared in 1976, explains why exchange rates fluctuate so heavily. Expectations formation and price stickiness played an important role in this socalled 'overshooting' model, on which Kenneth Rogoff (2002) remarked: “His justly celebrated "overshooting" paper is, indeed, arguably the most influential article written in the field of international economics since World War II." In a contribution to commemorate the $25^{\text {th }}$ anniversary of the paper, a few months earlier while Dornbusch was still alive, he also noted (Rogoff, 2002b): 'There is little question that Dornbusch's rational expectations reformulation of the Mundell - Fleming model extended the latter's life for another twenty-five years, keeping it in the forefront of practical policy analysis."

\subsection{Rational expectations and financial equilibrium}

As explained in Box 2.3, the uncovered interest parity condition, a crucial building block in international monetary economics, automatically ensures that the way in which economic agents form expectations is an important determinant of the equilibrium exchange rate at each point in time. If economic agents have forward-looking behavior, we have to somehow solve the nested-ness problem, because the exchange rate today depends on the expected exchange rate tomorrow, while the exchange rate tomorrow will depend on the expected exchange rate as of tomorrow for the day after tomorrow, etc. We return to these issues in section 4.6. For now, we will assume that agents have rational expectations, that is individual agents must form expectations in a way consistent with the economic model itself. In sections 4.2-4.5, in the absence of any uncertainty, this hypothesis amounts to perfect foresight, that is individuals know the exact future path of the exchange rate and all other relevant economic variables when making their decisions. 


\section{Basic exchange rate theories}

The Dornbusch model is one of the first papers in international finance to incorporate rational expectations, only predated in this respect by Black (1973). It is based on four underlying assumptions, (i) in the long-run the quantity theory of money and purchasing power parity (PPP) holds, (ii) in the short-run goods prices are sticky and there is slow adjustment to disturbances, (iii) uncovered interest rate parity always holds, and (iv) the economic agents are endowed with rational expectations (here: perfect foresight). This section discusses the financial equilibrium. Section 4.3 introduces price stickiness and the phase diagram. Section 4.4 then analyzes rational expectations and equilibrium dynamics, which is used in section 4.5 to discuss exchange rate overshooting.

The building blocks for determining the financial equilibrium are given in equations (4.1) - (4.3). The real demand for money $M / P$ depends positively on the income level $y$ (transactions demand) and negatively on the interest rate $i$ (opportunity costs). Using a logarithmic specification, equilibrium in the money market is given by equation (4.1). The assets held by individual agents in the economy are deflated by the weighted average of domestic prices $p_{h}$ and foreign prices, where the latter are equal to $p_{f}$ denominated in foreign currency and $s+p_{f}$ denominated in domestic currency $(s$ denotes the spot exchange rate), see equation (4.2). ${ }^{8}$ Finally, the uncovered interest rate parity condition as discussed in Chapter 22 relates the expected change in the exchange rate to the difference between Home and Foreign interest rates $\left(i_{h}-i_{f}\right)$. In combination with imposing rational expectations (such that the actual change in the exchange rate is equal to the expected change) and using continuous rather than discrete time (such that the change over time is equal to $\dot{s}$ using the convention introduced in Chapter 2), the uncovered interest parity condition is given in equation (4.3).

$$
\begin{array}{ll}
\text { (4.1) } & m-p=\alpha y-\beta i_{h} \\
\text { (4.2) } & p=\gamma p_{h}+(1-\gamma)\left(s+p_{f}\right) \\
\text { (4.3) } & \dot{s}=i_{h}-i_{f}
\end{array}
$$

\footnotetext{
${ }^{8}$ The qualitative implications are the same if domestic assets are simply deflated by the domestic price level only. In this case the $\dot{p}_{h}=0$ curve in Figure 4.3 is vertical, rather than downward sloping.
} 


\section{Basic exchange rate theories}

By combining equations (4.1) - (4.3) we can determine the financial equilibrium as a first order differential equation of the exchange rate $s$ and the domestic prices $p_{h}$ :

$$
\dot{s}=[\gamma p_{h}+(1-\gamma) s+\underbrace{(\delta-m)}_{\text {exogenous }}](1 / \beta),
$$

where the constant $\delta$ is a combination of the exogenous variables $\left(p_{f}, y\right.$, and $\left.i_{f}\right)$ and the parameters ( $\alpha, \beta$, and $\gamma$ ), see Technical Note 4.1 .

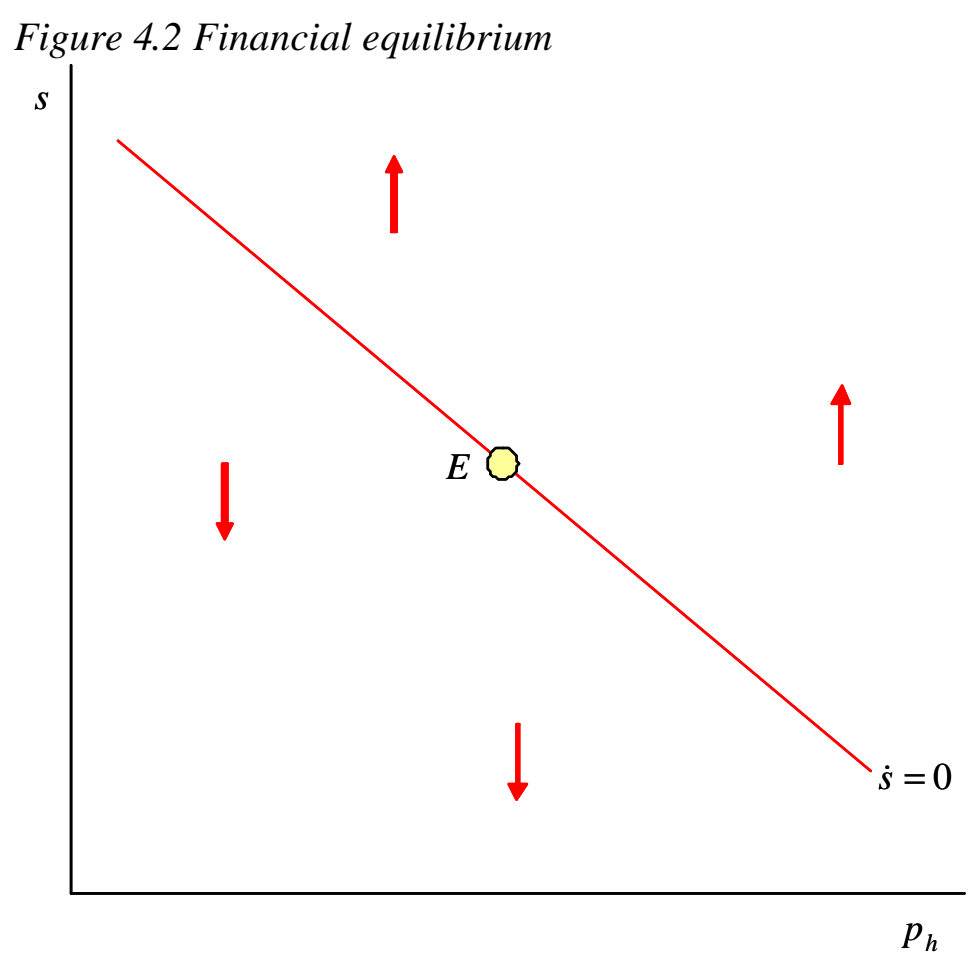

Equation (4.4) describes the motion of the exchange rate in a rational expectations environment. It is illustrated in Figure 4.2 by taking two steps. The first step is to determine combinations of the exchange rate $s$ and the domestic price level $p_{h}$ for which the exchange rate does not change. This gives the downward sloping $\dot{s}=0$ curve in Figure 4.2. The second step is to determine whether the exchange rate increases or decreases above and below this curve, that is whether $\dot{s}$ is larger or smaller than zero. Consider point $E$ on the $\dot{s}=0$ curve in Figure 4.2, where the exchange rate does not change. From equation (4.4) it is then clear that if we increase the exchange rate (move up in the figure) the expected change in the exchange rate $\dot{s}$ will increase. Since it was 


\section{Basic exchange rate theories}

zero at point $E$, it must become positive above that point. This implies that the exchange rate will increase for all points above the $\dot{s}=0$ curve. Similarly, the exchange rate will decrease for all points below this curve, as indicated by the vertical arrows in Figure 4.2.

\subsection{Price stickiness and the phase diagram}

As already noted earlier, it is an empirical fact that goods prices are much less volatile than exchange rates for a variety of reasons, see Box 2.1. The Dornbusch model takes this fact as given, that is it does not try to explain it, and assumes that prices are 'sticky'. This means that prices cannot adjust instantaneously (cannot 'jump'), but only gradually change in response to goods market disequilibrium. Exchange rates, in contrast, can (and will) adjust instantaneously to ensure market equilibrium. The sluggish adjustment of prices is given in equation (4.5), where $\lambda$ is a parameter to measure the speed of adjustment and $\bar{s}$ is the long-run equilibrium PPP exchange rate, see equation (4.6).

(4.5) $\quad \dot{p}_{h}=\lambda(s-\bar{s})$

(4.6) $\bar{s}=p_{h}-p_{f}$

Figure 4.3 Sluggish price adjustment

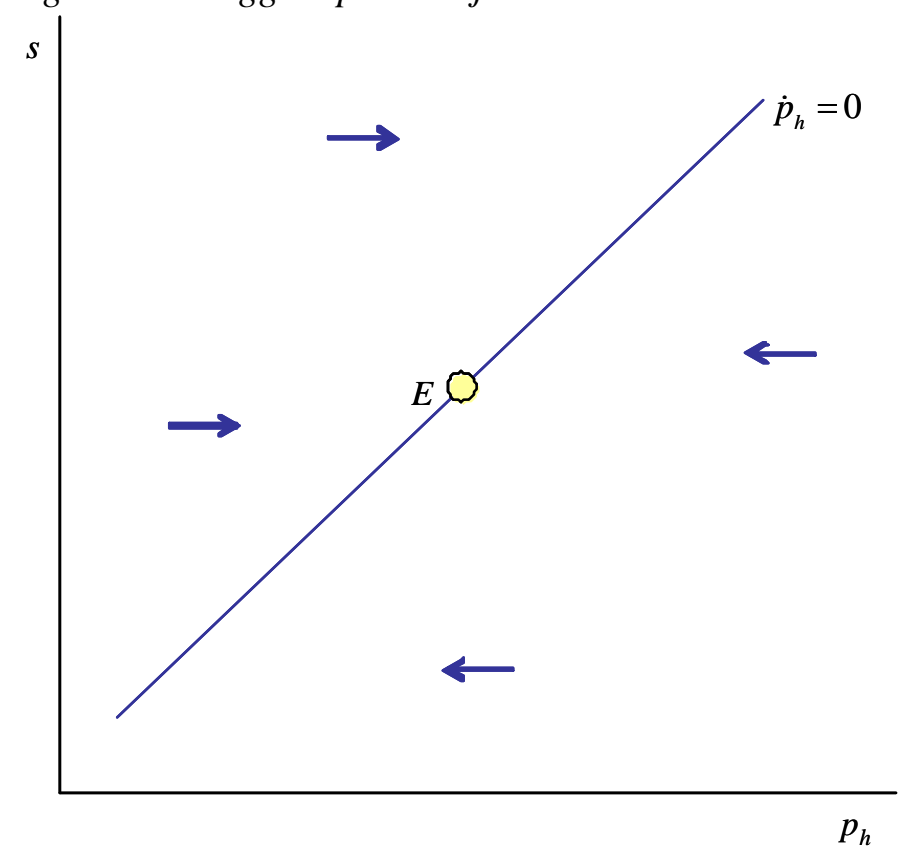

By combining equations (4.5) and (4.6) we can determine the price adjustment equation, giving the speed at which domestic prices adjust to disequilibrium: 
Basic exchange rate theories

$$
\dot{p}_{h}=\lambda\left(s-p_{h}+p_{f}\right)
$$

If the exchange rate is above its PPP value (and the domestic currency is undervalued) the price level is increasing, and vice versa if it is below its PPP value. The sluggish price adjustment is illustrated in Figure 4.3 using the two-step procedure of section 4.2. The first step determines combinations of the exchange rate $s$ and the domestic price level $p_{h}$ for which the domestic price level does not change. This gives the upward sloping $\dot{p}_{h}=0$ curve in Figure 4.3. The second step is to determine whether prices are rising or falling above and below this curve. Consider point $E$ on the $\dot{p}_{h}=0$ curve in Figure 4.3, where the price level does not change. From equation (4.7) it is then clear that if we increase the exchange rate (move up in the figure) $\dot{p}_{h}$ will increase. Since it was zero at point $E$, it must become positive above point $E$. This implies that the price level will increase for all points above the $\dot{p}_{h}=0$ curve. Similarly, the price level will decrease for all points below this curve, as indicated by the horizontal arrows in Figure 4.3.

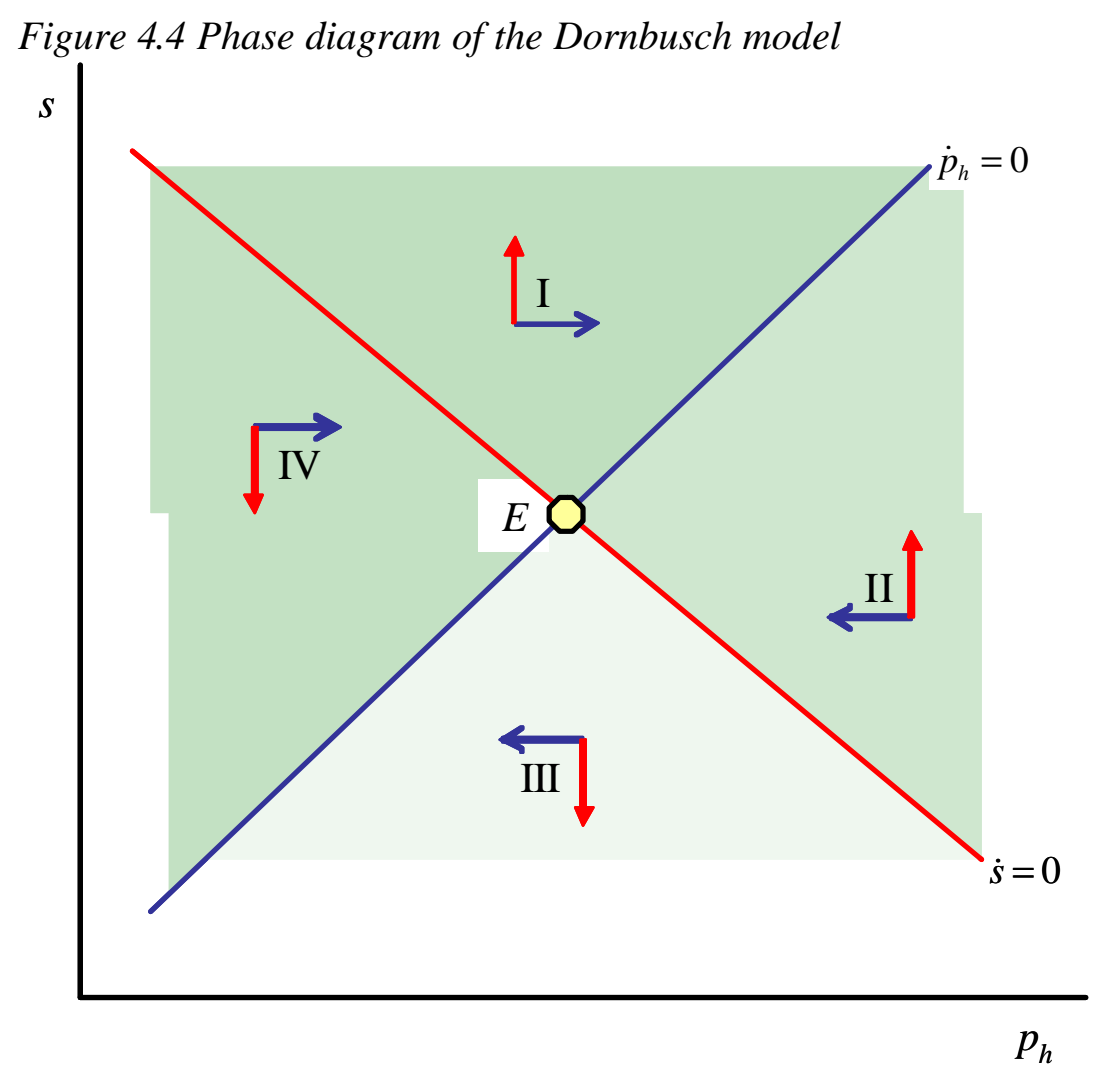


Figure 4.4 combines the information of Figures 4.2. and 4.3 in one picture called a phase diagram. It summarizes the direction of motion for both the exchange rate and the price level. At point $E$, the intersection of the $\dot{s}=0$ and $\dot{p}_{h}=0$ curves, both the exchange rate and the price level do not change. Once the economy has reached this point, a full equilibrium is reached and there is no incentive to move away from this point. The intersection of the two curves subdivide the plane into four different areas, labeled I, II, III, and IV. Each of these areas is characterized by specific movements in exchange rates and prices, as indicated by the arrows in Figure 4.4. In area I, for example, both the price level and the exchange rate are increasing. Similarly, in area II the exchange rate is increasing while the price level is decreasing, etc. The next section analyzes how rational expectations can be used to determine the equilibrium price and exchange rate movements. Section 4.5 then uses the equilibrium dynamics to explain the empirically observed phenomenon of exchange rate overshooting.

\subsection{Equilibrium dynamics}

The equilibrium dynamics for the economy are given in equations (4.4) and (4.7), for the financial equilibrium and price adjustment, respectively. It is illustrated in the phase diagram of Figure 4.4. If agents have rational expectations, they understand how the economy works, that is they are aware of the above information and take this into account for determining their decisions and equilibrium in the economy. Figure 4.5 illustrates how this may be useful for determining this equilibrium. We already know that, given the exogenous variables (such as the money stock and the foreign price level) and the parameters in this economy (such as the income elasticity of money demand and the speed of price adjustments), full equilibrium is achieved at point $E$, the intersection of the $\dot{s}=0$ and $\dot{p}_{h}=0$ curves. Now suppose that we are initially not at the equilibrium point $E$, but rather that the domestic price level at time 0 is too high, say equal to $p_{h 0}$. We know that (i) prices are sticky (cannot adjust instantaneously) and (ii) exchange rates are fully flexible. This implies that the initial price level-exchange rate combination at time 0 must be somewhere along the vertical line determined by $p_{h 0}$, see Figure 4.5. 


\section{Figure 4.5 Dornbusch model dynamics}

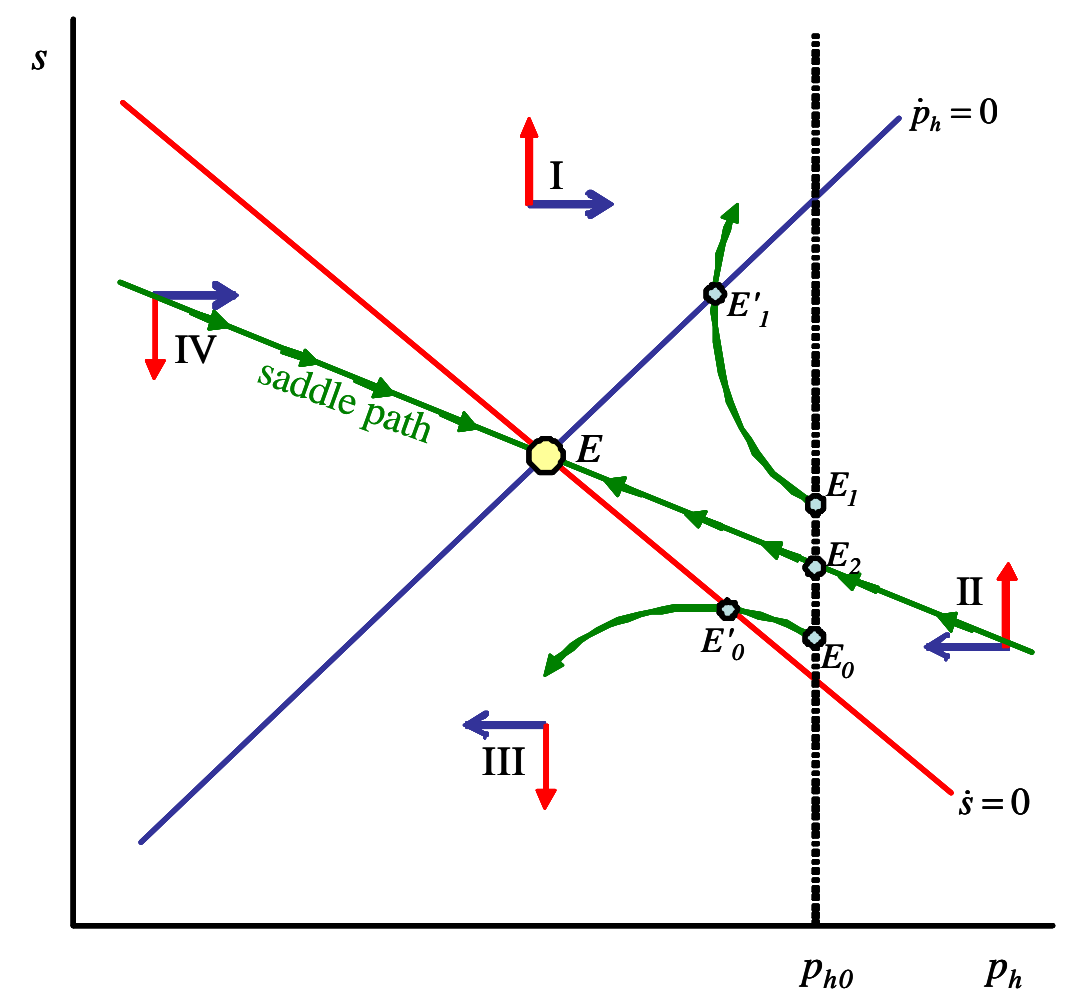

Now that we have established that initially we must be somewhere along the vertical line in Figure 4.5, it remains to determine where exactly the equilibrium will be. The figure illustrates three possible trajectories out of an infinite number of possibilities to assist us in determining this equilibrium.

- First, suppose that the initial price level - exchange rate combination is given by point $E_{0}$ in the figure. As this point is in area II, we know that the exchange rate is increasing and the price level is decreasing. The speed at which this occurs is determined by equations (4.4) and (4.7). As we follow the trajectory in Figure 4.5, we note that at some time in the future we reach point $E_{0}{ }_{0}$ and cross over from area II to area III, such that henceforth both the exchange rate and the price level are decreasing. It is obvious that this trajectory will not lead us to the long-run equilibrium at point $E$.

- Second, suppose that the initial price level - exchange rate combination is given by point $E_{l}$ in the figure. Again, this point is in area II such that the exchange rate is increasing and the price level is decreasing. As we follow the trajectory from point $E_{l}$ in Figure 4.5 , we note that at some time in the future we reach point $E_{1}{ }_{1}$ and cross over from 


\section{Basic exchange rate theories}

area II to area I, such that henceforth both the exchange rate and the price level are increasing. Again, this trajectory will not lead us to the long-run equilibrium at point $E$.

- Third, suppose that the initial price level - exchange rate combination is given by point $E_{2}$ in the figure, a well-chosen point in between points $E_{0}$ and $E_{1}$. It is determined such that all points below $E_{2}$ will eventually cross over from area II to area III, while all points above $E_{2}$ will eventually cross over from area II to area I. Point $E_{2}$ is therefore very special as the trajectory determined by equations (4.4) and (4.7) does not cross over from area II to area I nor from area II to area III. Instead, the trajectory will lead us on a delicate path to the long-run equilibrium at point $E$. It is 'delicate' because if the initial exchange rate is just a little bit higher or a little bit lower, the trajectory will lead us in a completely different direction. Such a path is called a saddle path.

Agents with rational expectations are now able to determine the economic equilibrium. After all, they (i) understand the underlying economic system, (ii) know that the initial price level $p_{h 0}$ can only adjust slowly over time to the long-run equilibrium, and (iii) know that any initial exchange rate other than point $E_{2}$ in Figure 4.5 is not sustainable as it ultimately leads away from the long-run equilibrium. In short, they understand that the saddle path leading to the long-run equilibrium is eventually the only viable solution. Note that the fact that the saddle path is 'delicate' (there is only one solution leading to point $E$ ) is not a problem but actually helps the economic agents in determining the equilibrium. If there were several solutions leading to point $E$, the agents would have to somehow coordinate their actions in determining which one to pick. As everyone knows there is only one solution leading to the long-run equilibrium the problem of choice does not arise. This is further discussed in sections 4.6 and 4.7.

\section{Box 4.1 An example of exchange rate overshooting ${ }^{9}$}

The term 'overshooting' is used when the short-run adjustment of an economic variable in a certain direction following an exogenous shock or policy change is larger then what is needed to restore the long-run equilibrium, necessitating a reversal of the direction at some time in the future. An example may clarify. Suppose that, following a policy shock, 


\section{Basic exchange rate theories}

the exchange rate increases instantaneously by 40 percent (from 1 to 1.4 ), while only a 20 percent rise is necessary to restore long-run equilibrium (from 1 to 1.2). This means that after the initial increase of 40 percent in the exchange rate there must be a subsequent decrease of 20 percent (from 1.4 to 1.2 ) to reach the long-run equilibrium. The initial response is therefore 'too large' and the exchange rate 'overshoots'. ${ }^{10}$

Figure 4.6 The Asian crisis in Thailand

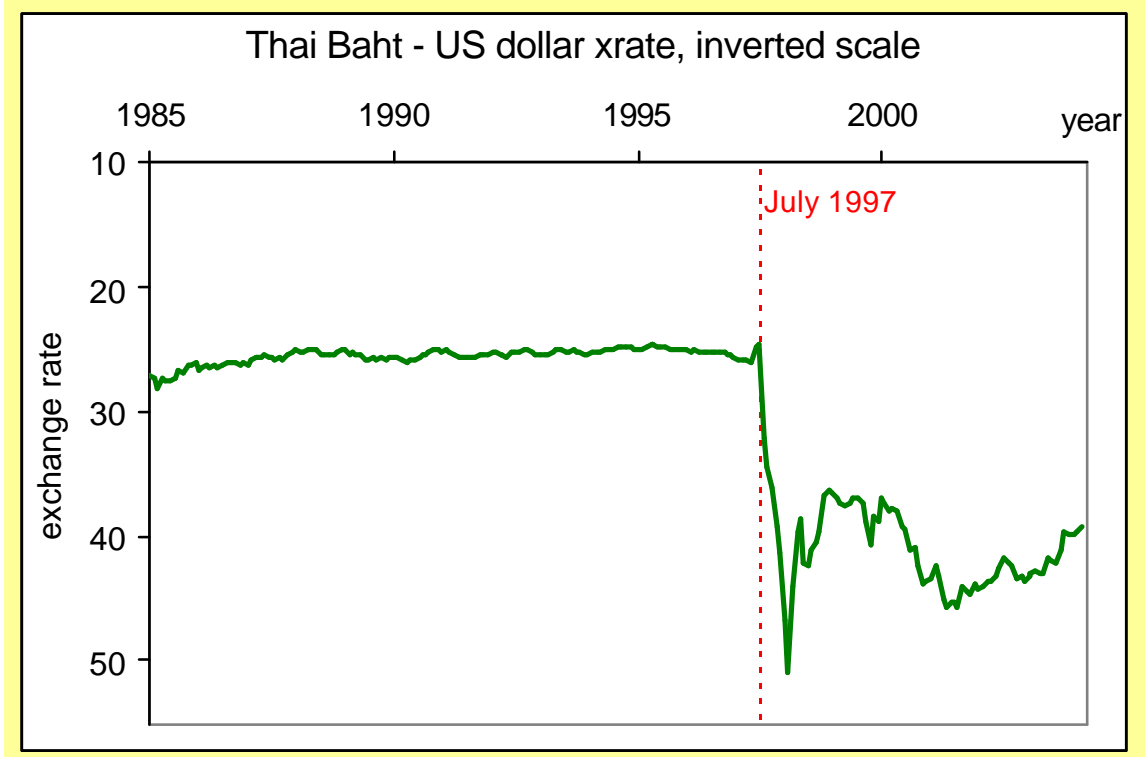

Source: IFS; noon NY exchange rate, monthly

The currency crisis that hit a number of South-East Asian economies during 1997 provides an example of the overshooting phenomenon. In the time period preceding the crisis the South-East Asian countries maintained a fixed exchange rate relative to the US dollar. There was mounting pressure on the existing exchange rate to depreciate (it does not matter at this point why this was the case). Investors collectively started to sell their investments denominated in the currency under pressure. Initially, the authorities (particularly the central bank) tried to defy depreciation of the currency by supporting the present exchange rate, either by raising interest rates or by selling part of their foreign exchange reserves (and thus buying the local currency). As the speculative attack continued, the authorities had to give in and the currency started its (steep) decline. As

${ }^{9}$ Based on Brakman et al. (2005, Ch. 8). 
illustrated for Thailand in Figure 4.6, the sharp decline following the July 1997 crisis was too large, and followed by substantial subsequent increases to restore equilibrium. These issues are further discussed in Chapter 30.

\subsection{Exchange rate overshooting}

We are now in a position to show how the model developed above can be used to explain the high variability of exchange rates caused by 'noise', 'new information', or 'exogenous shocks', as well as the empirical phenomenon of exchange rate overshooting, see Box 4.1. It should be noted from the start that, although the Dornbusch sticky-price model was the first model able to explain this type of behavior, there are many alternative specifications using the same general methodology but not based on sticky prices which also give rise to exchange rate overshooting, see De Grauwe (1996) and Sarno and Taylor (2002).

\section{Figure 4.7 Monetary expansion: exchange rate overshooting}

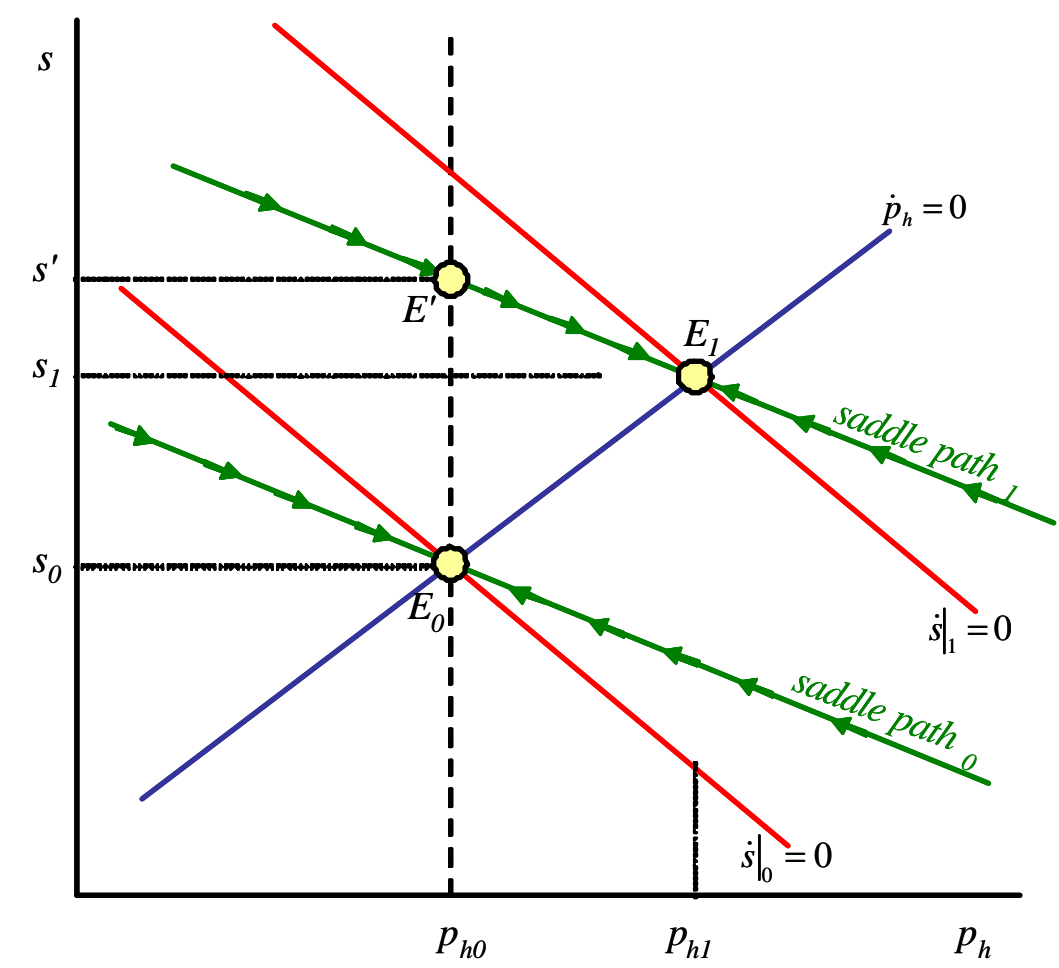

\footnotetext{
10 The same terminology is usually also applied when the initial decrease is too large, although the term 'undershooting' is sometimes also used.
} 


\section{Basic exchange rate theories}

The core argument is illustrated in Figure 4.7. Suppose the economy is initially in a state of rest (long-run equilibrium) at point $E_{0}$, with price level $p_{h 0}$ and exchange rate $s_{0}$. In the absence of any disturbances, exogenous shock, or policy changes, the economy will remain at point $E_{0}$ indefinitely and the price level and exchange rate do not change. At time period $t_{0}$, however, the monetary authorities unexpectedly decide to increase the money supply. ${ }^{11}$ As is clear from equations (4.4) and (4.7), this does not affect the $\dot{p}_{h}=0$ schedule associated with (long-run) purchasing power parity, but it does shift the $\dot{s}=0$ curve up from $\left.\dot{s}\right|_{0}=0$ to $\left.\dot{s}\right|_{1}=0$, see Figure 4.7. Since the domestic price level is fixed in the short-run and cannot adjust instantaneously, the rational economic agents know that the only path that will take the economy to the new long-run equilibrium at point $E_{1}$ is the trajectory following saddle path in $_{1}$ the figure. At time period $t_{0}$ the economy therefore immediately jumps from the initial long-run equilibrium $E_{0}$ to the short-run equilibrium $E^{\prime}$ associated with the new saddle path at the price level $p_{h 0}$. Over time, the domestic price level gradually increases, bringing about a whole sequence of short-run equilibria along the new saddle path in which the exchange rate gradually declines. This process continues until the new long-run equilibrium at point $E_{l}$ is reached.

\section{Figure 4.8 Overshooting}

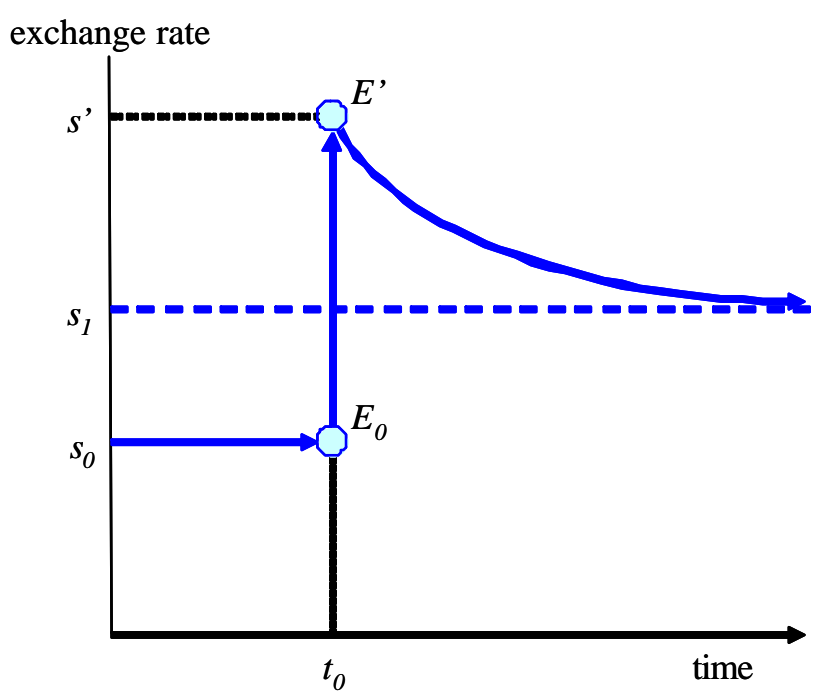

\footnotetext{
${ }^{11}$ We abstain from delving into the philosophical problems associated with analyzing unexpected policy changes in a perfect foresight model.
} 


\section{Basic exchange rate theories}

The overshooting adjustment path is illustrated in Figure 4.8. Initially, the exchange rate is stable at $s_{0}$ until the time of the policy change $t_{0}$. As a result of the increase in the money supply the long-run domestic price level increases to $s_{1}>s_{0}$. The impact effect of the increase in the money supply at time $t_{0}$, however, is an immediate jump to $s^{\prime}>s_{1}$, followed by a subsequent gradual decline to the long-run equilibrium, that is the exchange rate 'overshoots'. Arguably, the fact that the exchange is flexible whereas the price level is not, forces the exchange rate to adjust by more than is necessary to restore long-run equilibrium, leading to a drastic change in the exchange rate as a result of the policy change.

Imagine, now, a world operating along the lines of the Dornbusch model, that is with sticky prices, flexible exchange rates, and agents with rational expectations, but in addition governed by uncertainty or 'news'. The latter may result from random shocks to the economic system, other components not explicitly modeled, unforeseen changes in economic policy, etc. The media (newspapers, television stations, radio programs, internet, etc.) bombard us with thousands of new pieces of information every day. Some of these are important to the economic system, others are not. It usually takes some time to filter out the relevance of each new piece of information, but anything that is deemed to ultimately influence the long-run equilibrium, will result in an instantaneous adjustment of the exchange rate. On the basis of rational expectations and sticky prices, even relatively small new pieces of information may give rise to substantial adjustments in the exchange rate, and possibly to overshooting. This, in a nutshell, is the explanation for the high variance of the exchange rate that we observe empirically.

\section{Box 4.2 Adaptive expectations}

Before the break-through of rational expectations, which is widely used today in all fields of economics, the modeling of the expectations formation process was mainly based on Cagan's (1956) adaptive expectations. The main idea is simple as individuals use information on past forecasting errors to revise their expectations. Let ${ }_{t} x_{t+1}^{e}$ be the value of the variable $x$ at time $t+1$ as expected by individuals forming expectations at time $t$. The adaptive expectations hypothesis is then given by: 
Basic exchange rate theories

$$
\underbrace{{ }_{t}^{x_{t+1}^{e}-{ }_{t-1} x_{t}^{e}}}_{\text {forecastadjustment }}=\theta \underbrace{\left(x_{t}-{ }_{t-1} x_{t}^{e}\right)}_{\text {forecasterror }}, \quad 0<\theta<1
$$

The hypothesis therefore asserts that individuals examine ex post in period $t$ how accurate their prediction last period was regarding the actual value of variable $x$ in this period (forecast error). They then revise their forecast for the variable $x$ one period later by some fraction $\theta$ of the forecast error.

Technical Note 4.2 shows that the adaptive expectations hypothesis implies that the forecast in this period for the value of variable $x$ in the next period is a (geometrically) weighted average of past observations, see equation (4.9). ${ }^{12}$ This is both the main advantage and the main disadvantage of the adaptive expectations hypothesis. It is the main advantage because the $u n$ observable expectations term ${ }_{t} x_{t+1}^{e}$ can be transformed into past observations of the variable $x$, which enables straightforward empirical analysis. It is the main disadvantage because any backward looking expectations formation process implies that individual agents can make structural forecast errors indefinitely. In a world inhabited by rational economic agents this presents a major problem as Bob Marley already observed that "you can fool some people some time, but you cannot fool all the people all the time."

$$
{ }_{t} x_{t+1}^{e}=\underbrace{\sum_{j=0}^{\infty} \theta(1-\theta)^{j} x_{t-j}}_{\text {pastobservations }}+\underbrace{\lim _{n \rightarrow \infty}(1-\theta)^{n+1}{ }_{t-n-1} x_{t-n}^{e}}_{=\text {zero }}
$$

\subsection{Expectations formation}

It has become clear from the above analysis that the role of expectations formation is crucial for determining the equilibrium economic outcome. It therefore pays to delve a little deeper into the expectations formation process. Along the way it will become evident that, for expository purposes, we have cut a few corners in deriving the equilibrium in section 4.4. This equilibrium is based on the rational expectations hypothesis introduced by Muth (1961), building on earlier work by Modigliani and Grunberg (1954). The concept is applied widely in (international) macroeconomics since

\footnotetext{
12 The limit in eq. (4.9) is equal to zero as long as the expected value term is finite (bounded from above).
} 
the path-breaking papers by Lucas (1972, 1973), Sargent (1972, 1973), and Dornbusch (1976). Before that time, the expectations formation process was mostly based on Cagan's (1956) backward-looking adaptive expectations hypothesis, see Box 4.2.

Our core arguments are most easily explained in a discrete time framework based on the flexible price monetary model discussed in section 24, including the uncovered interest rate parity condition, see Box 2.3. The model is briefly reviewed in Technical Note 4.3, which shows that the functioning of the model can be summarized in one forwardlooking difference equation, namely:

(4.10) $s_{t}=x_{t}+\phi_{t} s_{t+1}^{e}, \quad 0<\phi<1$,

where $s_{t}$ is the spot exchange rate, $x_{t}$ is a combination of parameters, money supplies, and output levels, and ${ }_{t} s_{t+1}^{e}$ is the value of the exchange rate at time $t+1$ as expected by individuals forming expectations at time $t$. As already observed in Box 2.3, there is a nested reasoning inherent in equation (4.10) in which the exchange rate today depends on the expected exchange rate tomorrow, while the exchange rate tomorrow will depend on the expected exchange rate as of tomorrow for the day after tomorrow, etc. Essentially, the rational expectations hypothesis provides a method for dealing with this infinitenested-ness issue, as explained below and illustrated in Figure 4.9.

Before we continue it is useful to distinguish between two different types of expectations, namely mathematical - statistical expectations and those held by individual agents.

- Individual expectations relate to what an economic agent today expects to hold regarding a particular value of some variable for some time in the future. It is this term denoted by ${ }_{t} s_{t+1}^{e}$ for the exchange rate in (4.10) which is crucial for determining the economic equilibrium. In principle, agents can form their expectations regarding the future value of the exchange rate in any way they like. They could role some dice, they could flip a coin, they could count the number of sun spots, or they could try to figure out the equilibrium value of the future exchange rate based on some economic model.

- Mathematical - statistical expectations relate to the expected value of some variable in the future based on an underlying mathematical - statistical model. It is denoted by the 


\section{Basic exchange rate theories}

operator $E_{t}$, where the sub index $t$ indicates that expectations are formed given all relevant information available up to time $t$. Suppose we flip a fair coin in time period $t+1$ and give the variable $y_{t+1}$ the value 0 if the outcome is head and 1 if the outcome is tails, then $E_{t} y_{t+1}=0.5$ since the outcome head is equally likely as the outcome tails (both occur with probability 0.5 , indicating that $E_{t} y_{t+1}=0.5 \cdot 0+0.5 \cdot 1=0.5$ ). Note that, in this case, the actual outcome cannot be equal to the mathematical expectation of 0.5 (it is either head, in which case $y_{t+1}=0$, or tails, in which case $\left.y_{t+1}=1\right)$. Obviously, if we were to evaluate the expected value of this experiment two periods earlier it would still be 0.5 , that is $E_{t-2} y_{t+1}=0.5$. In general, this need not be the case.

Figure 4.9 Infinite nested-ness, fundamentals, and bubbles

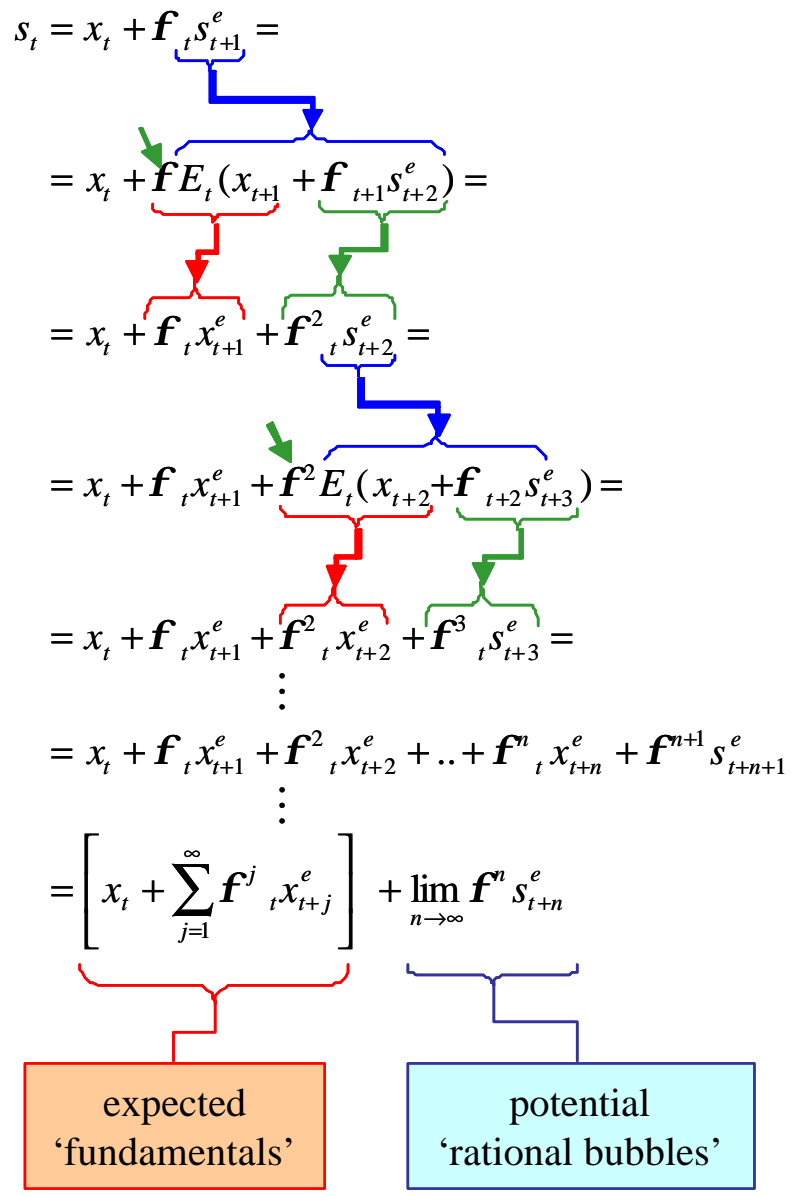




\section{Basic exchange rate theories}

The rational expectations hypothesis argues that agents form expectations in a way that is consistent with the model itself, that is the individual expectations are equal to the mathematical - statistical expectations. ${ }^{13}$ Figure 4.9 shows how this hypothesis is applied to the flexible price monetary model summarized in equation (4.10).

- First, ${ }_{t} s_{t+1}^{e}=E_{t}\left(x_{t+1}+\phi_{t+1} s_{t+2}^{e}\right)$; the individual expectation for the exchange rate next period is equal to the value determined by the economic model. This value is given by equation (4.10) one period ahead and depends on the underlying 'fundamentals' next period $\left(x_{t+1}\right)$ and the value of the exchange rate expected next period by the individual agents one period ahead $\left(\phi_{t+1} s_{t+2}^{e}\right)$. For both of these terms expectations are formed given the available information at time $t\left(E_{t}\right)$.

- Second, $\phi E_{t}\left(x_{t+1}\right)=\phi_{t} x_{t+1}^{e}$; the expected value for the fundamentals next period is equal to the individual expectations. If we recall that the variable $x$ is a combination of parameters, money supplies, and output levels (Technical Note 4.3), then this implies that the agents must find a way to forecast these values, for example based on rules imposed by the monetary authorities, or announcements concerning the future, etc.

- Third, $\phi E_{t}\left(\phi_{t+1} s_{t+2}^{e}\right)=\phi^{2}{ }_{t} s_{t+2}^{e}$; this uses a fundamental property of rational expectations, namely the fact that $E_{t}\left({ }_{t+1} s_{t+2}^{e}\right)$, which is what you expect today that you are going to expect tomorrow for the day after tomorrow, is equal to ${ }_{t} s_{t+2}^{e}$, which is what you expect today for the day after tomorrow. In essence it argues that all available information is used efficiently, that is individuals have no basis for predicting how they will change their expectations about future variables.

- Fourth, the infinite continuation of the above three arguments shows that the equilibrium solution for the exchange rate today is given by equation (4.11) below, as discussed in the next section.

\footnotetext{
13 This simultaneously implies that all agents will have the same individual expectations, as long as they all have rational expectations and have identical access to all relevant information (as we assume here). See Begg (1982) for an excellent treatment of these and related issues.
} 
Basic exchange rate theories

\subsection{Fundamentals and bubbles}

As shown in the previous section and illustrated in Figure 4.9, the rational expectations solution to the flexible price monetary model is given by:

$$
s_{t}=\underbrace{\left[x_{t}+\sum_{j=1}^{\infty} \phi^{j}{ }_{t} x_{t+j}^{e}\right]}_{\text {fundament } \delta=\tilde{s}_{t}}+\underbrace{\lim _{n \rightarrow \infty} \phi^{n} s_{t+n}^{e}}_{\text {potentialrationalbubble }}
$$

We have decomposed this solution into two components, the fundamentals (which we define $\tilde{s}_{t}$ ) and the potential rational bubble. The short cut taken in the exposition in sections 4.2-4.5 is therefore that we have focused attention exclusively on the fundamentals and ignored the possibility of bubbles (see below). This does not mean that restricting attention to fundamentals only is easy or unwarranted. Indeed, it can be shown that in a long-run economic growth perspective, of which the Dornbusch model can be viewed as a simple example, it is necessary to restrict attention to the fundamentals and bubbles cannot arise, but this issue is too complex to deal with in this setting. ${ }^{14}$

A fundamental aspect of the rational expectations hypothesis is that it is forward-looking rather than the backward-looking adaptive expectations hypothesis, compare equations (4.11) and (4.9), respectively. This implies, as already noted above, that the economic agents must form forecasts for all relevant future economic variables, such as money supplies and outputs, in order to be able to determine today's exchange rate. Although this puts a formidable task on the shoulders of these agents, the advantage is that the expectations formation process takes place in a coherent framework and economic agents will not make structural forecast errors. They will, of course, make errors in their predictions, but there is no opportunity for the government or the central bank to consistently manipulate economic behavior in a particular direction.

One of the disadvantages of the forward-looking character of the rational expectations hypothesis is that it creates possibilities of disturbances and coordination problems associated with 'bubbles'. The possibility arises because of the forward-looking expectations term in equation (4.11). Note that we have a very similar backward-looking 
expectations term in the adaptive expectations hypothesis, see equation (4.9). We have put that term equal to zero based on the argument that in retrospect the limiting expectations term is bounded from above (such that the term as a whole becomes zero). We cannot use the same argument for the forward-looking expectations term in equation (4.11), because why would we think today that the exchange rate cannot surpass some arbitrary upper bound some time into the indefinite future?

This is where the potential for rational bubbles appears, that is 'something' that determines the current exchange rate in addition to the expected fundamentals term. From equations (4.10) and (4.11) it is clear that an arbitrary deviation from the fundamentals term that is expected to grow from period to period at the speed $\phi^{-1}$ will provide a solution to the equilibrium condition (4.10), see Technical Note 4.4 for details. There are therefore multiple rational expectations solutions according to:

(4.12) $s_{t}=\tilde{s}_{t}+B_{t}$, where bubble $B_{t}$ satisfies $E_{t}\left(B_{t+1}\right)=\phi^{-1} B_{t}$

So if all economic agents believe that there is a bubble $B_{t}$ on top of the fundamentals $\tilde{s}_{t}$ which grows at the rate $\phi^{-1}$ governing the exchange rate, then this satisfies the equilibrium condition and is thus a self-fulfilling prophecy. This, of course, poses a coordination problem, because how are the individual agents in the economy going to decide on the occurrence and size of the bubble $B_{t}$ ? It has been jokingly said that they perhaps count the number of sunspots to coordinate their actions, giving rise to the term 'sunspot equilibria'. Alternatively, the role of some large market players are thought to be instrumental in this respect, as discussed in Chapter 30 (financial crises). In the general foreign exchange market, however, it is now frequently argued that chartists play a crucial role in generating bubbles.

Chartist or 'technical' analysis involves using charts of past foreign exchange rate movements in conjunction with descriptive statistics to try to predict future exchange rate movements, which is then used as a basis for trading strategies. According to Frankel and

\footnotetext{
${ }^{14}$ On economic growth models see, for example, Romer (2001) or Barro and Sala-i-Martin (2003).
} 
Froot (1990, p. 183): "Many so-called "chartist" forecasters, or technical analysts, are thought to use rules that are extrapolative, such as, "Buy when the 1-week moving average crosses above the 12-week moving average."' Various surveys show that the weight given to forecasting the exchange rate based on 'chartist' analysis is high for short-term forecasting horizons, while the weight given to 'fundamental' analysis increases for longer horizon forecasts, see Allen and Taylor (1990), Taylor and Allen (1992), and Lui and Mole (1998). In all cases, a substantial portion of short-run exchange rate forecasts is based on chartist analysis.

Figure 4.10 The real value of the US dollar

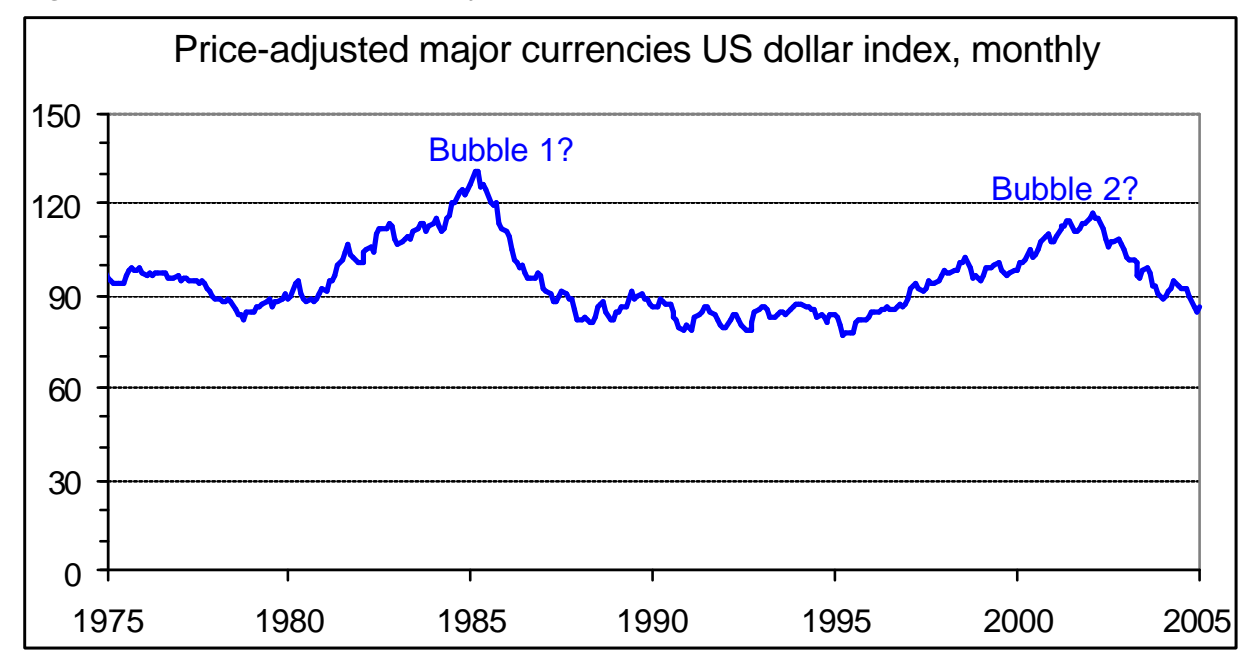

Data source: Federal Reserve website, 7 February 2005

Frankel and Froot $(1987,1990)$ distinguish between different types of economic agents to model and explain empirical exchange rate phenomena. The 'fundamentalists' base their expectations on a Dornbusch overshooting model and the 'chartists' on extrapolation (autoregressive integrated moving average). The value of a currency is determined by portfolio managers on the basis of a weighted average of the expectations of chartists and fundamentalists, where the weight given to each varies over time.

Frankel and Froot argue that the high value of the US dollar in 1984 and 1985 as illustrated in Figure 4.10 can best be explained as a speculative bubble, based on the selfconfirming market expectations driven by the increase in forecasting-weight given to the chartists as a result of their previous forecasting-success. They find the alternative, that 
the exchange rate is determined exclusively by fundamentals, unlikely (Frankel and Froot, 1990, p. 182): 'ft is difficult to believe that there could have been an increase in the world demand for U.S. goods (or in U.S. productivity) sufficient to increase the equilibrium real exchange rate by more than 20 percent over a 9-month period, and that such a shift would then be reversed over the subsequent 9 months."

In short, a speculative bubble driven by chartist behavior is thought to be responsible for the high real value of the US dollar in 1984 and 1985. The politically-driven burst in the bubble in 1985 then quickly drove the dollar down to its fundamental equilibrium value. A similar, second bubble could be responsible for the high real value of the US dollar in 2001 and 2002, again followed by a rapid decline to restore the fundamental equilibrium. Note, however, that these are not fully rational bubbles as the three different types of economic agents (fundamentalists, chartists, and portfolio managers) do not base their forecasts on the complete information set of the model. Similar models with different types of agents are constructed, for example, by DeLong, Shleifer, Summers, and Waldmann (1990) and De Grauwe and Dewachter (1993).

\subsection{Empirical evidence}

The reader must have noted in this and the previous chapters that we provide ample anecdotal, historical, and heuristic information on the goodness-of-fit of the various exchange rate models based on simple graphs, statistics, and tests. So far we have not, however, thoroughly discussed and evaluated the empirical literature on econometric tests of exchange rate theories. As explained below, we will not do this here either.

Throughout this chapter we have analyzed the importance of the expectations formation process for determining the exchange rate. Even in the absence of (rational) bubbles, forward-looking age nts with rational expectations will take their best guess regarding the future values of all fundamental variables and expected policy responses by the monetary authorities into consideration when determining the exchange rate. This makes exchange rate models notoriously difficult to estimate empirically. A proper discussion of this literature, which is complex, technically advanced, and full of pitfalls and errors, requires 
a better understanding of econometric techniques than we take for granted in this book. We refer the reader to the overview and discussion in Sarno and Taylor (2002). At this point we want to emphasize two main results: the short-run result and the long-run result.

Box 4.3 Meese and Rogoff: forecasting and random walks

Consider the following experiment. Your initial money holdings are $\$ 100$. You start flipping a fair coin sequentially. Each time the outcome is head your money holdings are increased by one dollar. Each time the outcome is tails your money holdings are decreased by one dollar. The evolution of your money holdings over time is now a simple example of a random walk. The process has various obvious properties, one of which is that the expected value of your future money holdings is equal to your current money holdings. If we say that you are 'bankrupt' if your money holdings become zero, another property is, unfortunately for you, the fact that you will become bankrupt at some time in the future, for sure, no matter what your initial money holdings were. ${ }^{15}$

Figure 4.11 Out-of-sample exchange rate forecasting

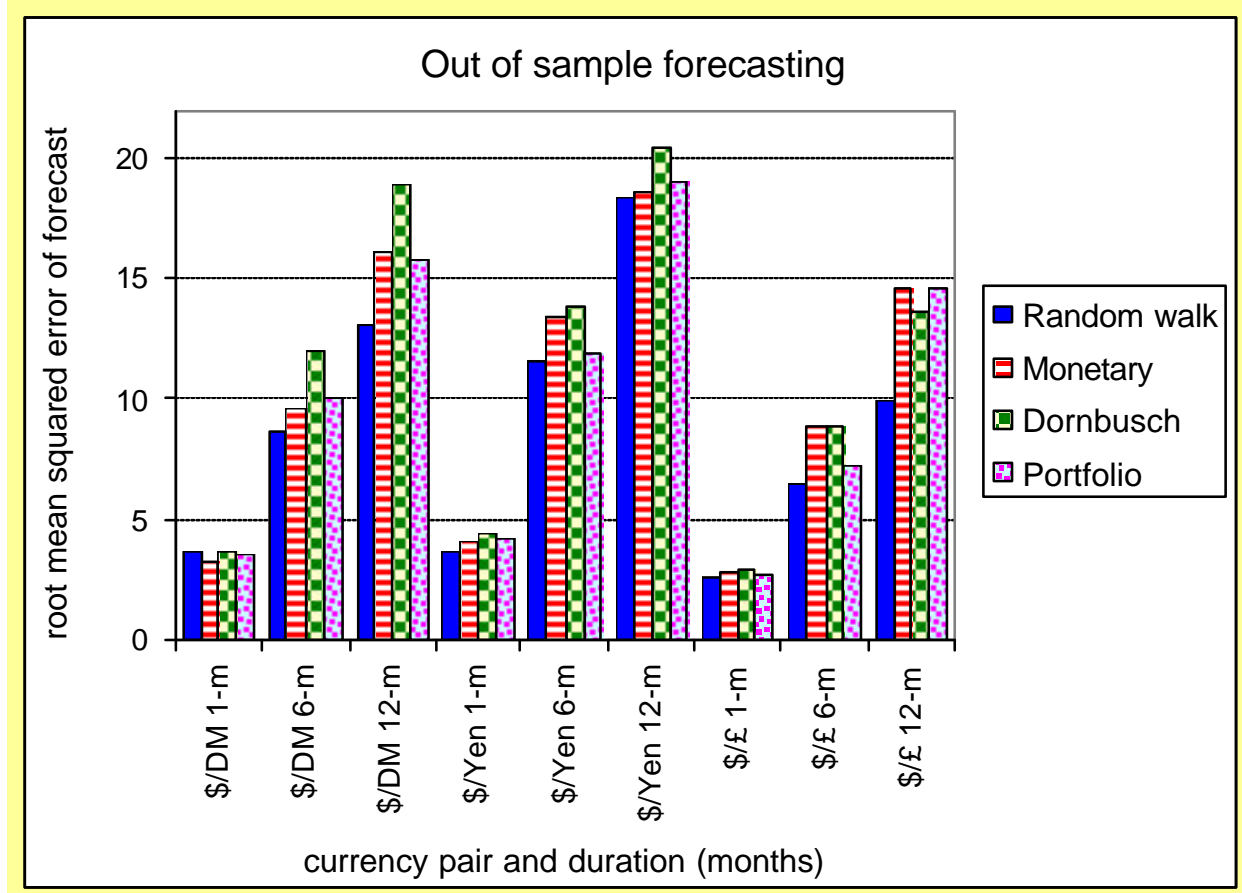

Data source: Meese and Rogoff (1983) 


\section{Basic exchange rate theories}

In a seminal contribution, Meese and Rogoff (1983) compare the out-of-sample forecasting accuracy of various exchange rate models with the accuracy of a random walk forecast for different, short-run time horizons. Using the root mean squared error of the forecast as a means for comparing the performance of different exchange rate models, they find that the random walk model performed as well as any of the estimated structural (monetary, Dornbusch, and portfolio) models, see Figure 4.11. Although one can always discuss the extent to which the structural models have been estimated accurately, the fact that a random walk model performed so well relative to these models did come as a shock. This is further discussed in section 4.8 .

The short-run result is discussed in Box 4.3; no structural model is better in short-run forecasting than a simple random walk model. In the presence of shocks and new information, the best forecast for tomorrow's exchange rate is today's exchange rate. In essence, this Meese and Rogoff (1983) result should not surprise us, as it is an efficiency criterion. If it was clear to everybody, based on some structural model and in the absence of interest rate differentials, that the exchange rate tomorrow is going to be higher than the exchange rate today, we could all make a profit by buying the currency today. This would immediately drive up the exchange rate today until the profit opportunity disappears, that is until the exchange rate today is equal to the expected exchange rate tomorrow.

The long-run result is somewhat more elusive; economic fundamentals are important for determining the long-run equilibrium exchange rate, see Koedijk and Schotman (1990). This aspect is usually emphasized in our boxes and anecdotal, historical, etc. discussions. The 'elusiveness' relates to exactly what the fundamentals are (what to include and exclude). Nonetheless, Sarno and Taylor (2002, p. 137) conclude:

"One finding which does, however, seem to have some validity, is that the monetary model does resurface in a number of empirical studies as a long-run equilibrium condition. .. This finding .. occurs with sufficient regularity in the empirical literature as to suggest .. the emergence of a stylized fact."

\footnotetext{
${ }^{15}$ This is not necessarily the case for random walks with 'drift'.
} 
It is clear that both results are important from a policy perspective. The short-run market efficiency result is important for realizing the limits and possibilities of policy interventions. The long-run (monetary) implications are important for realizing the extent to which the authorities can ultimately influence the nominal and real exchange rate. These and related issues are discussed in the next part of this book.

\subsection{Conclusion}

The Dornbusch model analyzes exchange rate adjustment in a model with sticky prices and rational expectations. Since prices are fixed in the short-run and fully flexible in the long-run, this framework provides a useful bridge between the fixed price analysis of Chapter 3 and the flexible price analys is of Chapter 2. At the same time, the Dornbusch model is able to shed some light on the overshooting phenomenon and the high variability of exchange rates. Basically, because prices are sticky and can adjust only gradually over time, the impact-adjustment of the exchange rate to any shocks or new information is magnified, and potentially adjusted by more than what is needed to restore the long-run equilibrium. In terms of historical impact in the international monetary arena, the Dornbusch model took over the baton from the Mundell - Fleming model and kept running for some 20 years before passing it on to the new open economy macro model. The latter is discussed in Chapter 32, which also provides more detail on how the economy moves from the short-run to the long-run equilibrium. 


\section{Basic exchange rate theories}

\section{Technical note 4.1 Derivation of the financial equilibrium}

From (4.1) we can determine the domestic interest rate as a function of money supply, output, and the price level, see equation (4A.1). Equation (4A.2) first recalls the uncovered interest parity condition under perfect foresight, then substitutes equations (4A.1) and the definition of the price index (4.2), respectively.

$(4 \mathrm{~A} .1) i_{h}=(1 / \beta)(p+\alpha y-m)$

(4A.2) $\dot{s}=i_{h}-i_{f}=(1 / \beta)(p+\alpha y-m)-i_{f}=(1 / \beta)\left[\gamma p_{h}+(1-\gamma)\left(s+p_{f}\right)+\alpha y-m\right]-i_{f}$

If we now define the auxiliary variable $\delta$, a combination of parameters and exogenous variables, as in equation (4A.3), then (4A.2) reduces to (4.4) as used in the main text.

(4.A3) $\delta \equiv(1-\gamma) p_{f}+\alpha y-\beta i_{f}$

\section{Technical Note 4.2 Adaptive expectations}

Equation (4.A4) is the adaptive expectations hypothesis. Rewriting leads to (4.A4'). The same equation one period earlier is given in (4.A5). A similar equation holds for all other earlier periods. Substituting first (4.A5) in (4.A4') and subsequently the similar equation for all other earlier periods gives equation (4.A4") as used in Box 4.2.

(4.A4) ${ }_{t} x_{t+1}^{e}-_{t-1} x_{t}^{e}=\theta\left(x_{t}-{ }_{t-1} x_{t}^{e}\right), \quad 0<\theta<1$

(4.A4') ${ }_{t} x_{t+1}^{e}=\theta x_{t}+(1-\theta)_{t-1} x_{t}^{e}$

(4.A5) ${ }_{t-1} x_{t}^{e}=\theta x_{t-1}+(1-\theta)_{t-2} x_{t-1}^{e}$

$$
\begin{aligned}
\text { (4.A4") }{ }_{t} x_{t+1}^{e} & =\theta x_{t}+(1-\theta)\left[\theta x_{t-1}+(1-\theta)_{t-2} x_{t-1}^{e}\right]=\theta x_{t}+\theta(1-\theta) x_{t-1}+(1-\theta)^{2}{ }_{t-2} x_{t-1}^{e}= \\
= & . .=\theta x_{t}+\theta(1-\theta) x_{t-1}+\theta(1-\theta)^{2} x_{t-2}+. .+\theta(1-\theta)^{n} x_{t-n}+(1-\theta)^{n+1}{ }_{t-n-1} x_{t-n}^{e}= \\
= & \sum_{j=0}^{\infty} \theta(1-\theta)^{j} x_{t-j}+\lim _{n \rightarrow \infty}(1-\theta)^{n+1}{ }_{t-n-1} x_{t-n}^{e}
\end{aligned}
$$

\section{Technical Note 4.3 Flexible price monetary approach once more}

There are two countries with monetary equilibrium given in (4.A6). Combining this with the Law of One Price (4.A7) gives (4.A8), see Chapter 2 for details.

(4.A6) $m-p=\alpha y-\beta i$

$$
m_{f}-p_{f}=\alpha y_{f}-\beta i_{f}
$$


Basic exchange rate theories

(4.A7) $p=s+p_{f}$

(4.A8) $s=\left(m-m_{f}\right)-\alpha\left(y-y_{f}\right)+\beta\left(i-i_{f}\right)$

Imposing uncovered interest arbitrage in a discrete time frame gives (4.A9). Substitution in (4.A8) gives (4.A8') and rearranging give (4.A8”).

(4.A9) ${ }_{t} s_{t+1}^{e}-s_{t}=\left(i_{t}-i_{f, t}\right)$

(4.A8') $s_{t}=\left(m_{t}-m_{f, t}\right)-\alpha\left(y_{t}-y_{f, t}\right)+\beta\left({ }_{t} s_{t+1}^{e}-s_{t}\right)$

(4.A8”) $s_{t}=\frac{\left(m_{t}-m_{f, t}\right)-\alpha\left(y_{t}-y_{f, t}\right)}{1+\beta}+\frac{\beta}{1+\beta} s_{t+1}^{e}=x_{t}+\phi_{t} s_{t+1}^{e}$

where $x_{t} \equiv \frac{\left(m_{t}-m_{f, t}\right)-\alpha\left(y_{t}-y_{f, t}\right)}{1+\beta} ; \phi \equiv \frac{\beta}{1+\beta}<1$

Technical Note 4.4 Rational bubbles in the flexible price monetary model

Equation (4.A10) recalls equilibrium condition (4.10) from the text and (4.A11) defines the fundamentals term $\tilde{s}_{t}$. The general rational expectations solution is then given in (4.A12) with the arbitrary bubble $B_{t}$.

$$
s_{t}=x_{t}+\phi_{t} s_{t+1}^{e}
$$

$$
\tilde{s}_{t} \equiv\left[x_{t}+\sum_{j=1}^{\infty} \phi^{j}{ }_{t} x_{t+j}^{e}\right]
$$

$$
s_{t}=\tilde{s}_{t}+B_{t} \text {, where bubble } B_{t} \text { satisfies } E_{t}\left(B_{t+1}\right)=\phi^{-1} B_{t}
$$

To verify that (4.A12) is indeed a solution to (4.A10), we first determine the expected exchange rate for the next period on the basis of (4.A12), using (4.A11):

$$
{ }_{t} s_{t+1}^{e}=E_{t}\left(s_{t+1}\right)=E_{t}\left(\tilde{s}_{t+1}\right)+E_{t}\left(B_{t+1}\right)=E_{t}\left[x_{t+1}+\sum_{j=1}^{\infty} \phi^{j}{ }_{t+1} x_{t+1+j}^{e}\right]+\phi^{-1} B_{t}=\phi^{-1}\left\{\left[\sum_{i=1}^{\infty} \phi^{i}{ }_{t} x_{t+i}^{e}\right]+B_{t}\right\}
$$

We then substitute this result in (4.A10) to get:

$$
s_{t}=x_{t}+\phi_{t} s_{t+1}^{e}=x_{t}+\left[\sum_{i=1}^{\infty} \phi^{i}{ }_{t} x_{t+i}^{e}\right]+B_{t}=\tilde{s}_{t}+B_{t},
$$

which is in accordance with the general solution (4.A12). 
Basic exchange rate theories

\section{References}

Alexander, S.S. (1951), "Devaluation versus import restrictions as a means for improving foreign trade balances," IMF Staff Papers, April: 379-396.

Allen, H., and M.P. Taylor (1990), "Charts, noise, and fundamentals in the London foreign exchange market," Economic Journal 100: 49-59.

Artus, J.R., and M.D. Knight (1984), "Issues in the assessment of the exchange rates of industrial countries," International Monetary Fund, Occasional Paper 29, Washington, D.C.

Barro, R.J., and X. Sala-i-Martin (2003), Economic growth, MIT Press.

Bean, D. (1976), "International reserve flows and money market equilibrium: the Japanese case," in: H.G. Johnson and J.A. Frenkel (eds), The monetary approach to the balance of payments, Allen and Unwin, London.

Begg, D.K.H. (1982), The rational expectations revolution in macroeconomics: theory and evidence, Philip Allen, Oxford, U.K.

Black, J. (1959), “A savings and investment approach to devaluation," The Economic Journal 69: 267-274.

Black, S. (1973), "International money markets and flexible exchange rates," Princeton Studies in International Finance, 32.

Brakman, S., H. Garretsen, C. van Marrewijk, and A. van Witteloostuijn (2005), Nations and firms in the global economy: an introduction to international economics and business, Cambridge University Press, Cambridge, U.K.

Connoly, M.B., and D. Taylor (1976), “Testing the monetary approach to devaluation in developing countries," Journal of Political Economy: 849-859.

De Grauwe, P. (1996), International money, Oxford University Press, Oxford, U.K.

De Grauwe, P., and H. Dewachter (1993), "A chaotic model of the exchange rate: the role of fundamentalists and chartists," Open Economies Review 4: 351-379.

DeLong, J.B., A. Shleifer, L.H. Summers, and R.J. Waldmann (1990), "Noise trader risk in financial markets," Journal of Political Economy 98: 703-738.

Dornbusch, R. (1976), “Expectations and exchange rate dynamics, Journal of Political Economy, 84: 1161-1176.

Dornbusch, R. (1980a), Open economy macroeconomics, Basic Books, New York. 
Dornbusch, R. (1980b), "Exchange rate economic: where do we stand?," Brookings Papers on Economic Activity 1: 143-185.

Dornbusch, R. (1987), "Exchange rates and prices," American Economic Review 77: 93106.

Fleming, M. (1962), "Domestic financial policies under fixed and under floating exchange rates," IMF Staff Papers 9.

Frankel, J.A., and K.A. Froot (1987), "Using survey data to test standard propositions regarding exchange rate expectations," American Economic Review 77: 133-153.

Frankel, J.A., and K.A. Froot (1990), "Chartists, fundamentalists, and trading in the foreign exchange market," American Economic Review 80: 181-185.

Friedman, M. (1953), "The case for flexible exchange rates," in: Essays in positive economics, University of Chicago Press, Chicago, pp. 157-203.

Friedman, M. (1968), "The role of monetary policy," American Economic Review 58: 117.

Genberg, H. (1976), “Aspects of the monetary approach to balance of payments theory: an empirical study of Sweden,” in: H.G. Johnson and J.A. Frenkel (eds), The monetary approach to the balance of payments, Allen and Unwin, London.

Guittan, M. (1976), "The balance of payments as a monetary phenomenon: empirical evidence, Spain 1955-71,” in: H.G. Johnson and J.A. Frenkel (eds), The monetary approach to the balance of payments, Allen and Unwin, London.

Hallwood, C.P., and R. MacDonald (2000), International money and finance, $3^{\text {rd }}$ edition, Blackwell publishers, Oxford, U.K.

Hume, D. (1752), Political Discourses, volume II, essay V: of the balance of trade, see www.econlib.org/library/LFbooks/Hume/hmMPL28.html

Koedijk, K.G., and P. Schotman (1990), "How to beat the random walk: an empirical model of real exchange rates," Journal of International Economics 29: 311-332.

Kouri, P.J.K., and M.G. Porter (1974), "International capital flows and portfolio equilibrium," Journal of Political Economy 82(3): 443-467.

Krugman, P.R. (1987), "Pricing to market when the exchange rate changes," in: S.W. Arndt and J.D. Richardson (eds.), Real-financial linkages among open economies, MIT Press, Cambridge, MA. 
Lerner, A. (1944), The economics of control, MacMillan, London.

Lucas, R.E. Jr. (1972), "Expectations and the neutrality of money," Journal of Economic Theory 4: 103-124.

Lucas, R.E. Jr. (1973), "Some international evidence on output - inflation tradeoffs," American Economic Review 68: 326-334.

Lui, Y.H., and D. Mole (1998), "The use of fundamental and technical analysis by foreign exchange dealers: Hong Kong evidence," Journal of International Money and Finance 17: 535-545.

Marrewijk, C. van (2002), International trade and the world economy, Oxford University Press, Oxford, U.K.

Marrewijk, C. van (2004), "An introduction to international money and foreign exchange markets," University of Adelaide, School of Economics, Working Paper 2004-02 and Centre for International Economic Studies, Discussion Paper 0407, University of Adelaide.

Marrewijk, C. van, and K.G. Berden (2004), "On the static and dynamic costs of trade restrictions," Working Paper 2004-06, University of Adelaide.

Marshall, A. (1923), Money, credit, and commerce, MacMillan, Basingstoke.

Meade, J. (1951), Theory of international economic policy: the balance of payments, Oxford University Press, Oxford, U.K.

Meese, R.A., and K. Rogoff (1983), "Empirical exchange rate models of the seventies: do they fit out of sample?" Journal of International Economics 14: 3-24.

Modigliani, F., and E. Grunberg (1954), "The predictability of social events," Journal of Political Economy 62: 465-478.

Mundell, R.A. (1962), "The appropriate use of monetary and fiscal policy for internal and external stability," International Monetary Fund Staff Papers 12: 70-79.

Mundell, R.A. (1963), "Capital mobility and stabilization policy under fixed and flexible exchange rates," Canadian Journal of Economics and Political Science 29: 475-485.

Mundell, R.A. (1968), International Economics, MacMillan, New York.

Mussa, M. (1976), “The exchange rate, the balance of payments and monetary and fiscal policy under a regime of controlled floating," Scandinavian Journal of Economics 78: 229-248. 
Mussa, M. (1979), "Empirical regularities in the behaviour of exchange rates and theories of the foreign exchange market," in: Brunner, K. and A.H. Meltzer (eds.), Policies for employment, prices, and exchange rates, pp. 9-57.

Muth, J.F. (1961), "Rational expectations and the theory of price movements," Econometrica 29: 315-335.

Rogoff, K. (2002), "Statement by Kenneth Rogoff on the death of Rudiger Dornbusch," International Monetary Fund, News Brief 02/77, July 26.

Rogoff, K. (2002b), "Dornbusch's overshooting model after twenty-five years," International Monetary Fund, Working Paper 02-39.

Romer, D. (2001), Advanced macroeconomics, McGraw Hill.

Sargent, T.J. (1972), "Rational expectations and the term structure of interest rates," Journal of Money, Credit, and Banking 4: 74-97.

Sargent, T.J. (1973), "Rational expectations, the real rate of interest, and the natural rate of unemployment,” Brookings Papers on Economic Activity 2: 429-472.

Sarno, L., and M.P. Taylor (2002), The economics of exchange rates, Cambridge University Press, Cambridge, U.K.

Swan, T. (1955), "Longer run problems of the balance of payments," in: Readings in international economics, American Economic Association, Allen and Unwin, London.

Taylor, M.P., and H. Allen (1992), "The use of technical analysis in the foreign exchange market," Journal of International Money and Finance 11: 304-314.

Tinbergen, J. (1952), On the theory of economic policy, North Holland, Amsterdam.

Whitman, M. (1975), "Global monetarism and the monetary approach to the balance of payments," Brookings Papers on Economic Activity 3: 491-536.

Zecher, J.R. (1976), "Monetary equilibrium and international reserve flows in Australia," in: H.G. Johnson and J.A. Frenkel (eds), The monetary approach to the balance of payments, Allen and Unwin, London. 